Antonio Henrique Pinto Selvatici

\title{
AAREACT: Uma Arquitetura Comportamental Adaptativa para Robôs Móveis que Integra Visão, Sonares e Odometria
}

Dissertação apresentada à Escola Politécnica da Universidade de São Paulo para obtenção do Título de Mestre em Engenharia Elétrica. 
Antonio Henrique Pinto Selvatici

\section{AAREACT: Uma Arquitetura Comportamental Adaptativa para Robôs Móveis que Integra Visão, Sonares e Odometria}

Dissertação apresentada à Escola Politécnica da Universidade de São Paulo para obtenção do Título de Mestre em Engenharia Elétrica.

Área de concentração:

Sistemas Digitais

Orientador:

Prof. Dr. Anna Helena Reali Costa 
Este exemplar foi revisado e alterado em relação à versão original, sob responsabilidade única do autor e com anuência de seu orientador

São Paulo, 18 de fevereiro de 2005.

Assinatura do autor

Assinatura do orientador

\section{Ficha Catalográfica}

Selvatici, Antonio Henrique Pinto

AAREACT: Uma Arquitetura Comportamental Adaptativa para Robôs Móveis que Integra Visão, Sonares e Odometria/Antonio Henrique Pinto Selvatici. — São Paulo, 2005. 101 p.

Dissertação (Mestrado) — Escola Politécnica da Universidade de São Paulo. Departamento de Engenharia de Computação e Sistemas Digitais.

1. Robótica. 2. Robôs. 3. Aprendizado computacional. 4. Visão computacional. I. Universidade de São Paulo. Escola Politécnica. Departamento de Engenharia de Computação e Sistemas Digitais. II. t. 


\section{Apoio}

Este trabalho foi realizado com bolsa de Mestrado no País, concedida pela Fundação de Amparo à Pesquisa do Estado de São Paulo - FAPESP — através do processo $n^{\circ} 02 / 11792-0$. 


\section{Resumo}

Para ter uma aplicação real, um robô móvel deve poder desempenhar sua tarefa em ambientes desconhecidos. Uma arquitetura para robôs móveis que se adapte ao meio em que o robô se encontra é então desejável. Este trabalho apresenta uma arquitetura adaptativa para robôs móveis, de nome AAREACT, que aprende como coordenar comportamentos primitivos codificados por Campos Potenciais através de aprendizado por reforço. Cada comportamento utiliza a informação de apenas um tipo de sensor (visão, sonar ou odometria). O sensor de visão foi desenvolvido neste trabalho, e utiliza os tempos para colisão obtidos através da análise de seqüências de imagens para indicar a disposição dos objetos à frente do robô. A atuação da arquitetura proposta é comparada com a apresentada por uma arquitetura com coordenação fixa dos comportamentos, demonstrando melhor desempenho. Os resultados obtidos neste trabalho também apontam a alta capacidade de adaptação da arquitetura AAREACT. 


\section{Abstract}

It is desirable that mobile robots applied to real world applications perform their operations in previously unknown environments. Thus, a mobile robot architecture capable of adaptation is very suitable. This work presents an adaptive architecture for mobile robots called AAREACT, that has the ability of learning how to coordinate primitive behaviors codified by the Potential Fields method through reinforcement learning. Each behavior uses the information of a single sensor (vision, sonar or odometer). This work also brings details about the vision sensor's development, which uses time-to-crash information in order to detect distances to frontal obstacles. The proposed architecture's actuation is compared to that showed by an architecture that performs a fixed coordination of its behaviors, and shows a better performance. The obtained results also suggest that AAREACT has good adaptation skills. 


\section{Sumário}

\section{Lista de Figuras}

\section{Lista de Tabelas}

1 Introdução 1

1.1 Arquiteturas para robôs móveis . . . . . . . . . . . . 2

1.1.1 Capacidade de adaptação . . . . . . . . . . . . 3

1.1.2 O sensor de visão em robótica móvel . . . . . . . . . . . 4

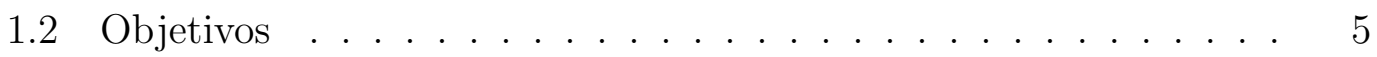

1.3 Justificativas . . . . . . . . . . . . . . . . 5

1.4 Contribuições . . . . . . . . . . . . . . . . . . . . 6

1.5 Organização . . . . . . . . . . . . . . . . . 7

2 Classificação de agentes $\quad 9$

2.1 O projeto de agentes artificiais . . . . . . . . . . 9

2.2 A classificação dos agentes segundo Russel e Norvig (2004) . . . . 10

2.2.1 Agentes reativos simples . . . . . . . . . . . . 11

2.2.2 Agentes reativos baseados em modelo . . . . . . . . . . 12

2.2.3 Agentes baseados em objetivo . . . . . . . . . . . . 13

2.2.4 Agentes baseados em utilidade . . . . . . . . . . . . . 14

2.2.5 Agente com aprendizado . . . . . . . . . . . . . . . 14

2.3 Arquiteturas de agentes . . . . . . . . . . . . . . . 16 
2.4 A arquitetura de agente proposta . . . . . . . . . . . 17

3 Arquiteturas de comportamentos para robôs móveis 19

3.1 Formalização dos comportamentos . . . . . . . . . . . . . . . 20

3.2 A codificação dos comportamentos . . . . . . . . . . . . . . 22

3.2.1 Codificações discretas . . . . . . . . . . . . . . . . . . . 22

3.2.2 Codificação contínua de comportamentos . . . . . . . . . 23

3.3 Coordenação dos comportamentos . . . . . . . . . . . . . . . . . 24

3.3.1 Coordenação competitiva . . . . . . . . . . . . . 25

3.3.2 Coordenação cooperativa . . . . . . . . . . . . . . . 27

3.4 Arquiteturas híbridas baseadas em comportamentos . . . . . . . . 30

3.4.1 Arquitetura de Campos Potenciais com planejamento sob demanda ...................... 30

3.4.2 A arquitetura comportamental proposta . . . . . . . 31

4 A arquitetura REACT 33

4.1 A codificação e coordenação dos comportamentos . . . . . . . . . 33

4.2 Os comportamentos utilizados na arquitetura REACT . . . . . . . 34

4.2.1 Comportamento avoidCollision . . . . . . . . . . 35

4.2.2 Comportamento moveAhead . . . . . . . . . . . . . 37

4.2.3 Comportamento moveToGoal . . . . . . . . . . . . . . 38

4.3 Observações sobre a arquitetura REACT . . . . . . . . . . . . 38

5 Sensor unidimensional de tempos para colisão 41

5.1 O campo de movimento e o fluxo ótico . . . . . . . . . . . . 42

5.1.1 Cálculo do fluxo ótico a partir da equação de restrição . . 44

5.1.2 Problemas no cálculo do fluxo ótico . . . . . . . . . . . . . 46 
5.1.3 A compatibilidade entre o fluxo ótico e o campo de movimento 47

5.2 A detecção de distâncias a partir do campo de movimento . . . 48

5.3 Cálculo do tempo para colisão a partir do fluxo ótico . . . . . . . 50

5.4 Cálculo direto do tempo para colisão . . . . . . . . . . . . . . . . 52

5.5 Descrição do sensor de distâncias desenvolvido . . . . . . . . . . 53

5.6 Experimentos com o sensor de distâncias . . . . . . . . . . . . 55

5.7 Conclusões sobre o sistema de visão . . . . . . . . . . . . . . . . 57

6 O comportamento moveToFree $\quad 60$

6.1 A codificação do comportamento moveToFree . . . . . . . . . . . 61

6.2 Experimentos com o comportamento moveToFree na arquitetura

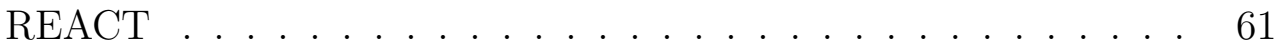

6.2.1 Plataforma robótica utilizada . . . . . . . . . . . 62

6.2.2 Experimento utilizando somente movetoFree . . . . . . . 63

6.2.3 Experimento com os demais comportamentos . . . . . . 64

6.3 Conclusão sobre a arquitetura REACT . . . . . . . . . . . . . 65

$\begin{array}{lll}7 & \text { A arquitetura AAREACT } & 67\end{array}$

7.1 O aprendizado na AAREACT . . . . . . . . . . . 67

7.2 Aprendizado por reforço . . . . . . . . . . . . . . 70

7.2 .1 O modelo de $\mathrm{AR} \ldots \ldots . \ldots 70$

7.3 Processos markovianos de decisão (MDPs) . . . . . . . . . . . 72

7.3.1 Algoritmos de AR . . . . . . . . . . . . . 73

7.4 A implementação do aprendizado por reforço . . . . . . . . . . . 75

7.4.1 A definição dos estados . . . . . . . . . . . . . . . 75

7.4.2 Definição das ações . . . . . . . . . . . . . . . . 78

7.4.3 O reforço utilizado . . . . . . . . . . . . . . 80 
8.1 O aprendizado inicial . . . . . . . . . . . . . . . . 83

8.2 Experimentos comparativos com o simulador . . . . . . . . . 86

8.3 Experimentos com um robô real . . . . . . . . . . . . . . . . . . . 91

$\begin{array}{llr}9 & \text { Conclusão } & 94\end{array}$

9.1 Discussão dos resultados . . . . . . . . . . . . . . . . . . . . 95

9.2 Sugestões de trabalhos futuros . . . . . . . . . . . . . . . . . . 97

$\begin{array}{ll}\text { Referências Bibliográficas } & 99\end{array}$ 


\section{Lista de Figuras}

2.1 Representação dos elementos conceituais de aprendizado na arquitetura proposta. . . . . . . . . . . . . . . . 18

3.1 Um exemplo simples da arquitetura de subsunção, retirado de Ribeiro, Costa e Romero (2001). . . . . . . . . . . . . . . . 27

3.2 Campo vetorial associado a um comportamento contínuo de rejeição a um obstáculo (retirado de Ribeiro, Costa e Romero (2001)). 28

3.3 Organização da arquitetura híbrida proposta. . . . . . . . . . . 32

4.1 Motor-Schema dos comportamentos avoidCollision, moveAhead, move To Goal e a composição vetorial. . . . . . . . . . . . . . 35

4.2 Campo vetorial radial repulsivo para um obstáculo puntiforme com decaimento exponencial. . . . . . . . . . . . . . . . 37

5.1 Representação do cenário considerado para a dedução do campo de movimento captado pela câmera do robô. . . . . . . . . . . . . 49

5.2 Quadro de uma seqüência de imagens. . . . . . . . . . . . 56

5.3 Representação dos valores do sensor de distâncias. . . . . . . . . . . 56

5.4 Resultados do sensor de distâncias obtidos com algumas seqüências de imagens. . . . . . . . . . . . . . . . . . . . . . . . 58

6.1 Sistema robótico utilizado nos primeiros experimentos com a arquitetura REACT. . . . . . . . . . . . . . . . . . 62

6.2 Ilustração das trajetórias do robô em um dos experimentos utilizando ambas as implementações da arquitetura REACT. . . . . . 65

7.1 Diagrama de blocos da arquitetura AAREACT implementada . . 69

8.1 Ambiente que o robô simulado iniciou seu aprendizado. . . . . . . 84 
8.2 Comparação gráfica dos resultados desempenhados pelas arquiteturas AAREAC e REACT no simulador para o cenário utilizado no aprendizado inicial. . . . . . . . . . . . . . . . . . . 87

8.3 Comparação entre trajetórias típicas apresentadas pelas arquiteturas REACT e AAREACT nos experimentos realizados no simulador, com o cenário do aprendizado inicial. . . . . . . . . . . . 88

8.4 Ambiente da segunda experiência no simulador. Os alvos estão indicados com um $\times \ldots \ldots$. . . . . . . . . . . . . . 89

8.5 Comparação gráfica dos resultados entre os desempenhos das arquiteturas AAREACT e REACT no segundo cenário do simulador. 90

8.6 Ambiente da experiência real com o robô. . . . . . . . . . . . . . . 92

8.7 Plataforma robótica utilizada nos experimentos finais. . . . . . . . 92

8.8 Trajetórias desenvolvidas durante os experimentos com o robô Pioneer. As setas indicam o sentido do movimento do robô. . . . . . 93 


\section{Lista de Tabelas}

5.1 Resultados dos testes experimentais do algoritmo de cálculo de $\lambda$ realizado com seqüências de imagens simuladas. . . . . . . . . . . 57

7.1 Relação dos conjuntos de pesos dos comportamentos que definem as possíveis ações do módulo de AR. . . . . . . . . . . . . . . 79

7.2 Relação entre os atributos definidos e o conjunto de pesos dos comportamentos associados a cada um. . . . . . . . . . . 80 


\section{Introdução}

A Robótica é, dos campos da Inteligência Artificial, um dos mais estudados e dos que mais têm se desenvolvido. Além do fascínio causado pela pesquisa sobre a construção de máquinas que se pareçam com animais ou com seres humanos em sua atuação, o interesse nessas máquinas é despertado por suas possíveis aplicações.

A Robótica Móvel Inteligente, no entanto, sempre se manteve restrita à academia, principalmente devido à dificuldade de operação de seus robôs em ambientes não estruturados. Contudo, ultimamente ela tem deixado de ser um campo meramente acadêmico para cada vez mais apresentar soluções viáveis para problemas de ordem prática. Várias aplicações vêm sendo desenvolvidas, tanto para empresas, quanto para a indústria e para o consumidor comum. Exemplos disso são o cachorro robótico Aibo ${ }^{\circledR}$, da Sony, e o aspirador de pó automático Trilobite ${ }^{\circledR}$, da Electrolux.

Define-se um robô móvel inteligente como um agente inteligente, artificial, autônomo, com capacidade de locomoção, imerso no mundo físico real. Agente inteligente por decidir de forma racional; artificial por ser máquina e não uma entidade criada pela natureza; autônomo por ser capaz de decidir por si só, de se auto-governar, de atuar no ambiente de forma propositada, não passiva, de se adaptar a mudanças ocorridas, no ambiente ou em si próprio, e continuar a atingir suas metas; com capacidade de locomoção por poder se mover no ambiente. (RIBEIRO; COSTA; ROMERO, 2001; MURPHY, 2000).

A execução da tarefa atribuída a um Robô Móvel Inteligente, ou simplesmente robô móvel, inclui necessariamente a sua locomoção de forma autônoma até localidades no espaço diferentes de sua posição inicial. É de interesse que essa locomoção possa ser feita em ambientes não estruturados, onde há, possivel- 
mente, a presença de objetos atrapalhando a navegação. Assim, o problema a ser tratado neste trabalho é o da navegação do robô até uma posição previamente estabelecida, com o desvio de obstáculos.

A atuação de um robô móvel é determinada por meio do processamento das informações advindas de seus sensores. Seu sistema de navegação pode estar presente no próprio robô, constituindo um sistema embarcado, ou pode estar presente em uma plataforma externa, comunicando-se com ele através de um canal de comunicação geralmente sem fio. Em geral, o processo de determinar as ações do robô se dá em ciclos de percepção e ação. Em cada ciclo, o robô faz uma leitura do ambiente através de seus sensores e determina uma ação a partir das informações adquiridas. Essa ação é então executada através de seus atuadores, que modificam o ambiente ou a relação entre o robô e o ambiente (a posição do robô por exemplo).

A ação a ser executada em cada ciclo é determinada pelo controle interno do robô. Em geral, esse controle implementa uma certa arquitetura robótica, que corresponde a uma estrutura fundamental que determina uma estratégia de atuação para o robô.

\subsection{Arquiteturas para robôs móveis}

Tradicionalmente, em robótica móvel utilizam-se dois paradigmas para o projeto de arquiteturas de robôs autônomos: o deliberativo e o reativo (RIBEIRO; COSTA; ROMERO, 2001). O paradigma deliberativo envolve o seqüenciamento de etapas a serem executadas desde a percepção (extração das características ambientais de interesse a partir das informações sensoriais) até a ação, passando por um estágio mais ou menos complexo de planejamento. As arquiteturas deliberativas tentam simular o processo deliberativo do ser humano quando executa suas ações, e apresentam soluções de alta complexidade, pois cada movimento é fruto de uma busca adequada no espaço de ações, muitas vezes através de custosos algoritmos de busca e planejamento tradicionalmente utilizados em Inteligência Artificial.

Já as arquiteturas reativas tentam simular a reação imediata e muitas vezes não deliberada dos animais aos estímulos do ambiente. Em vez de decompor a tarefa de determinar a ação em estágios, de forma seqüencial, essa tarefa é 
normalmente decomposta de forma paralela em termos de regras que definem uma relação direta e rapidamente computável entre percepção e ação. Então a ação tomada é resultado de uma ponderação global das saídas dessas regras baseada na percepção sensorial imediata. Essa estrutura paralela das arquiteturas reativas sugere uma organização em forma da comportamentos para as regras que a compõem. Cada comportamento é um módulo que determina uma ação a partir dos dados sensoriais. Caso a ação seja determinada de forma direta a partir dos dados sensoriais imediatos, o comportamento é reativo. No entanto, o conceito de comportamento abrange também possibilidades de maior complexidade, de forma que um comportamento pode ser também deliberativo, ou ainda pode combinar ambos os paradigmas.

Cada uma das abordagens (reativa e deliberativa) possui vantagens. No entanto, uma arquitetura robótica pode ser projetada com base em ambos os paradigmas, resultando em uma arquitetura híbrida. Esse tipo de arquitetura é a que potencialmente possui melhor desempenho, uma vez que pode combinar as vantagens e desvantagens dos paradigmas reativo e deliberativo, atenuando as desvantagens. Há diversos modos de se combinar o paradigma reativo com o deliberativo em uma arquitetura híbrida. Uma possibilidade é a elaboração de um plano de atuação que, em vez de determinar diretamente a atuação do robô, coordena a ação de comportamentos reativos individuais.

\subsubsection{Capacidade de adaptação}

Em muitas situações, um robô inteligente deverá se adaptar a um ambiente dinâmico para que obtenha sucesso. Para que possa se adaptar a novas condições, a arquitetura do robô deve ter um módulo de aprendizado. Esse módulo deve ser capaz de observar a atuação do robô e criticá-la, julgando-a segundo alguma medida de otimalidade. Deve também poder modificar parâmetros da arquitetura. Dessa forma o papel do módulo de aprendizado é observar a atuação do robô ao mesmo tempo em que testa vários conjuntos de parâmetros, comparando o seu desempenho e procurando aqueles que proporcionam a melhor atuação para o robô.

Devido à natureza autônoma dos robôs móveis, é mais interessante que o aprendizado a ser executado por eles seja não-supervisionado. Dessa forma, o robô 
pode aprender através de sua própria experiência, sem a necessidade de um tutor, podendo adaptar-se automaticamente a mudanças no ambiente. Aprendizado por reforço (AR) mostra-se assim bastante adequado para a utilização em arquiteturas de robôs móveis. De fato, AR é um dos mais largamente utilizados em sistemas robóticos para a adaptação do sistema de controle (ARKIN, 1998).

\subsubsection{O sensor de visão em robótica móvel}

Principalmente em arquiteturas baseadas em comportamentos reativos, o sucesso de uma ação depende fortemente da qualidade obtida na percepção, o que envolve a riqueza de informação contida nos dados sensoriais, a acurácia dos mesmos e o correto processamento desses dados. Por exemplo, o sistema de navegação de um robô deve se preocupar em evitar colisões com os obstáculos do ambiente até chegar à localização desejada. Os sensores mais comumente utilizados para a percepção dos obstáculos são o sonar e o laser, projetados exclusivamente para medir distâncias. O sensor de laser tem boa precisão, mas além de apresentar alto custo, e por isso não está presente em muitas plataformas robóticas, só consegue detectar objetos na altura do feixe. O sonar, além de ter alcance limitado, consegue apenas detectar objetos relativamente grandes com boa precisão. Além disso, possui grandes erros quando ocorre uma reflexão irregular do pulso de ultra-som nos objetos, inviabilizando o seu uso para a detecção de superfícies muito inclinadas ou em ambientes muito pequenos e fechados, propícios a múltiplas reflexões do sinal, gerando o retorno de pulsos espúreos ao sensor.

Sabe-se que o ser humano e a maior parte das aves e mamíferos utilizam o sentido da visão como principal sensor para tarefas de navegação. A informação fornecida por esse sentido é muito rica e completa, de forma que delas podem ser extraídas diversas características do ambiente, como o limite dos objetos, a rugosidade de superfícies, as distâncias entre os objetos e do observador aos objetos. Além disso, a informação da visão possui alta densidade, permitindo a detecção de objetos bem pequenos, dependendo da distância a que eles se encontram.

Em robótica móvel, o sensor de visão é geralmente composto por uma câmera de vídeo e pelo algoritmo de visão computacional utilizado para processar as imagens. As características da informação fornecida dependem do algoritmo uti- 
lizado, projetado para atender as necessidades específicas. Uma das formas de uso do sensor de visão em robótica móvel é como detector de distâncias, através do uso de algoritmos de visão estéreo ou, quando se possui apenas uma câmera de vídeo, através de algoritmos que extraem o tempo para colisão até os objetos. Como a visão não possui as limitações intrínsecas apresentadas pelos sensores de laser e sonar, ela pode ser utilizada como sensor complementar ou até mesmo substituir os outros, como fizeram Camus et al. (1996), Pardo et al. (2002), Sarcinelli-Filho, Schneebeli e Caldeira (2002).

\subsection{Objetivos}

Os objetivos deste trabalho são:

- Apresentar uma arquitetura híbrida para robôs móveis que utilize comportamentos reativos cuja participação na atuação do robô seja ponderada por uma função adaptativa implementada por uma camada de aprendizado por reforço inserida nessa arquitetura, dotando-a da capacidade de adaptação.

- Elaborar um comportamento que utilize visão computacional para encontrar caminhos livres entre os obstáculos à frente do robô, comportamento este a ser integrado na arquitetura proposta, juntamente com outros comportamentos previamente desenvolvidos.

- Implementar e testar a arquitetura e o comportamento propostos em um robô real.

\section{$1.3 \quad$ Justificativas}

Um robô deve ser capaz de responder rapidamente e de forma eficiente às mudanças dinâmicas e não modeladas que ocorrem no mundo. Se ele agir de uma forma puramente deliberativa e tentar modelar e pré-planejar todas as eventualidades, corre-se o risco de que o processo de planejamento demore muito ou mesmo nunca termine. Também não é seguro para o robô fazer suposições grosseiras sobre o mundo, que não reflitam a sua natureza dinâmica, traduzindo-as num plano inalterável, que guiará todas as suas ações ou decisões futuras. 
Se, por um lado, uma arquitetura puramente reativa responde eficientemente a dados sensoriais imediatos, por outro, é menos eficaz na integração de conhecimentos sobre o mundo. As ações determinadas por comportamentos reativos não sofrem um processo de crítica racional antes de sua execução, podendo resultar em ações indevidas. Dessa forma, é importante a adição de um elemento de aprendizado na arquitetura do robô que supervisione e controle a atuação dos comportamentos, resultando em uma arquitetura híbrida.

Se os comportamentos estiverem bem projetados, em geral as ações geradas por eles serão satisfatórias, havendo a necessidade apenas de uma boa coordenação entre elas. Desse modo, é desejável que o processo de coordenação seja "inteligente". O uso de algoritmos de aprendizado por reforço é uma boa alternativa para a determinação dessa coordenação, já que eles utilizam dados da própria experiência do robô nos ambientes e tarefas a que ele está designado.

É desejável também que um robô móvel execute trajetórias suaves. Caso o robô possua somente comportamentos de desvio de obstáculos que respondam apenas a obstáculos próximos, eles muitas vezes serão uma obstrução a ser contornada, gerando um caminho com guinadas abruptas. Por isso é necessário um comportamento que responda a obstáculos mais distantes, dirigindo o robô a regiões desimpedidas. Dessa forma os obstáculos são evitados em vez de contornados, gerando trajetórias mais diretas, com menos curvas. O sensor de visão parece ser o mais adequado para esse comportamento, pois possui um longo alcance e se concentra sobre a região à frente do robô.

Tudo isso justifica a importância da arquitetura desenvolvida neste trabalho, que aprende a coordenação dos seus comportamentos baseada na experiência do robô e que incorpora um comportamento baseado em visão computacional que auxilia na tarefa de desvio de obstáculos.

\subsection{Contribuições}

Neste trabalho distinguem-se duas contribuições principais. A primeira contribuição a ser destacada é a proposta de uma arquitetura híbrida baseada em comportamentos reativos e com capacidade de adaptação. A influência de cada comportamento na atuação final do robô é ajustada de acordo com a percepção 
do robô sobre a disposição dos obstáculos ao seu redor e sobre a posição relativa do alvo aonde deve ir. Esse ajuste da participação de cada comportamento é feito através de aprendizado por reforço, um tipo de aprendizado não supervisionado. A arquitetura proposta procura, então, contornar as limitações do paradigma reativo através de um plano que ajusta a ponderação entre as saídas dos comportamentos de acordo com a percepção do robô sobre o estado do ambiente. Esse plano, que poderia ser elaborado a priori, vai sendo construído com base na própria experiência do robô.

A segunda contribuição é a elaboração de um comportamento baseado em visão computacional, incorporado à arquitetura proposta, de forma que sua atuação sirva de complemento para outros comportamentos baseados em sensores de distância tradicionais. Mais especificamente, esse comportamento utiliza em sua percepção os dados obtidos através de um sensor de distâncias desenvolvido neste trabalho. Esse sensor é baseado no cálculo dos tempos para colisão dos objetos do cenário captado por uma câmera de vídeo fixada no robô. Essa medida é calculada através da análise de uma seqüência de imagens capturada por essa câmera.

\subsection{Organização}

Esta dissertação se inicia com uma discussão sobre a classificação de agentes no capítulo 2. Com isso, pretende-se situar a arquitetura robótica proposta dentro de um panorama mais geral. O capítulo 3 traz então uma breve revisão sobre arquiteturas baseadas em comportamentos, trazendo as técnicas mais conhecidas, bem como algumas arquiteturas da literatura que representam bem essas técnicas. O capítulo 4 discute a arquitetura REACT, utilizada como base neste trabalho, descrevendo como é o seu funcionamento bem como detalhando os comportamentos utilizados.

As modificações na arquitetura REACT se iniciam com a introdução de um comportamento que utiliza visão computacional. O capítulo 5 traz detalhadamente o sistema de visão desenvolvido para ser integrado à arquitetura existente. Então o capítulo 6 mostra como é feita essa integração, descrevendo o comportamento proposto e trazendo os resultados de sua utilização, tanto isoladamente 
quanto em conjunto com os outros comportamentos da arquitetura REACT. Esses resultados evidenciam a conveniência de se incorporar a capacidade de aprendizado nessa arquitetura. A arquitetura aprendiz proposta é tema do capítulo 7 . Os resultados obtidos com essa arquitetura são discutidos no capítulo 8. Finalmente, o capítulo 9 traz as conclusões finais deste trabalho, bem como sugestões para trabalhos futuros. 


\section{Classificação de agentes}

Um robô móvel é, antes de tudo, um agente artificial imerso no mundo físico real. Sendo assim, o desenvolvimento de uma arquitetura para robôs móveis passa necessariamente pela definição do tipo de agente robótico a ser implementado por essa arquitetura.

Este capítulo discute a classificação dos agentes segundo (RUSSEL; NORVIG, 2004). O critério apresentado considera o grau de abstração das informações utilizadas para o controle do agente. Embora esse critério se aplique a agentes em geral, não se restringindo a agentes robóticos, ele se mostra de especial interesse neste trabalho, pois permite enquadrar muito bem o tipo de agente implementado pela arquitetura proposta. Desse modo, o contexto no qual se insere essa arquitetura fica bem definido, destacando sua importância face às outras possibilidades e justificando essa escolha.

\subsection{O projeto de agentes artificiais}

Agente é tudo o que pode ser considerado capaz de perceber seu ambiente por meio de sensores e de agir sobre esse ambiente por intermédio de atuadores (RUSSEL; NORVIG, 2004). O papel de um agente artificial consiste em responder aos estímulos do meio, determinando a ação que seus atuadores devem executar a partir do histórico das suas percepções.

Considerando que as percepções do agente são constituídas de amostras discretas, uma maneira de implementá-lo seria através de uma tabela onde a entrada fosse todo o histórico das percepções e a saída fosse a ação desejada. Dessa forma, todos as situações que o agente pode encontrar teriam uma resposta adequada. No entanto, a utilização de todo o histórico de percepções a cada atuação tornar- 
se-ia impraticável com o tempo, tanto devido à limitação de espaço de memória para armazená-las quanto à crescente demanda de tempo computacional para processar um conjunto cada vez maior de dados. Do ponto de vista de projeto, a elaboração de uma tabela desse tipo é impraticável, pois o seu tamanho teria de ser infinito. Mesmo para agentes que possuem um tempo de atuação máximo predefinido, o que definiria um tamanho finito para a tabela, ela provavelmente teria que ser muito grande, inviabilizando a sua elaboração. Finalmente, a implementação de um agente por meio de uma tabela não o dota da capacidade de generalização de seu conhecimento: o agente não saberia como atuar em situações não previstas pela tabela.

O desafio no projeto de um agente é fazer com que ele cumpra a sua tarefa utilizando de forma inteligente um conjunto limitado de informações do ambiente. Essa limitação provém tanto da quantidade finita de informações que o agente pode armazenar e processar quanto da parcialidade das observações que seus sensores podem captar — os sensores, por melhores que sejam, dificilmente conseguem fornecer uma descrição do ambiente completa o suficiente para que o agente consiga cumprir sua tarefa com apenas uma observação. Para tentar direcionar a difícil tarefa de se projetar um agente artificial, alguns autores propuseram algumas classificações dos agentes, o que permite uma abordagem inicial do problema através da escolha do tipo de agente mais adequado.

\subsection{A classificação dos agentes segundo Russel e Norvig (2004)}

Russel e Norvig (2004) propõem uma classificação dos agentes segundo o grau de abstração das informações e das leis utilizadas no seu controle. O interessante desse enfoque é a possibilidade de que numa determinada implementação de uma classe de agente pensada em um nível mais abstrato seja utilizada como base uma outra classe, pensada em um nível menor de abstração. Dessa forma, mesmo que para cumprir tarefas mais complicadas muitas vezes seja necessário um agente mais sofisticado, de difícil implementação, ele pode aproveitar vantagens dos agentes mais simples incorporando-os à sua estrutura. Essa possibilidade de incorporação de um tipo de agente em outro é melhor explicada na seção 2.3 


\subsubsection{Agentes reativos simples}

O agente reativo simples adota o paradigma reativo de controle, selecionando as ações com base na percepção momentânea e ignorando todo o histórico de percepções. O controle do robô é realizado através de regras que mapeiam de maneira simples e direta a percepção daquele instante em uma ação a ser realizada, sem nenhum tipo de planejamento ou adaptação. Essas regras são chamadas de regras condição/ação.

Toda a intencionalidade das ações dos agentes reativos encontra-se implícita nas regras que regem sua atuação, mas ele não age segundo uma intencionalidade explícita. Dessa forma, um agente desse tipo que simulasse um predador atrás da presa não teria uma modelagem interna da necessidade do alimento para a sobrevivência, chegando à decisão de ir atrás da presa. Porém, teria implementada dentro de si uma regra do tipo: observou a presa, vai atrás dela. A intenção de sobrevivência se encontra implícita nessa regra.

Considera-se percepção do agente o conjunto de informações utilizadas no controle do robô, extraídas dos dados dos sensores. Assim, um agente que se encontre em um mundo contínuo com paredes e que perceba o seu ambiente através de um sensor de laser pode extrair de seu sensor a informação da presença de alguma parede ou quina e a distância até elas. A percepção é o conjunto dessas informações extraídas a partir da leitura do sensor de laser.

Entretanto, em um agente reativo simples, embora os dados de diversos sensores possam ser fundidos para a obtenção de uma determinada informação perceptual, não há a construção de um modelo do mundo que evolua de maneira consistente. Dessa forma, um agente desse tipo pode abstrair de seus sensores apenas a percepção de um evento. Sem utilizar o histórico de percepções é possível apenas perceber situações eventuais e reagir a elas. Assim, um agente reativo simples que simulasse uma presa fugindo do predador, poderia ter apenas duas reações:

- perceber a presença do predador e fugir, ou

- não perceber a presença do predador e realizar outra atividade. 


\subsubsection{Agentes reativos baseados em modelo}

Os agentes reativos simples possuem sérios problemas em lidar com observações parciais do mundo. Muitas vezes, o sucesso de um agente depende de sua capacidade de conhecer aspectos do mundo que não podem ser observados a todo o instante. Por exemplo, o agente presa mencionado anteriormente só fugiria do predador enquanto percebesse a sua presença, ou seja, enquanto esse estivesse em seu campo de visão. Assim que iniciasse o comportamento de fuga, virando as costas para o predador, já não o veria mais e pararia de fugir. Seria interessante que esse agente pudesse saber ou estimar quando o predador realmente ficou para trás e não mais representa um perigo iminente.

Dessa forma, um modo mais efetivo de lidar com a possibilidade de observação parcial é controlar a parte do mundo que não pode ser vista naquele instante. Ele deve manter algum tipo de estado interno que dependa do histórico de percepções e assim reflita pelo menos alguns dos aspectos não percebido do estado corrente, como a proximidade do predador quando está fora do campo de visão. A atualização dessas informações internas de estado à medida que o tempo passa exige que dois tipos de conhecimentos sejam codificados no agente. Primeiro, são necessárias algumas informações sobre o modo como o mundo evolui independentemente do agente. Em segundo lugar, precisa-se de informações sobre como as ações do próprio agente afetam o mundo. Esse conhecimento de como o mundo funciona é chamado de modelo do mundo. A percepção corrente é combinada com o estado interno anterior para gerar a descrição atualizada do estado naquele instante.

O interessante dessa abordagem é a possibilidade de que o agente abstraia dos seus sensores não apenas eventos, mas também situações duradouras. Além das percepções de como o mundo está num certo instante, é possível abstrair algo de como o mundo é. Um caso mais concreto é o da construção de mapas do ambiente. Caso o agente perceba algum obstáculo sempre que passe em determinada região, ele pode incorporar ao seu modelo a presença daquele obstáculo. Dessa forma, a partir de eventos contumazes - que já são uma abstração dos dados sensoriais - é possível abstrair uma característica do mundo.

O agente baseado em modelo do mundo não se enquadra unicamente no paradigma reativo, pois incorpora um elemento de deliberação: a construção 
de um modelo. Porém, da mesma forma, seu controle é baseado em regras de condição/ação.

\subsubsection{Agentes baseados em objetivo}

Uma das limitações dos agentes reativos é a falta de flexibilidade na sua programação, uma vez que todo o controle é executado por regras do tipo condição/ação projetadas para um determinado tipo de ambiente e para uma tarefa específica. Caso haja alguma modificação na estrutura do ambiente ou na tarefa, as regras devem ser reescritas para se adaptar às novas condições. Retomando o exemplo do agente presa, caso aparecesse algum esconderijo não esperado durante a fuga, um agente reativo cujas regras não contemplassem a ida àquele esconderijo específico continuaria correndo, ignorando a nova possibilidade. Assim, conhecer o estado do ambiente nem sempre é suficiente para uma boa decisão sobre o que fazer. Da mesma forma que o agente precisa de uma descrição do estado corrente, ele também precisa de alguma espécie de informação sobre os objetivos que descrevem situações desejáveis. O agente pode combinar isso com informações sobre o resultado de ações possíveis a fim de escolher as que alcancem o objetivo. Dessa forma, seria mais interessante que o agente presa fosse guiado pelo objetivo de se livrar do predador. Isso tornaria possível a decisão de se esconder em algum esconderijo que se tornasse disponível, levando em consideração a evolução dos fatos.

Às vezes a seleção da ação baseada em objetivos é direta, quando a satisfação do objetivo resulta de imediato de uma única ação. Outras vezes será mais complicada, quando o agente tiver de considerar seqüências de ações até encontrar um meio de atingir o objetivo. Nesses casos, a implementação do agente deve envolver técnicas de busca e planejamento, característica do paradigma de controle deliberativo. A tomada de decisões desse tipo é fundamentalmente distinta das regras condição/ação do agente reativo, pelo fato de envolver considerações acerca do futuro.

Em termos da lei de controle do agente, os objetivos a serem alcançados representam um nível de abstração superior ao dos comportamentos. O agente baseado em objetivos possui já uma intencionalidade explícita, que não depende do ambiente nem do tipo de tarefa. No caso do agente presa, a intenção é fugir 
do predador, não importando se para isso deve apenas correr ou se esconder em algum esconderijo. As ações são concretizações dos objetivos para situações determinadas.

\subsubsection{Agentes baseados em utilidade}

Apesar da representação de objetivos na elaboração do agente dar a este maior flexibilidade, ainda não lhe permite uma total independência. Os objetivos são determinados pelo projetista, de forma que o agente não toma realmente uma decisão sobre o rumo que vai seguir. Retomando o exemplo do agente presa, seria necessário estipular previamente uma hierarquia de objetivos para o caso de não haver um predador por perto e assim não ser necessário fugir. Entretanto, é de interesse que o próprio agente determine o que é mais conveniente para si. Para tanto, é necessário um plano de mais alto nível de abstração no controle do agente, algo que represente, de certo modo, a sua "vontade". Isso pode ser obtido através de uma medida de desempenho mais geral que permita uma comparação entre estados diferentes do mundo de acordo com o grau de "conveniência" ou "felicidade" que proporcionariam ao agente caso pudessem ser alcançados. Essa medida, por sua vez, pode ser implementada através de uma função de utilidade, que mapeia um estado ou uma seqüência de estados em um número real que descreve o grau de "conveniência" associado.

Uma especificação completa da função de utilidade permite decisões racionais em dois tipos de casos nos quais os objetivos sozinhos são inadequados. Primeiro, quando existem objetivos contraditórios, dos quais apenas alguns podem ser atingidos, a função de utilidade especifica o compromisso adequado. Em segundo lugar, quando existem vários objetivos que o agente deseja alcançar e nenhum deles pode ser atingido com certeza, a utilidade fornece um meio pelo qual a probabilidade de sucesso pode ser ponderada em relação à importância dos objetivos.

\subsubsection{Agente com aprendizado}

O agente baseado em utilidade é normalmente bastante complexo, pois o conceito de utilidade implementado em seu sistema de controle já se encontra em um alto 
nível de abstração. No entanto, existe uma característica dos seres inteligentes que nenhum dos agentes previamente descritos possui: a capacidade de aprendizado. Um agente que aprende modifica as suas leis de controle de forma a se adaptar ao ambiente em que se encontra e cumprir melhor a sua tarefa. O fato de poder modificar essas leis internas significa que ele consegue se reprogramar. Dessa forma, o aprendizado pode ser entendido como um meio de programar o agente para atuar em um ambiente desconhecido ou simplesmente um modo menos trabalhoso para o projetista, que em vez de planejar previamente uma ação para cada uma das situações que o robô pode encontrar, procura fazer que o próprio agente possa aprender quais são essas ações.

No entanto, o aprendizado realizado por agentes artificiais, assim como o aprendizado de máquina em geral, possui uma estrutura que depende fortemente do objeto desse aprendizado, ou seja, daquilo que deverá aprender. Nos animais, e em especial nos seres humanos, a capacidade de aprendizado parece não ter limites: podem aprender a correr, falar e desempenhar muitas outras tarefas altamente distintas entre si. No entanto, no aprendizado de máquina é necessário antes especificar o que será aprendido, mais especificamente, que variáveis ou parâmetros serão modificados para se melhorar o desempenho do agente, e também qual será esse critério.

Para tanto, um agente com aprendizado pode ser dividido em quatro componentes conceituais. A distinção mais notória se dá entre o elemento de aprendizado, responsável pela execução de aperfeiçoamentos e o elemento de desempenho, responsável pela seleção de ações a serem executadas pelos atuadores. O elemento de desempenho é equivalente a um agente completo de alguma das classes discutidas anteriormente: ele recebe percepções do ambiente e decide sobre as ações. O elemento de aprendizado é então o responsável por ajustar parâmetros do elemento de desempenho para que a escolha das ações seja aprimorada. Para tanto, ele utiliza a realimentação do crítico sobre como o agente está funcionando e determina de que maneira o elemento de desempenho deve ser modificado para desempenhar melhor sua função.

O crítico informa ao elemento de aprendizado como o agente está se comportando com relação a um padrão fixo de desempenho. A presença do crítico é necessária porque as próprias percepções do agente não oferecem nenhuma in- 
dicação de sucesso. As percepções precisam ser interpretadas por um elemento externo, que informe sobre a evolução da eficiência da atuação do elemento de desempenho. É importante que o padrão de desempenho utilizado pelo crítico seja fixo, pois, conceitualmente, deve-se pensar nele como um elemento que se encontra à parte, fora do agente. O crítico não deve ser modificado pelo agente para fazer críticas satisfatórias; pelo contrário, deve ser imutável, de modo a fazer o agente se adaptar ao seus critérios.

O último componente do agente com aprendizado é o gerador de problemas. Ele é o responsável por sugerir ações que levarão a experiências novas e informativas. A questão é que, se o elemento de desempenho tivesse a possibilidade, realizaria sempre as melhores ações dadas as informações que possui, desempenhando uma explotação — do inglês exploitation. Porém, caso o agente realize uma pequena exploração do ambiente, executando algumas ações que não são ótimas a curto prazo, ele poderia descobrir ações muito melhores a longo prazo.

O aprendizado em agentes inteligentes pode ser resumido como um processo de modificação de parâmetros que fazem parte da estrutura interna do agente, a fim de que este atue de forma mais coerente com as informações de realimentação disponíveis, melhorando assim o seu desempenho global.

\subsection{Arquiteturas de agentes}

A classificação de agentes apresentada considera o tipo de informação que o agente utiliza para o seu controle, confrontando-os segundo uma escala de abstração dessas informações. Desse modo, o agente reativo simples se encontra num nível de abstração menor do que um agente baseado em objetivo, o que torna o projeto deste mais complicado do que o do primeiro. No entanto, essa classificação não leva em consideração o modo como é projetado o agente, ou ainda a sua estrutura interna. Após a escolha do tipo de agente a ser utilizado, deve-se definir como será a sua arquitetura, ou seja, como será a organização interna do controle do agente. A arquitetura define passos a serem dados para se determinar a atuação do robô a partir das suas percepções.

Entretanto, a taxonomia de Russel e Norvig (2004) sugere um caminho muito interessante para o projeto da arquitetura de um agente mais complexo: a incor- 
poração de outros agentes mais simples. A classificação apresentada permite que na arquitetura de um agente mais sofisticado, cujo controle utiliza níveis mais altos de abstração, seja incorporada uma estrutura de agente mais simples. Desse modo, a arquitetura de um agente reativo baseado em modelo pode ser projetada com base na arquitetura de um agente reativo simples cuja percepção é formada pela extração das informações de interesse do modelo do mundo. Murphy (2000) denomina a interface que extrai uma informação do modelo construído do mundo de sensor virtual. Do mesmo modo, um agente baseado em objetivos pode ser implementado através de um plano que coordena a ação de comportamentos reativos para o cumprimento desses objetivos. Um agente baseado em utilidade pode ser implementado por um planejador que decide qual dos possíveis objetivos o agente irá perseguir segundo o grau de utilidade de cada um. Finalmente, como sugerido por Russel e Norvig (2004), a arquitetura de um agente com aprendizado pode ser projetada com base na arquitetura de um outro tipo de agente, acrescentando a ela os elementos conceituais do agente aprendiz discutidos na seção 2.2.5.

\subsection{A arquitetura de agente proposta}

A arquitetura para robôs móveis proposta neste trabalho implementa um agente com aprendizado. Como sugerido na seção 2.3, essa arquitetura é constituída por uma camada de supervisão, crítica e aprendizado que supervisiona e modifica a arquitetura de um outro tipo de agente que serve como elemento de desempenho; no caso, de um agente reativo simples, como mostra a figura 2.1.

Apesar do alto grau de sofisticação dos agentes que conceitualmente estão em um maior nível de abstração, o que permite o uso de alguma forma de deliberação, o agente reativo simples merece grande atenção. Em primeiro lugar, a implementação desse tipo de agente leva geralmente a um processamento mais simples, permitindo sua operação em tempo real. Isso porque não há a preocupação em projetar estados futuros ou em elaborar um modelo do mundo, tarefas que demandam maior esforço computacional do que o simples processamento de regras predefinidas. E por utilizar informações com um nível muito baixo de abstração para o seu controle, o projeto e a implementação de um agente reativo simples costumam ser tarefas relativamente fáceis. 


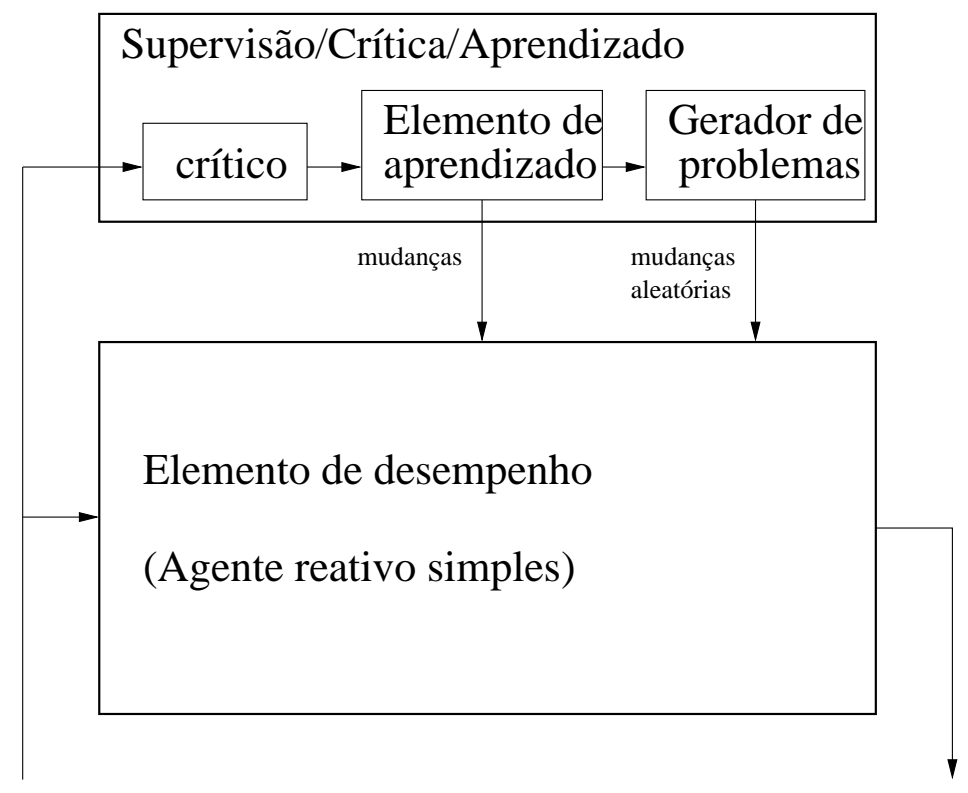

Sensores

Atuadores

Figura 2.1: Representação dos elementos conceituais de aprendizado na arquitetura proposta.

Além do mais, a utilização de regras reativas é muito apropriada em robótica móvel, uma vez que essa abordagem foi desenvolvida pensando justamente nos aspectos encontrados pelos agentes robóticos. A presença do robô em um ambiente incerto e não estruturado favorece a utilização do controle reativo como uma solução simples face a soluções deliberativas complexas, que podem resultar ineficientes devido a modelagens incorretas ou insuficientes do mundo.

Somado a tudo isso, o paradigma reativo pode ser empregado também em arquiteturas mais complexas. Dado que os agentes com arquiteturas híbridas são potencialmente os que apresentam melhor desempenho, a sua atuação depende fortemente da qualidade dos comportamentos reativos utilizados. Além disso, seguindo a classificação de Russel e Norvig (2004), o agente reativo simples pode servir de base para qualquer outro tipo de agente, o que reforça a importância do estudo desse tipo de agente.

Entretanto, implementar um agente reativo simples de interesse real, que implique definir um conjunto de regras muito grande é uma tarefa difícil. Uma maneira mais fácil de lidar com uma grande quantidade de regras condição/ação é organizá-las em comportamentos. 


\section{Arquiteturas de comportamentos para robôs móveis}

De maneira geral, um comportamento é uma função que relaciona estímulos sensoriais a ações produzidas sobre os atuadores do agente, de acordo com um plano realizado a partir de um modelo interno do ambiente (RIBEIRO; COSTA; ROMERO, 2001). Posta desta maneira, essa definição de comportamento relacionase com a definição de agente dada no capítulo 2. De fato, um agente pode ser expresso através de um único comportamento. No entanto, o comportamento vem a servir como uma unidade básica para a construção das ações, que são assim determinadas pela coordenação de comportamentos distintos. Cada um deles responde com a indicação de uma determinada ação a partir dos estímulos recebidos, de modo que a atuação final do agente vem da coordenação dessas respostas. Dessa forma, arquiteturas baseadas em comportamentos são inerentemente modulares do ponto de vista de projeto de software. Isso permite que elas sejam expansíveis, possibilitando o aumento das competências do robô adicionando novos comportamentos sem a necessidade de redefinir ou descartar os antigos.

De acordo com a complexidade do plano utilizado pelo comportamento, é possível situá-lo dentro de uma escala crescente de complexidade (RIBEIRO; COSTA; ROMERO, 2001). Os comportamentos denominados reativos compõem a extremidade de menor complexidade da escala, não possuindo nenhum plano. Eles realizam um mapeamento simples e direto entre a percepção daquele instante e a ação correspondente. No extremo oposto da escala estão os comportamentos deliberativos mais complexos.

A Inteligência Artificial (IA) tradicionalmente sempre se preocupou com técnicas 
de raciocínio lógico baseadas em complexas representações simbólicas, levando a uma representação explícita do conhecimento sobre o mundo. Dessa forma, a inteligência de um agente fica vinculada à sua capacidade de construir e manipular sua base de conhecimento, procurando simular a deliberação realizada pelo ser humano. Entretanto, a abordagem comportamental nasceu dentro da robótica móvel como uma contraproposta à essa abordagem deliberativa. Os robôs móveis são agentes reais, e, como tais, devem atuar satisfatoriamente no mundo real. Segundo Arkin (1998), a abordagem comportamental proporciona um meio para que o robô navegue em um mundo incerto e imprevisível sem planejamento, dotando o robô de comportamentos que lidam com tarefas específicas independentemente, e coordenando-os propositadamente.

Essa abordagem comportamental reativa foi também defendida por Brooks (1990) como a nova IA, onde a inteligência do agente robótico não mais viria através de construções lógicas nem de modelagens abstratas do mundo, mas sim da interação direta com o mundo real. Dessa forma, é mais importante que o robô apresente um comportamento simples, mas consiga atuar de maneira satisfatória no ambiente em que está inserido, do que planejar sobre representações simbólicas abstratas, que muitas vezes são inconsistentes e funcionam apenas em simulações.

Uma conseqüência dessa nova IA é que o conceito de racionalidade fica então dissociado do conceito de raciocínio. A atuação racional é aquela que cumpre a tarefa designada. Assim, caso um robô seja projetado para carregar pilhas de material de um ponto a outro dentro do galpão de uma fábrica, e ele o faz, conseguindo desviar dos obstáculos e depositando o material no lugar correto, diz-se que ele agiu racionalmente.

Desse modo, embora este capítulo trate de comportamentos em geral, maior ênfase será dada a comportamentos reativos.

\subsection{Formalização dos comportamentos}

Ribeiro, Costa e Romero (2001) trazem uma interessante formalização para os comportamentos e sua coordenação. Cada comportamento $c_{i}$ mapeia (possivelmente de modo não-determinístico) um conjunto de estímulos $\left\{s_{i}^{1}, s_{i}^{2}, \ldots, s_{i}^{k_{i}}\right\}$ e um plano $p_{i}$ em uma ação $a_{i}$. Assim, para um agente possuindo um número $n$ de 
comportamentos, tem-se

$$
\begin{aligned}
a_{1}= & c_{1}\left(\mathbf{s}_{\mathbf{1}}, p_{1}, w_{1}\right) \\
a_{2}= & c_{2}\left(\mathbf{s}_{\mathbf{2}}, p_{2}, w_{2}\right) \\
\vdots & \vdots \\
a_{n}= & c_{n}\left(\mathbf{s}_{\mathbf{n}}, p_{n}, w_{n}\right)
\end{aligned}
$$

onde $\mathbf{s}_{\mathbf{i}}=\left[\begin{array}{llll}s_{i}^{1} & s_{i}^{2} & \cdots & s_{i}^{k_{i}}\end{array}\right]$ é o vetor real formado pelos estímulos advindos dos sensores e $w_{i}$ é uma variável aleatória cuja distribuição de probabilidade é um parâmetro de projeto. Cada comportamento $c_{i}$ é, portanto, uma função $c_{i}: \Re^{k_{i}} \times \mathcal{P} \times \Re \rightarrow \mathcal{A} \cup \lambda$, cujos argumentos são um vetor real $\mathbf{s}_{\mathbf{i}}$, de tamanho $k_{i}$, formado pelos estímulos usados pelo comportamento $c_{i}$, um plano $p_{i} \in \mathcal{P}$ convenientemente codificado ( $\mathcal{P}$ representa o espaço de possíveis planos), e uma perturbação aleatória $w_{i} \in \Re$, presente apenas quando o comportamento considerado é definido como não-determinístico. Ao conjunto de possíveis ações $\mathcal{A}$ é acrescida a ação inócua $\lambda$, que atua apenas como uma marca para indicar a inatividade do comportamento correspondente. A notação vetorial correspondente a (3.1) é

$$
\mathbf{A}=\mathbf{C}(\mathbf{S}, \mathbf{P}, \mathbf{W})
$$

onde:

- $\mathbf{S}=\left[\begin{array}{llll}\mathbf{s}_{1} & \mathbf{s}_{\mathbf{2}} & \cdots & \mathbf{s}_{\mathbf{n}}\end{array}\right]^{\mathrm{T}}$ é a matriz de estímulos;

- $\mathbf{P}=\left[\begin{array}{llll}p_{1} & p_{2} & \cdots & p_{n}\end{array}\right]^{\mathrm{T}}$ é o vetor de planos;

- $\mathbf{W}=\left[\begin{array}{llll}w_{1} & w_{2} & \cdots & w_{n}\end{array}\right]^{\mathrm{T}}$ é o vetor de perturbações;

- $\mathbf{C}=\left[\begin{array}{lll}c_{1}\left(\mathbf{s}_{\mathbf{1}}, p_{1}, w_{1}\right) & \cdots & c_{n}\left(\mathbf{s}_{\mathbf{n}}, p_{n}, w_{n}\right)\end{array}\right]^{\mathrm{T}}$ é o vetor de comportamentos do agente;

- $\mathbf{A}=\left[\begin{array}{llll}a_{1} & a_{2} & \cdots & a_{n}\end{array}\right]^{\mathrm{T}}$ é o vetor de ações definidas pelos comportamentos.

A coordenação dos vários comportamentos $c_{i}$ é feita por uma função de coordenação $C c$ tal que

$$
a=C c(\mathbf{C}(\mathbf{S}, \mathbf{P}, \mathbf{W}), \mathbf{S}, \mathbf{P})=C c(\mathbf{A}, \mathbf{S}, \mathbf{P})
$$

onde $a$ denota a ação resultante da coordenação dos comportamentos. Segundo essa notação, a coordenação dos comportamentos também pode envolver in- 
formações sensoriais e planos. (3.3) sugere que esses os planos e dados sensoriais são também utilizados por um ou vários comportamentos. Caso não sejam, podem-se definir comportamentos inócuos, com saída $\lambda$, a serem acrescentados a $\mathbf{C}(\mathbf{S}, \mathbf{P}, \mathbf{W})$, e que utilizam as informações de sensores e os planos necessários à coordenação.

No caso de arquiteturas reativas, não há execução de planos. Logo, nessas arquiteturas temos $\mathbf{P}=0$ e $c_{\text {reativo }}: \Re^{k} \times \Re \rightarrow \mathcal{A} \cup \lambda$.

\subsection{A codificação dos comportamentos}

A notação formal apresentada sugere que o comportamento reativo é uma função que codifica as informações sensoriais (e possivelmente uma perturbação) em um elemento do espaço de ações. Dessa forma, o espaço de estímulos é mapeado em uma imagem no espaço de ações. Arkin (1998) identifica três categorias para esse mapeamento:

- Mapeamento nulo: os estímulos nunca produzem uma ação, caracterizando comportamentos inócuos do tipo $c_{\lambda}: \Re^{k} \times \Re \rightarrow \lambda$.

- Mapeamento discreto: a ação produzida pelos estímulos pertence a um conjunto enumerável de ações predefinidas, que são assim indexadas por uma discretização do espaço de estímulos.

- Mapeamento contínuo: o domínio de estímulos, representado por um espaço real com dimensão finita $\left(\Re^{k}\right)$, é mapeado em uma imagem contínua no contradomínio de ações.

\subsubsection{Codificações discretas}

As codificações discretas de comportamentos são aquelas que realizam um mapeamento discreto do domínio de estímulos em um conjunto de respostas predefinidas para o comportamento em questão. Dessa forma, há determinadas ações preestabelecidas que o comportamento pode evocar, tais como vire à direita, avance a $1 \mathrm{~m} / \mathrm{s}$, abra a garra, retroceda $20 \mathrm{~cm}$ e gire $180^{\circ}$, etc. 
De modo geral, no contexto de Robótica Móvel Inteligente, as ações são realizações de alto nível, que podem corresponder a um ou mais controladores de baixo nível de projeto bastante complexo (RIBEIRO; COSTA; ROMERO, 2001). Dessa forma, não está codificada no comportamento a descrição física de como se realiza determinada ação, mas isso fica a cabo do controlador responsável por ela. Assim, no caso de o robô agarrar um objeto, uma ação do tipo feche a garra não leva em consideração o tamanho dele para se calcular o quanto a garra deve fechar. Isso fica a cabo do seu controlador, que deve sentir quando ela já travou o objeto.

Um comportamento reativo que realiza um mapeamento discreto implementa um conjunto de regras formadas por pares (condição, ação), onde a condição é dada por uma região no espaço de estímulos sensoriais. Assim, é realizado um mapeamento intermediário, onde o conjunto de estímulos é usado para se determinar uma percepção sobre o estado momentâneo do ambiente; então essa percepção é usada para a escolha de uma ação. A codificação discreta pode ser expressa também através de regras de produção do tipo SE-ENTÃo.

Caso o movimento do robô seja controlado por um ou mais comportamentos com codificação discreta, diferentes percepções gerarão ações motoras diversas. Um comportamento de contornar um obstáculo provavelmente comandará ações do tipo vire $90^{\circ}$ à esquerda ou pare e vire $90^{\circ}$ à direita. Dessa forma, uma mudança na percepção pode acarretar mudanças bruscas de orientação do robô, gerando trajetórias com quebras na direção. Em algumas situações é interessante que mudanças graduais de percepção gerem também mudanças sutis nas ações.

\subsubsection{Codificação contínua de comportamentos}

As codificações contínuas de comportamentos são aquelas que realizam um mapeamento contínuo do domínio de estímulos em uma imagem no contradomínio de ações. Isso significa que leves mudanças nos estímulos sensoriais levarão a mudanças sutis nas ações.

A continuidade da imagem da função de comportamento $c$ no espaço de ações supõe que estas sejam parametrizadas por uma variável ou um conjunto de variáveis reais, de modo que o mapeamento de um volume no espaço real de 
estímulos resulte em um volume contínuo e não nulo no espaço real de parâmetros das ações. Esse mapeamento é muito adequado para ações motoras de robôs móveis, pois costuma gerar trajetórias suaves.

No caso de robôs móveis terrestres, a ação motora corresponde, de modo geral, a um vetor que indica um movimento no plano do chão. Assim, a ação possui como parâmetros duas magnitudes, translação $(T \in \Re)$ e rotação $(R \in \Re)$, e pode ser expressa como

$$
a=a(T, R)
$$

Tanto a rotação quanto a translação do robô pode ser expressa através de uma magnitude de deslocamento, de velocidade, de aceleração ou de força/torque, o que depende da abordagem de controle utilizada.

Considere o caso de um comportamento de atração a um objetivo que utilize como percepção a posição do robô com relação a ele, e cuja ação é parametrizada por um vetor de aceleração $\vec{a}$, representado por uma intensidade $|\vec{a}|$ e uma orientação $\alpha$. Nesse caso, o comportamento com codificação contínua pode ser uma função analítica que relaciona a distância do robô a uma magnitude de aceleração. A orientação é dada pela direção da reta que liga o robô ao alvo. Um exemplo típico de função que pode ser utilizada é a da lei de interação das cargas elétricas de Coulomb:

$$
|\vec{a}|=\frac{K}{d^{2}}
$$

onde $K$ é uma constante (parâmetro de projeto) e $d$ é a distância euclidiana do robô ao alvo.

Contudo, é interessante notar que a realização de baixo nível da ação desejada é implementada pelo controlador dos motores do robô, de forma que o comportamento não se preocupa com os detalhes de controle, como o nível de corrente ou de tensão aplicados nos motores.

\subsection{Coordenação dos comportamentos}

Dependendo de como foram projetados os comportamentos de uma arquitetura, eles podem atuar conjuntamente ou, pelo contrário, podem ser incompatíveis. Isso influencia na escolha da função $C c$ de coordenação a ser utilizada. De modo 
geral, existem duas modalidades básicas para a coordenação de comportamentos: a competitiva e a cooperativa.

\subsubsection{Coordenação competitiva}

Na coordenação competitiva, a ação a ser executada é escolhida dentre as ações associadas a cada um dos comportamentos ativos. Dessa forma, apenas um comportamento é atuante a cada vez. O uso de uma função competitiva é adequado para coordenar comportamentos projetados para atuarem isoladamente. Geralmente, comportamentos com codificação discreta são mais difíceis de serem combinados, o que torna apropriada a coordenação competitiva.

\section{Arquitetura de subsunção}

Um exemplo relevante de arquitetura reativa com coordenação de comportamentos por competição é a arquitetura de subsunção (subsumption) (BROOKS, 1986). Ela organiza os comportamentos em camadas de competência: comportamentos em níveis mais altos correspondem àqueles direcionados ao objetivo da tarefa especificada, enquanto que aqueles em níveis mais baixos correspondem a ações mais simples, menos propositadas. Além das características intrínsecas do paradigma reativo, tais como simplicidade dos comportamentos (mapeamentos estímulo-ação) e processamento local da informação sensorial em cada comportamento, a arquitetura de subsunção estabelece um mecanismo de prioridade de comportamentos das camadas em nível mais alto sobre aqueles em nível mais baixo, configurando uma coordenação competitiva de comportamentos com hierarquia pré-definida, onde a atuação do robô é definida pelo comportamento ativo de maior grau hierárquico.

É importante observar que a hierarquia na arquitetura de subsunção é estabelecida de forma específica entre os comportamentos. A prioridade de um comportamento de nível mais alto ocorre apenas sobre uma coleção específica de comportamentos de nível mais baixo, e não sobre todos esses, indiscriminadamente. Assim, comportamentos básicos mas não necessários para preservar a integridade do robô, como por exemplo um comportamento de exploração nãodirecionada do ambiente, pode ser inibido ou suprimido por um comportamento de nível mais alto, como um comportamento de aproximação de alvo, sem que 
este último exerça prioridade sobre um comportamento para evitar colisões com obstáculos.

$\mathrm{Na}$ arquitetura de subsunção identificam-se dois mecanismos primários para a coordenação competitiva e hierárquica dos comportamentos:

- o mecanismo de inibição, pelo qual a ação resultante de um comportamento é impedida de comandar os atuadores;

- o mecanismo de supressão, pelo qual a percepção de um comportamento é trocada por um sinal de supressão, que comanda a inatividade do comportamento.

A figura 3.1 ilustra um exemplo simples de implementação da arquitetura de subsunção para um robô móvel que se move em um ambiente, desviando-se de obstáculos quando necessário, mas sem perder a direção do seu movimento. Neste exemplo, o robô tem como sensores um conjunto de oito sonares distribuídos uniformemente em sua periferia, capazes de estimar a distância de obstáculos nas direções correspondentes. Um módulo de processamento da informação sensorial Calcula Vetor interpreta as leituras dos sensores como vetores e os soma, produzindo um vetor resultante que indica a direção e magnitude relativas à posição e distância de um obstáculo imaginário, que resume estas leituras. O movimento do robô é comandado por dois motores independentes: o motor 1, que produz velocidades iguais nas rodas, e o motor 2 , que realiza um giro no eixo das rodas.

O comportamento Parar, de codificação discreta, não faz parte da hierarquia de comportamentos e tem prioridade absoluta sobre todos os outros e atua da seguinte forma: ao detectar, pelas leituras dos sonares, a proximidade de algum obstáculo (leitura de algum sonar maior do que o limiar de proximidade perigosa $L_{s r}$ ), força a parada do robô enviando um comando apropriado para o motor responsável pelo controle de velocidade das rodas.

Na camada mais baixa da hierarquia de comportamentos está o comportamento básico Afastar, de codificação contínua, que produz: a) um giro do eixo das rodas do robô até que este fique com sua frente na direção oposta à do vetor, e b) um posterior avanço proporcional à magnitude do vetor. Numa camada mais alta, um comportamento Explorar combina um vetor de magnitude fixa e direção 
aleatória, produzido a intervalos regulares, a um vetor de direção oposta ao daquele produzido pelo módulo Calcula Vetor. Desta forma, obtém-se uma nova direção para o movimento do robô, correspondente a um desvio de obstáculos mais suave, que leva em consideração uma direção preferencial de movimento (aquela estabelecida pelo comportamento Explorar). Este comportamento suprime (ou seja, substitui) a saída produzida pelo comportamento Afastar, que no entanto continua ativo: caso o comportamento Explorar seja desativado (possivelmente por algum outro comportamento em nível mais alto), o robô ainda terá a capacidade de desviar de obstáculos satisfatoriamente.

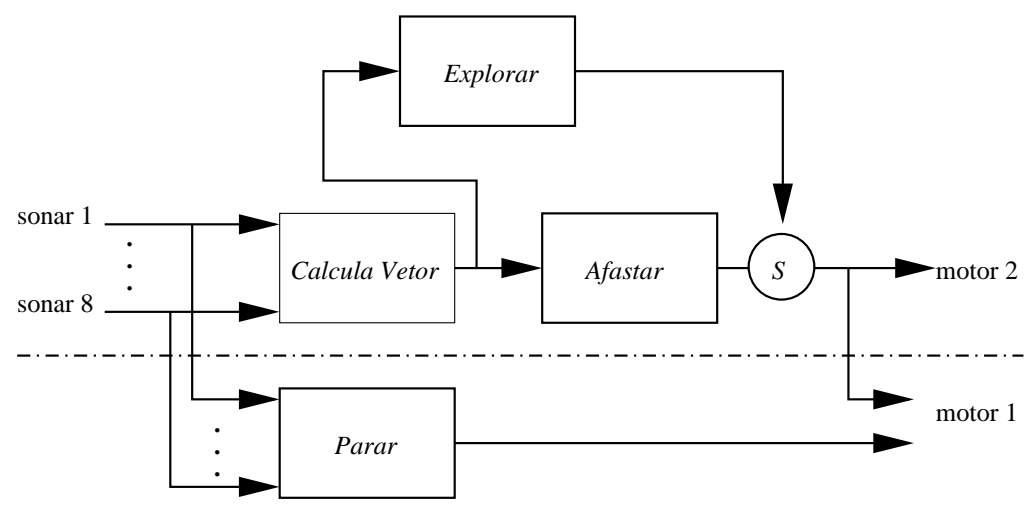

Figura 3.1: Um exemplo simples da arquitetura de subsunção, retirado de Ribeiro, Costa e Romero (2001).

\subsubsection{Coordenação cooperativa}

Na coordenação por cooperação dos comportamentos, cada um deles colabora, em maior ou menor grau, para a determinação da ação a ser executada pelo robô. Dessa forma é necessário que as ações resultantes dos comportamentos sejam facilmente combináveis, de preferência através de operações matemáticas simples como adição ou multiplicação. Para isso é conveniente que as ações do robô sejam parametrizadas por variáveis reais, de forma que a atuação final seja obtida através de uma operação realizada sobre o conjunto de valores dessas variáveis retornados pelos comportamentos. Uma vez que a codificação contínua de comportamentos exige esse tipo de parametrização das ações, a coordenação cooperativa geralmente se mostra bastante adequada para comportamentos desse tipo. 


\section{Arquitetura baseada em Campos Potenciais}

Esta arquitetura corresponde à implementação de comportamentos representados de forma contínua através de campos potenciais, coordenados de acordo com um mecanismo de cooperação de soma vetorial. A técnica de campos potenciais é uma implementação típica de codificação contínua para comportamentos reativos (ARKIN, 1998), e associa um vetor de ação a cada estado em um espaço contínuo. Dessa forma, cada comportamento gera um campo vetorial, que, por sua vez, dá origem a um campo potencial. Um exemplo típico é um comportamento reativo repulsivo a obstáculos. A ação calculada tem a direção da reta imaginária ligando o robô à posição do obstáculo, o sentido é o de afastamento relativo ao obstáculo, e a magnitude é calculada por alguma função de decaimento espacial (linear, quadrática ou exponencial). Um comportamento deste tipo gera um campo vetorial como ilustrado na figura 3.2. É interessante notar, porém, que este campo não precisa ser calculado durante o projeto do comportamento: quando ativado, o comportamento calcula o vetor de ação apenas para a situação correspondente.

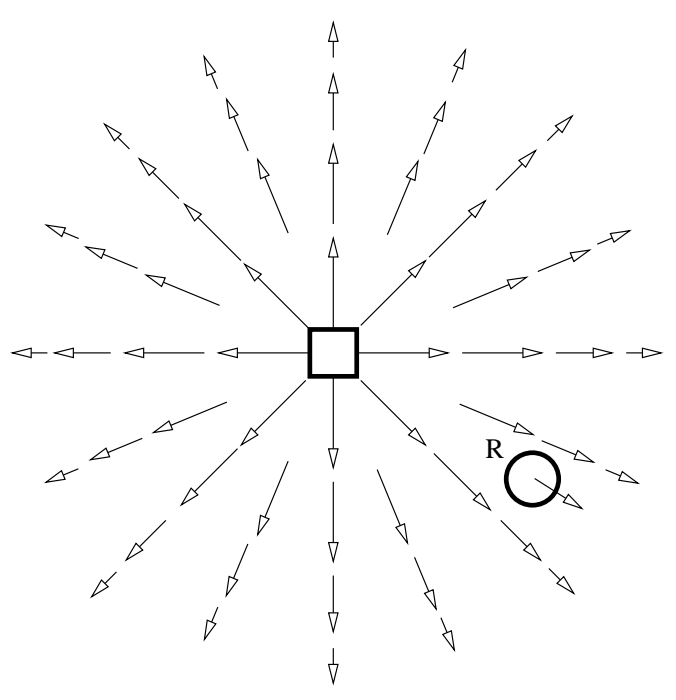

Campo vetorial associado a um comportamento contínuo de rejeição do obstáculo representado pelo pequeno quadrado. Apenas alguns vetores estão representados, pois o campo é contínuo. O robô deverá produzir a ação indicada pela magnitude e direção do vetor do campo cuja origem coincide com a posição do seu centro.

Figura 3.2: Campo vetorial associado a um comportamento contínuo de rejeição a um obstáculo (retirado de Ribeiro, Costa e Romero (2001)).

Diferentemente de robôs projetados com base na arquitetura de subsunção, 
um robô de arquitetura baseada em campos potenciais tem todos os comportamentos em um mesmo nível de prioridade, sem uma hierarquia explícita entre eles. A cada comportamento corresponde uma ação (expressa como um vetor), produzida em qualquer situação (ou seja, todos os comportamentos estão sempre ativos). A atuação efetivamente produzida é resultante da soma dos vetores correspondentes à contribuição de cada comportamento. A magnitude dos vetores em pontos diferentes do ambiente em que o robô atua pode variar, o que equivale na prática a um mecanismo de inibição: um vetor de magnitude grande somado a um de pequena magnitude e direção oposta efetivamente inibe a ação deste último.

Uma arquitetura baseada em campos potenciais requer que a ação correspondente a cada comportamento seja expressa como um entre quatro possíveis tipos de campo:

Uniforme, que corresponde a vetores de mesma intensidade e direção em qualquer ponto do ambiente. Um comportamento Avançar, que faz o robô se mover para a frente independentemente da informação sensorial, pode ser expresso como um campo deste tipo.

Perpendicular, que orienta o robô na direção perpendicular a alguma fronteira (normalmente uma parede).

Atrativo, que corresponde a vetores orientados a um ponto atrator, e geralmente com magnitude inversamente proporcional a uma função crescente da distância relativa até esse ponto, em um efeito similar ao da gravidade ou atração eletrostática. Este tipo de campo é útil para expressar o efeito de tropismo em sistemas biológicos (atração por um objetivo, luz ou "comida").

Repulsivo, que é o oposto do campo atrativo. Útil para modelar comportamentos para evitar obstáculos.

Uma vantagem de uma arquitetura baseada em campos potenciais é a facilidade de visualização do comportamento global do robô, ainda na fase de projeto: a observação do campo resultante da combinação dos vários comportamentos permite prever com relativa facilidade o que o robô fará em cada situação. 


\subsection{Arquiteturas híbridas baseadas em compor- tamentos}

Até agora foram apresentados apenas exemplos de arquiteturas comportamentais reativas. No entanto, a abordagem comportamental pode ser empregada também em arquiteturas híbridas, que combinam o paradigma reativo com algum grau de planejamento. Um modo bastante utilizado para combinar os paradigmas reativo e deliberativo é através da incorporação de um elemento de planejamento sobre a definição e seleção de comportamentos reativos individuais. Uma arquitetura híbrida desse tipo corresponde a uma arquitetura reativa controlada por um plano de execução e seqüenciamento de comportamentos. Através da incorporação da habilidade de raciocínio baseado em modelos internos do mundo (planejamento), estas arquiteturas permitem a reconfiguração dinâmica de sistemas de controle reativo.

A integração de planejamento e reatividade é um problema complexo. Contudo, existe um consenso que nenhuma abordagem - reativa ou deliberativa - é completamente satisfatória isoladamente, e ambas devem ser levadas em consideração para produzir um sistema flexível, robusto e inteligente. Para o desenvolvimento de um sistema híbrido deve-se saber qual é a fronteira apropriada para subdivisão de funcionalidades e como deve ser conduzida a coordenação entre estas.

\subsubsection{Arquitetura de Campos Potenciais com planejamento sob demanda}

Um exemplo recente de arquitetura híbrida baseada em replanejamento de comportamentos reativos é a apresentada por Ranganathan e Koenig (2003). Essa arquitetura é composta por três camadas: a camada reativa, responsável pela navegação reativa do robô, a camada deliberativa, responsável pelo planejamento de trajetórias e a camada de seqüenciamento, que decide quando as camadas reativa e deliberativa devem atuar.

A camada reativa é formada por dois comportamentos codificados pelo método de Campos Potenciais e coordenados de forma cooperativa. Os comportamentos envolvidos são: move to goal, que procura dirigir o robô até uma posição alvo, 
e avoid obstacle, que procura fazer o robô desviar de obstáculos. Essa camada é a que geralmente está ativa. No entanto, a atuação isolada da camada reativa pode levar a situações nas quais os efeitos de ambos os comportamentos se anulam ou geram ações motoras indevidas, deixando o robô incapaz de evoluir em seu caminho. A camada de seqüenciamento funciona então como supervisor da arquitetura, e ativa a camada deliberativa para que determine uma posição alvo intermediária, que se encontre no caminho até o objetivo final. Assim o comportamento move to goal sofre um replanejamento do objetivo. Espera-se que a mudança da configuração do campo vetorial produzido pelo comportamento move to goal, gerada pela troca da posição do alvo, seja suficiente para que o robô consiga sair da situação em que se encontra e chegar até o objetivo intermediário usando os mesmos comportamentos reativos. No entanto, caso o robô ainda não seja capaz de chegar até lá, a camada de seqüenciamento comanda à camada de deliberação que planeje uma trajetória fixa até esse objetivo. Com isso, a atuação do robô passa a ser totalmente deliberativa, o que é utilizado como último recurso.

O modelo do mundo utilizado pela camada deliberativa para o planejamento de trajetória é uma grade de ocupação de pequeno alcance, que configura um mapa numérico das posições dos obstáculos do ambiente. O algoritmo D* Lite (KOENIG; LIKHACHEV, 2002, apud Ranganathan e Koenig (2003)) é então utilizado para gerar um planejamento de trajetória de curto alcance, suficiente para se determinar um caminho até uma posição intermediária entre o robô e o alvo final.

\subsubsection{A arquitetura comportamental proposta}

A arquitetura híbrida proposta por este trabalho também executa uma forma de planejamento sobre comportamentos reativos codificados por Campos Potenciais, mas em vez de modificar os parâmetros internos a esses comportamentos, ajusta o grau de participação de cada um deles na atuação final do robô. Esse planejamento é realizado através de aprendizado por reforço, que em vez de considerar possibilidades futuras para a atuação do robô - no caso do planejamento de trajetórias, são consideradas aquelas que o robô pode vir a percorrer e então se escolhe a melhor - determina como ele deve agir com base somente na experiência 
adquirida.

A organização dessa arquitetura está ilustrada na figura 3.3. Em relação aos comportamentos, a percepção permanece como na arquitetura reativa original: local, específica a cada comportamento. No entanto, o módulo de supervisão/crítica/aprendizado, como precisa supervisionar a atuação do robô, além de dividir os mesmos sensores usados pelos comportamentos, pode conhecer também as percepções obtidas por eles.

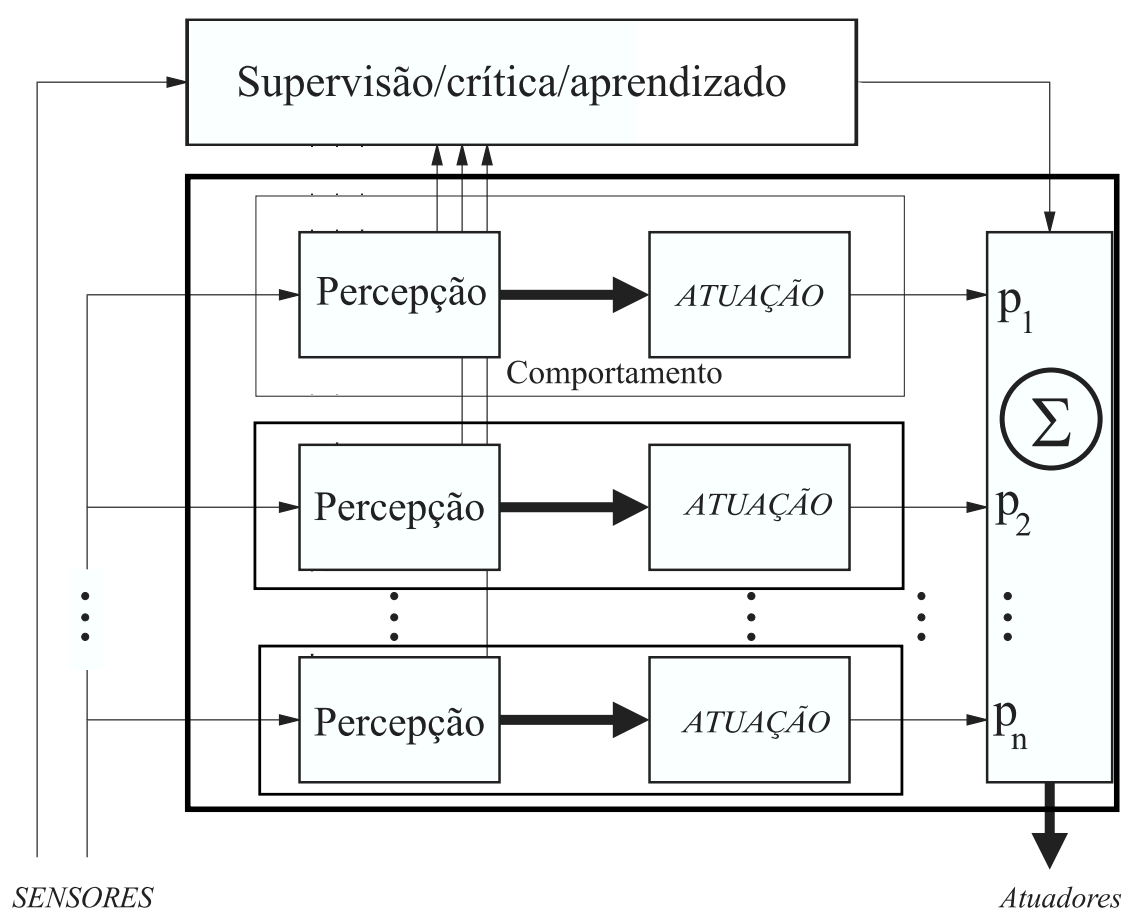

Figura 3.3: Organização da arquitetura híbrida proposta.

A camada de aprendizado observa o estado do ambiente e o movimento do robô através dos sensores presentes e das percepções obtidas em cada comportamento, composto por um módulo de percepção e um módulo de codificação da ação. Então a cada estado observado, essa camada fornece ao módulo de cooperação dos comportamentos (um mero somador vetorial com ponderação por pesos na entrada) um conjunto de pesos $\left\{p_{1}, p_{2}, \ldots, p_{n}\right\}$, onde $n$ é o número de comportamentos da arquitetura.

A camada de comportamentos reativos da arquitetura proposta corresponde a uma arquitetura preexistente puramente reativa de nome REACT (PACHECO; COSTA, 2002), discutida no capítulo 4. 


\section{A arquitetura REACT}

REACT é uma arquitetura reativa aplicada à navegação de robôs móveis, projetada com base em comportamentos modelados por Motor-Schemas, utilizando o método dos Campos Potenciais, desenvolvida no Laboratório de Técnicas Inteligentes do Departamento de Engenharia de Computação e Sistemas Digitais da Escola Politécnica da USP (PACHECO; COSTA, 2002). Sua composição original é formada por três comportamentos atuando de forma coordenada: comportamento de evitar colisões (avoidCollision), de se dirigir ao alvo (moveToGoal) e de priorizar a permanência na direção de navegação (comportamento inercial moveAhead).

Este capítulo descreve a arquitetura REACT original. Primeiro, é discutida a sua estrutura principal, explicando o funcionamento geral dos comportamentos e como eles são coordenados. Depois, cada comportamento é abordado individualmente com informações sobre o seu funcionamento interno.

\subsection{A codificação e coordenação dos comporta- mentos}

A arquitetura REACT é baseada em comportamentos modelados por MotorSchemas(ARKIN, 1998). Um Motor-Schema permite, essencialmente, a definição e implementação de um comportamento em dois módulos principais: o módulo de percepção, que é responsável por extrair dos estímulos sensoriais as informações relevantes para o comportamento em questão, e o módulo de codificação do comportamento que, alimentado pelo módulo de percepção, executa o mapeamento dos estímulos sensoriais nas respostas motoras. Os parâmetros que definem uma ação - que corresponde à saída de cada Motor-Schema — são a magnitude e a 
direção do movimento. Estes parâmetros são representados por um vetor, e correspondem, respectivamente, à velocidade e à rotação que o robô deve executar, segundo o comportamento em questão.

O módulo de percepção é composto por algoritmos que extraem dos estímulos sensoriais as informações que tenham significado relevante para um dado comportamento. Caso haja mais de um tipo de sensor, é neste módulo que ocorre a fusão sensorial, ou seja, a interpretação dos diferentes tipos de estímulos do ambiente de forma a compor a percepção global à qual o robô deve reagir. Na arquitetura REACT, apesar de serem usados dois tipos de sensores — sonares e odômetro não há fusão sensorial, uma vez que estes sensores são utilizados isoladamente, em comportamentos distintos.

A codificação das percepções em ações se dá de forma contínua, utilizando a metodologia de campos potenciais. A coordenação dos vários comportamentos é feita de forma cooperativa, onde a ação resultante que o robô deve executar deriva das contribuições advindas de todos os comportamentos. A abordagem de campos potenciais sugere uma maneira muito simples para a coordenação dos comportamentos: a superposição dos campos, onde as contribuições (vetores) de cada comportamento são somadas, de maneira que o problema da coordenação se resume a dimensionar corretamente os campos dos diferentes comportamentos de forma que a sua soma resulte no comportamento global desejado para o robô. A figura 4.1 ilustra a coordenação dos comportamentos na arquitetura REACT.

\subsection{Os comportamentos utilizados na arquite- tura REACT}

Como mencionado no capítulo introdutório, o problema de aplicação de robôs móveis a ser tratado aqui é o da navegação em ambiente com obstáculos para atingir uma posição alvo conhecida. Este problema sugere duas tarefas básicas para o robô: o desvio de obstáculos e o direcionamento até o alvo. Desse modo, convém que a arquitetura base possua pelo menos dois comportamentos, um associado a cada tarefa. No entanto, notou-se a conveniência de se adicionar um comportamento inercial que amenizasse as oscilações da trajetória do robô, de modo que a arquitetura REACT original é dotada de três comportamentos, cujas saídas são 


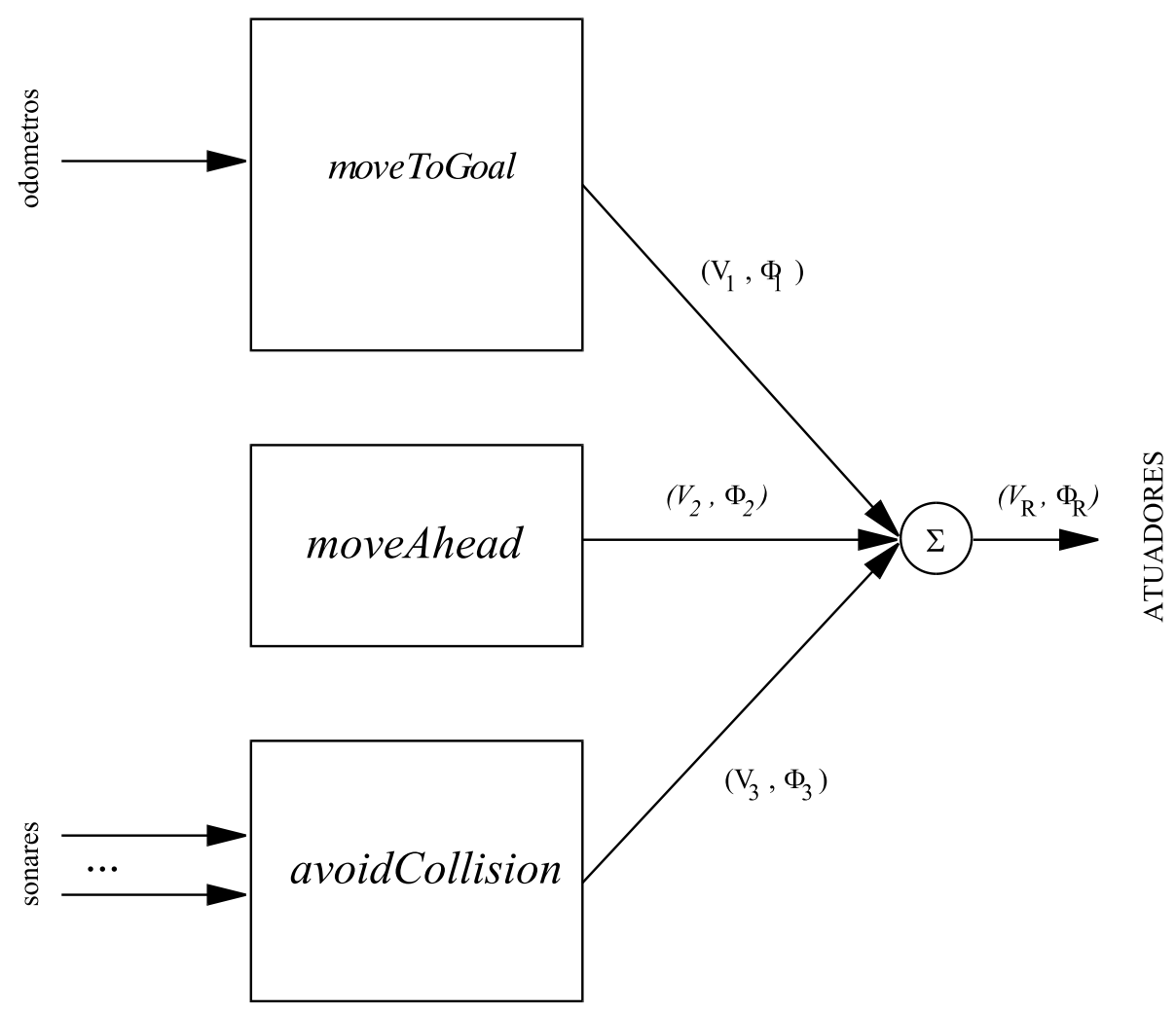

Figura 4.1: Motor-Schema dos comportamentos avoidCollision, moveAhead, moveToGoal e a composição vetorial.

vetores de movimentos parametrizados por velocidade escalar e direção. Aqui, cada comportamento é detalhado individualmente, com explicações de como a velocidade, a direção e o sentido do vetor de saída são calculados diretamente a partir das leituras dos sensores.

\subsubsection{Comportamento avoidCollision}

Este comportamento tem por objetivo evitar colisões em relação a múltiplos obstáculos. O módulo de percepção deste comportamento interpreta as leituras dos sonares de modo a identificar os obstáculos presentes no ambiente. Esta interpretação adota a restrição de continuidade espacial do ambiente, no intuito de evitar que duas leituras advindas de um mesmo obstáculo sejam interpretadas como dois obstáculos diferentes. Tal interpretação faria com que o robô reagisse de modo muito intenso ao obstáculo, dificultando a navegação por caminhos estreitos.

A continuidade espacial é determinada por dois fatores: a vizinhança dos 
sonares e a diferença entre os valores absolutos das leituras. Deste modo, duas leituras correspondem a um espaço contínuo - e, portanto, representam um mesmo obstáculo - se tiverem sido obtidas por sonares vizinhos e se a diferença entre os valores absolutos das leituras (que correspondem às distâncias medidas) não ultrapassar um limiar pré-estabelecido. Este limiar consiste em um parâmetro do comportamento e pode ser ajustado conforme o tipo de ambiente em que o robô deve navegar. No caso da detecção de um obstáculo por dois ou mais sonares, a posição deste obstáculo é definida como sendo a leitura que indique maior proximidade ao robô. Dessa forma, a leitura de dois sonares vizinhos é interpretada como um único obstáculo se

$$
R_{i+1}-R_{i}<L_{\mathrm{obs}}
$$

onde $R_{i+1}$ e $R_{i}$ são as leituras de dois sonares vizinhos e $L_{\text {obs }}$ é o limiar definido para a observação.

O módulo de codificação deste comportamento, alimentado pelo módulo de percepção, determina qual a ação motora adequada àquela percepção, ou seja, constrói o campo de velocidades do comportamento, associando cargas repulsivas aos obstáculos. Como se trata de um campo vetorial, este módulo deve fornecer a direção e a magnitude do campo no ponto em que se encontra o robô. A direção é definida como radial. Deste modo, na presença de um obstáculo, o robô sofre uma força repulsiva na direção da reta que une o seu centro de massa ao obstáculo detectado. O resultado final do comportamento é a soma vetorial de cada uma das forças devidas a cada obstáculo detectado. A magnitude da força é determinada por uma função de decaimento que depende apenas da distância do centro de massa do robô ao obstáculo em questão. Deste modo, o módulo de codificação deste comportamento é composto pelas seguintes equações:

$$
\begin{aligned}
& V(d)=V_{A C} e^{\frac{S-d}{T}} \\
& \phi=\pi-\phi_{\text {robô-obstáculo }}
\end{aligned}
$$

onde $V$ é a magnitude do comportamento (velocidade), $d$ é a distância do centro de massa do robô ao obstáculo, $V_{A C}$ é a velocidade máxima do comportamento, $S$ é o stand off do robô (distância mínima de um obstáculo devido ao diâmetro do robô, na qual a magnitude do comportamento satura em seu valor máximo), $T$ é a constante de escala da curva de decaimento, $\phi$ é a direção do vetor resul- 


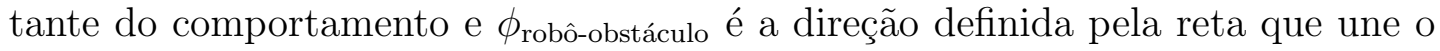
obstáculo ao centro de massa do robô. O uso da exponencial se justifica por esta função apresentar um decaimento rápido e passível de ser controlado através do parâmetro T. O rápido decaimento evita que obstáculos distantes influenciem no controle do robô. A figura 4.2 representa o campo vetorial resultante de um suposto obstáculo puntiforme.

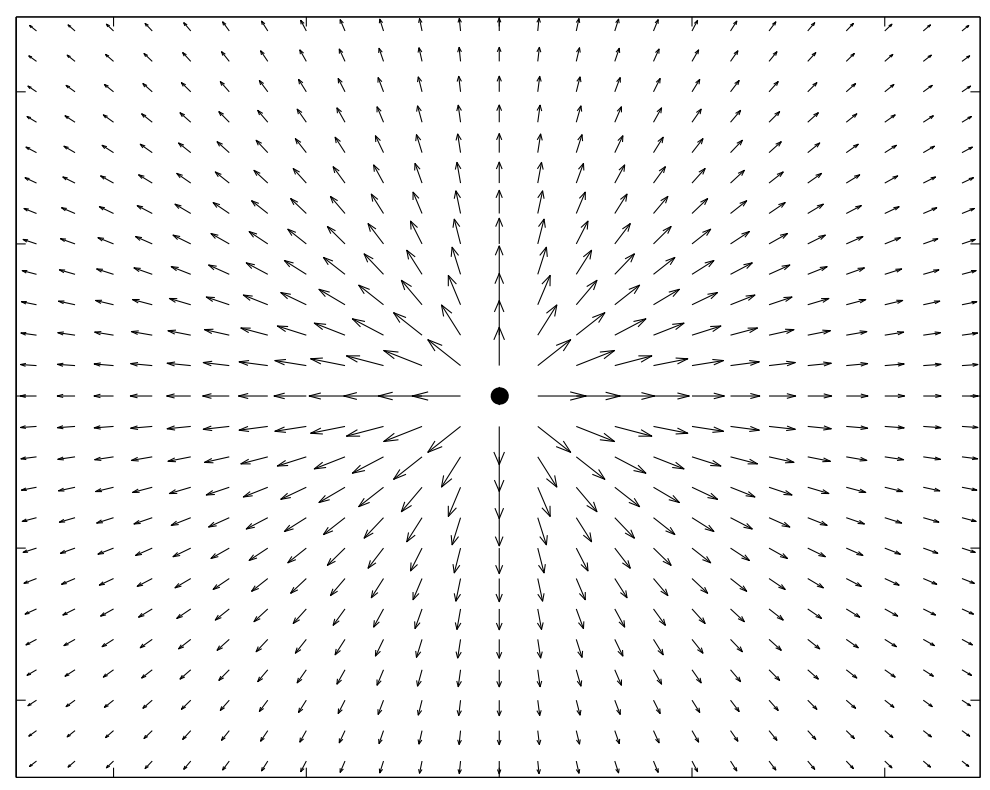

Figura 4.2: Campo vetorial radial repulsivo para um obstáculo puntiforme com decaimento exponencial.

\subsubsection{Comportamento moveAhead}

Este comportamento é responsável por fazer com que o robô sempre tenha uma forte tendência de continuar em sua direção momentânea, ou seja, que ele tenha uma certa inércia. Apesar da simplicidade de sua codificação, este comportamento tem grande importância, pois ele compensa a oscilação que pode resultar do comportamento avoidCollision e suaviza significativamente a trajetória do robô, uma vez que contribui para a diminuição da magnitude da rotação executada. Este comportamento também demonstra importância especial quando o robô navega por corredores. Neste caso, dado que os sonares abrangem apenas a parte frontal do robô, verifica-se que, sem o comportamento moveAhead, o robô executa um movimento de ziguezague entre as paredes. Isto porque, ao perceber 
uma das paredes laterais, o robô gira para o lado contrário bruscamente, devido à repulsão à parede detectada; no entanto, ao executar este movimento, os sonares então detectam a outra parede, causando nova repulsão e gerando a oscilação. Com a introdução do comportamento moveAhead, as rotações são suavizadas, permitindo que a cada giro para um dos lados, o giro seguinte seja menor. Desta maneira, a trajetória se estabiliza rapidamente.

O comportamento moveAhead não possui módulo de percepção e o seu módulo de codificação é elementar, consistindo em um campo onde a magnitude é constante $\left(V_{M A}\right)$ e direção sempre igual à do próprio robô naquele instante $\left(\phi_{\text {robô }}\right)$ :

$$
\begin{aligned}
& V=V_{M A} \\
& \phi=\phi_{\text {robô }} .
\end{aligned}
$$

\subsubsection{Comportamento moveToGoal}

Este comportamento tem o objetivo de atrair o robô para um determinado ponto alvo no ambiente. A posição da meta no sistema global de coordenadas é informada ao robô por meio de um agente externo. A posição corrente do robô (também no sistema global de coordenadas) é estimada pelo módulo de percepção, tomando como base a posição inicial do robô e acrescentando as informações fornecidas pelos seus odômetros. O módulo de codificação fica encarregado de determinar a direção do movimento, que será a mesma direção dada pela reta que une os pontos que definem as posições do robô e do alvo ( $\left.\phi_{\text {robô-alvo }}\right)$. A magnitude apresenta valor constante $\left(V_{M T G}\right)$, de modo que a codificação do comportamento é dada por

$$
\begin{aligned}
& V(d)=V_{M T G} \\
& \phi=\phi_{\text {robô-alvo }}
\end{aligned}
$$

O resultado desta codificação é um campo radial atrativo de magnitude constante, onde o foco de atração está na posição do alvo.

\subsection{Observações sobre a arquitetura REACT}

A arquitetura REACT, utilizando os três comportamentos descritos anteriormente é suficiente para que o robô chegue até seu objetivo em diversos ambientes 
(PACHECO; COSTA, 2002). Entretanto, observa-se também que o seu desempenho ao desviar dos obstáculos é prejudicado devido a limitações do sonar utilizado no comportamento avoidCollision. Ele consegue detectar uma parede a distâncias relativamente grandes - até $4 \mathrm{~m}$ ou $5 \mathrm{~m}$ - mas obstáculos de menor porte, quando estão mais distantes, podem estar localizados numa região entre os feixes de sonares consecutivos e assim não são percebidos. Outra limitação do sonar é a dificuldade em medir a distância até superfícies muito inclinadas com relação ao feixe de ultra-som. Nesses casos, apenas uma pequena parcela da potência emitida é rebatida de volta para a direção do sonar, o que acrescenta muito erro na medida.

Uma conseqüência dessas limitações do sonar é que alguns obstáculos só são percebidos quando estão a uma pequena distância, gerando uma grande repulsão repentina, resultando em manobras bruscas do robô. Assim, para melhorar o seu desempenho no desvio de obstáculos pode-se utilizar um sensor complementar, que consiga detectar aquilo que não é percebido pelo sonar.

Os sensores de laser e de visão parecem ser os mais adequados para esse fim. O sensor de laser, assim como o sonar, detecta as distâncias dos objetos ao redor, mas realizando uma varredura com um feixe de laser. Dessa forma, o contorno do cenário é detectado com grande densidade e precisão, captando inclusive objetos pequenos. O laser também não tem problemas em detectar superfícies inclinadas ao feixe. Com essas características, esse sensor poderia muito bem substituir o sonar. Entretanto, seu custo é muito elevado, muitas vezes inviabilizando a sua aquisição.

O sensor de visão, geralmente composto por uma câmera de vídeo comum, também traz informações com alta densidade, e consegue detectar objetos pequenos e superfícies inclinadas sem problemas. Além de ter um preço muito mais acessível do que o laser, consome menos energia por ser um sensor passivo - a câmera capta a luz do próprio ambiente. No entanto, o sensor de visão fornece informações sobre a intensidade luminosa e a tonalidade das cores do cenário. As distâncias aos objetos devem ser calculadas através de algum algoritmo de processamento de imagens, e nem sempre é possível conseguir uma boa precisão. Além disso, a maioria das câmeras possui um ângulo de abertura limitado, de modo que são percebidos apenas os obstáculos à frente do robô. No entanto, tanto a 
detecção de obstáculos laterais quanto a medição mais precisa das distâncias dos objetos são necessários apenas quando estes estão mais próximos, situação em que podem ser muito bem detectados pelo sonar.

O sensor de visão desenvolvido neste trabalho, e detalhado no capítulo 5, procura resolver o problema da percepção de objetos à frente do robô a uma distância suficientemente grande para que a manobra de desvio seja iniciada com antecedência. Dessa forma o comportamento baseado em visão proposto neste trabalho e descrito no capítulo 6 utiliza o sensor de visão desenvolvido e tem justamente a finalidade de complementar a atuação o comportamento avoidCollision, cuja percepção utiliza apenas os sonares. 


\section{Sensor unidimensional de tempos para colisão}

Originalmente, o desvio de obstáculos na arquitetura REACT é executado apenas pelo comportamento avoidCollision, que utiliza a informação dos sonares do robô. Esse tipo de sensor, conforme discutido no fim do capítulo 4, é bem complementado pelo sensor de visão, que consegue abranger com um bom nível de detalhe a região à frente do robô, permitindo a detecção e o desvio antecipado de obstáculos.

Um modo de realizar essa detecção é através da determinação das distâncias do robô até os objetos presentes no cenário imageado. No caso da utilização de uma só câmera de vídeo como sensor de visão, essas distâncias podem ser estimadas através do tempo para colisão aos obstáculos. Essa medida é extraída de uma seqüência de imagens capturadas pela câmera, sendo que existem vários algoritmos propostos na literatura com essa finalidade (PARDO et al., 2002; DEV; KRÖSE; GROEN, 1997; CAMUS et al., 1996).

No entanto, observa-se que muitos dos algoritmos propostos envolvem a prévia determinação do fluxo ótico das imagens antes do cálculo da medida de interesse, enquanto em outros não há essa etapa. Aqui, métodos de cálculo do tempo para colisão que necessitam da determinação prévia do fluxo ótico são chamados métodos indiretos, enquanto os outros são chamados métodos diretos.

Este capítulo trata especificamente do sensor de visão desenvolvido para complementar a percepção do robô. A saída desse sensor consiste em um vetor de tempos para colisão, determinados por um método direto proposto nesta dissertação, o que é uma contribuição deste trabalho.

Primeiramente é apresentada uma breve revisão teórica sobre os conceitos 
utilizados e então é feita uma descrição do sistema de visão desenvolvido.

\subsection{O campo de movimento e o fluxo ótico}

O campo de movimento de uma seqüência de imagens é a função que atribui um vetor de velocidade a cada ponto dessa seqüência a cada instante de tempo (HORN, 1986). Cada posição espacial nas imagens é identificada como sendo a projeção na superfície onde a imagem é formada do ponto equivalente do cenário real observado. Assim, o campo de movimento é resultado do rebatimento do campo de velocidades relativas entre a câmera e cada ponto do cenário na superfície de formação da imagem. Como o mais comum é que as imagens sejam capturadas por uma câmera de vídeo com CCD plano, como no caso deste trabalho, essa superfície será aqui chamada de plano da imagem. Com algumas restrições, o campo de movimento de uma seqüência de imagens pode ser recuperado a partir do chamado fluxo ótico, constituído pelo movimento aparente dos pixels na seqüência de imagens (HORN, 1986).

Quando os objetos observados por uma câmera de vídeo se movem ou quando a câmera se move em um ambiente estático, mudanças na imagem ocorrem devido a esse movimento. Entretanto, essas mudanças podem não refletir fielmente o movimento relativo entre câmera e cenário. Isso acontece, por exemplo, com a imagem de uma esfera de cor homogênea rodando sobre seu eixo, que não sofre modificação com o tempo. Nesse caso, o campo de movimento correspondente à região da imagem ocupada pela esfera é composto por vetores orientados para a direção e sentido de rotação da mesma. Entretanto, o campo de velocidade de deslocamento dos pixels, chamado de fluxo ótico, é nulo em toda a imagem, uma vez que ela não se modifica. Para quem observa a imagem, não há movimento aparente. Desse modo o fluxo ótico pode refletir ou não o campo de movimento gerado pelo movimento dos objetos presentes na imagem.

A suposição básica do fluxo ótico é que a cor e a intensidade luminosa de um ponto na imagem não sofrem modificação de uma imagem para outra. Pensando em imagens em tons de cinza, onde os valores dos pixels em cada ponto representam sua luminância a cada instante $E(x, y, t)$, pode-se afirmar que entre uma imagem adquirida no instante $t$ e outra adquirida no instante $t+\delta t$, o valor do 
pixel que se deslocou da posição $(x, y)$ para $(x+\delta x, y+\delta y)$ não muda, ou seja

$$
E(x+\delta x, y+\delta y, t+\delta t)=E(x, y, t) .
$$

Considerando que as variações de luminância são suaves no espaço e no tempo $(E(x, y, t)$ diferenciável), pode-se aproximar (5.1) por seus termos da série de Taylor de primeira ordem:

$$
E(x, y, t)+\frac{\partial E}{\partial x} \delta x+\frac{\partial E}{\partial y} \delta y+\frac{\partial E}{\partial t} \delta t=E(x, y, t)
$$

Dividindo (5.2) pelo incremento temporal $\delta t$ e fazendo o limite $\delta t \rightarrow 0$, tem-se

$$
\frac{\partial E}{\partial x} \frac{d x}{d t}+\frac{\partial E}{\partial y} \frac{d y}{d t}+\frac{\partial E}{\partial t}=0 .
$$

Assumindo a representação:

- $E_{x}=\frac{\partial E}{\partial x}$ : derivada parcial da imagem com respeito a $x$,

- $E_{y}=\frac{\partial E}{\partial y}$ : derivada parcial da imagem com respeito a $y$,

- $E_{t}=\frac{\partial E}{\partial t}$ : derivada parcial da imagem com respeito a $t$,

- $u=\frac{d x}{d t}$ : componente $x$ do vetor de fluxo ótico e

- $v=\frac{d y}{d t}$ : componente $y$ do vetor de fluxo ótico,

obtém-se

$$
E_{x} u+E_{y} v+E_{t}=0,
$$

chamada de equação de restrição do fluxo ótico. Os termos u e $v$ são respectivamente as velocidades de deslocamentos horizontal e vertical dos pixels na imagem, representando os componentes $x$ e $y$ do fluxo ótico.

Algebricamente é fácil de verificar que, para o caso geral, não é possível obter localmente o fluxo ótico apenas a partir de (5.4). A princípio, pode-se afirmar apenas que os valores de $u$ e $v$ devem estar sobre a reta $v=-\frac{E_{x}}{E_{y}} u-E_{t}$ no espaço $(u, v)$. Ao se reescrever (5.4) como um produto interno de vetores, obtém-se

$$
\left(E_{x}, E_{y}\right) \cdot(u, v)=-E_{t}
$$


que pode ser reescrita como

$$
\sqrt{E_{x}^{2}+E_{y}^{2}} \sqrt{u^{2}+v^{2}} \cos \alpha=-E_{t} \Longrightarrow \sqrt{u^{2}+v^{2}} \cos \alpha=-\frac{E_{t}}{\sqrt{E_{x}^{2}+E_{y}^{2}}},
$$

onde $\alpha$ é o ângulo entre as direções dos vetores $\left(E_{x}, E_{y}\right)$ e $(u, v)$. Desse modo, conclui-se que é possível determinar localmente apenas o componente do fluxo ótico na direção do gradiente da imagem $\left(\nabla E=\left(E_{x}, E_{y}\right)\right)$, correspondente à direção de maior variação de luminância. O componente perpendicular ao gradiente, orientado em uma direção de luminância constante, não pode ser obtido a partir de (5.4). A este problema chama-se problema de abertura (TRUCCO; VERRI, 1998).

\subsubsection{Cálculo do fluxo ótico a partir da equação de res- trição}

Uma vez que não se pode calcular o fluxo ótico apenas com informação pontual, torna-se necessário fazer restrições adicionais que envolvam uma certa vizinhança do ponto onde se deseja realizar o cálculo. Várias restrições foram propostas, gerando vários métodos diferentes para o cálculo. Essas restrições geralmente exploram a suavidade do campo de fluxo ótico para um mesmo objeto. Especialmente no caso de corpos rígidos, que não apresentam deformação, o fluxo ótico esperado na área da imagem correspondente ao objeto apresenta uma variação muito tênue.

Visando à obtenção de um algoritmo leve e de simples implementação, Lucas e Kanade (1981) propuseram a restrição de que o fluxo ótico é constante em uma dada área da imagem. Essa restrição é bastante razoável em se tratando de objetos não deformáveis, porém pode não ser observada nas regiões das bordas. Uma vez assumida essa restrição para uma região $R$ predeterminada na imagem, pode-se encontrar valores para $u$ e $v$ através do estimador de mínimos quadrados, também chamado de LS (Least Squares). Seja uma medida de erro $\varepsilon(\theta)$ dada pela diferença entre uma observação y e uma estimação paramétrica dessa observação $\hat{y}=\phi^{\mathrm{T}} \theta$ :

$$
\varepsilon(\theta)=y-\hat{y}=y-\phi^{\mathrm{T}} \theta
$$

onde $\theta$ é o vetor de parâmetros e $\phi$ é o vetor de regressores que relacionam um 
conjunto de parâmetros a uma observação estimada.

Dadas $N$ amostras de observações $y_{i}$ e dos respectivos vetores de regressores $\phi_{i}$, o estimador de mínimos quadrados fornece o vetor de parâmetros que minimiza a soma dos erros ao quadrado, de forma que

$$
\begin{aligned}
\hat{\theta} & =\underset{\theta}{\operatorname{argmin}} \mathrm{E}(\theta)^{\mathrm{T}} \mathrm{E}(\theta) \\
& =\underset{\theta}{\operatorname{argmin}} \sum_{i=1}^{N}\left(y_{i}-\phi_{i}^{\mathrm{T}} \theta\right)^{2},
\end{aligned}
$$

onde $\mathrm{E}(\theta)=\left[\begin{array}{llll}\varepsilon_{1}(\theta) & \varepsilon_{2}(\theta) & \cdots & \varepsilon_{N}(\theta)\end{array}\right]^{\mathrm{T}}, \operatorname{com} \varepsilon_{i}(\theta)=y_{i}-\phi_{i}^{\mathrm{T}} \theta$.

Assim, a estimação por mínimos quadrados do vetor de parâmetros é dada por (ASTRÖM; WITTENMARK, 1995)

$$
\hat{\theta}=\left(\Phi^{\mathrm{T}} \Phi\right)^{-1} \Phi^{\mathrm{T}} \mathbf{Y}
$$

onde

- $\Phi$ é a matriz composta pelas várias amostras dos regressores $\phi_{i}$, de forma que:

$$
\Phi=\left[\begin{array}{c}
\phi_{1}{ }^{\mathrm{T}} \\
\phi_{2}^{\mathrm{T}} \\
\vdots \\
\phi_{N}^{\mathrm{T}}
\end{array}\right] .
$$

O termo $\left(\Phi^{\mathrm{T}} \Phi\right)^{-1} \Phi^{\mathrm{T}}$ é chamado de pseudo-inversa de $\Phi$.

- Y é a matriz coluna composta pelas observações $y_{i}$ :

$$
\mathbf{Y}=\left[\begin{array}{llll}
y_{1} & y_{2} & \ldots & y_{N}
\end{array}\right]^{\mathrm{T}}
$$

No caso do algoritmo de Lucas e Kanade (1981), o erro a ser minimizado corresponde ao lado esquerdo de (5.4), a ser computado em cada ponto da imagem:

$$
\varepsilon(u, v)=E_{x} u+E_{y} v+E_{t}
$$

que pode ser reescrita da forma de (5.7) fazendo-se

$$
\begin{aligned}
\theta & =\left[\begin{array}{ll}
u & v
\end{array}\right]^{\mathrm{T}} \\
\phi & =\left[\begin{array}{ll}
E_{x} & E_{y}
\end{array}\right]^{\mathrm{T}}
\end{aligned}
$$




$$
y=-E_{t}
$$

Após a aplicação da regra de estimação por mínimos quadrados, obtêm-se as equações finais para a estimação dos componentes do fluxo ótico:

$$
\begin{aligned}
& \hat{u}=\frac{\sum_{R} E_{x} E_{y} \sum_{R} E_{y} E_{t}-\sum_{R} E_{x} E_{t} \sum_{R} E_{y}^{2}}{\sum_{R} E_{x}^{2} \sum_{R} E_{y}^{2}-\left(\sum_{R} E_{x} E_{y}\right)^{2}} \\
& \hat{v}=\frac{\sum_{R} E_{x} E_{y} \sum_{R} E_{x} E_{t}-\sum_{R} E_{y} E_{t} \sum_{R} E_{x}^{2}}{\sum_{R} E_{x}^{2} \sum_{R} E_{y}^{2}-\left(\sum_{R} E_{x} E_{y}\right)^{2}} .
\end{aligned}
$$

\subsubsection{Problemas no cálculo do fluxo ótico}

A equação de restrição do fluxo ótico foi derivada considerando a imagem de vídeo uma função contínua e diferenciável no espaço e no tempo. Entretanto, em visão computacional se trabalha com seqüências de vídeo, compostas por imagens adquiridas com um certo intervalo de tempo e que apresentam valores pontuais de pixels. Assim sendo, os valores das derivadas da imagem devem ser obtidos por meio de filtragens com kernels apropriados.

No caso da obtenção das derivadas espaciais $\left(E_{x}\right.$ e $\left.E_{y}\right)$, os kernels geralmente utilizados, além de fazerem a diferença entre pixels vizinhos, realizam uma filtragem passa-baixas para diminuir o efeito do ruído e para suavizar as transições na imagem nas regiões de borda. Entretanto, isso atenua o valor das derivadas obtidas, o que afeta os valores resultantes do fluxo ótico calculado.

No caso da derivada temporal, há ainda o problema das transições bruscas de uma imagem para outra. Enquanto que as transições espaciais costumam ser mais suaves, é freqüente que duas imagens capturadas em seqüência sejam muito diferentes devido a movimentos bruscos da câmera ou dos objetos na imagem. Dessa forma, os valores de derivada temporal determinada através das diferenças entre as imagens não são mais válidos. Aumentar a taxa de aquisição e utilizar mais imagens em seguida para o cálculo da derivada podem ser algumas soluções para esse problema. Assim, aumentar a taxa de aquisição para mais de 30 quadros por segundo muitas vezes se faz necessário; entretanto tal recurso exige hardware de aquisição de maior custo além de um grande poder de processamento, já que a aquisição a essas taxas exigem que as imagens também seja processadas na 
mesma freqüência.

\subsubsection{A compatibilidade entre o fluxo ótico e o campo de movimento}

Há vários fatores que podem invalidar a correspondência entre os pixels na imagem e os pontos dos objetos, fazendo com que o fluxo ótico não reflita o campo de movimento dos objetos imageados. O primeiro fator, que ocorre com bastante freqüência, é a pobreza de variações na imagem. Um caso extremo corresponde a uma situação de ausência de textura. Entretanto, mesmo no caso de variações muito pequenas, o cálculo das derivadas espaciais da imagem torna-se problemático, uma vez que o ruído torna-se muito relevante quando comparado com os pequenos valores de derivadas obtido. O algoritmo de Horn (1986) trata esse problema interpolando os valores de regiões ricas em textura em regiões de poucas variações na imagem. Entretanto, esse algoritmo é iterativo e computacionalmente muito custoso.

Outro fator são as variações de iluminação. Quando a intensidade das fontes luminosas se alteram, os valores dos pixels correspondentes a determinados objetos também se modificam, desrespeitando a suposição básica da equação de restrição. O mesmo acontece quando o cenário possui iluminação não uniforme, possibilitando que, de uma imagem para outra, um objeto transite entre regiões de diferente iluminação. Sabendo-se de antemão quanto vale essa variação, pode-se modificar a suposição básica para incluir a nova informação:

$$
E(x+\delta x, y+\delta y, t+\delta t)=E(x, y, t)+\delta E .
$$

Assim, a equação de restrição fica

$$
E_{x} u+E_{y} v+E_{t}=I
$$

onde $I=\frac{d E}{d t}$ é a variação temporal da iluminação. 


\subsection{A detecção de distâncias a partir do campo de movimento}

Considere um sistema de coordenadas cartesianas $X Y Z$ originado no centro ótico da objetiva da câmera, tendo o eixo $Z$ coincidente com o eixo ótico. Considerando o modelo pin-hole (BALLARD; BROWN, 1982) para a câmera, a equação do plano da imagem é $Z=f$, onde $f$ é a distância focal da objetiva. A projeção $\vec{r}=(x, y)$ no plano da imagem de um ponto $\vec{R}=(X, Y, Z)$ do cenário é dada por

$$
\vec{r}=\frac{f}{Z} \vec{R}
$$

enquanto o campo de movimento é dado por (HORN, 1986)

$$
\vec{v}=\frac{d \vec{r}}{d t}=\frac{f}{Z^{2}}(\vec{R} \times \vec{V}) \times \hat{\mathbf{z}}
$$

onde $\vec{V}=\frac{d \vec{R}}{d t}$ é a velocidade do ponto $\vec{R}$ do cenário em relação ao centro das coordenadas, e $\vec{v}=(\dot{x}, \dot{y})$ é a projeção da velocidade $\vec{V}$ no plano da imagem.

Seja o movimento da câmera dado por uma velocidade de translação $\vec{T}$ e uma velocidade de rotação $\vec{\omega}$. Se a câmera se move em um ambiente estático, diz-se que ela se encontra em navegação passiva (HORN, 1986). Nesse caso, a velocidade de ponto $\vec{R}$ com relação ao centro das coordenadas é

$$
\vec{V}=-\vec{T}-\vec{\omega} \times \vec{R}
$$

Substituindo (5.17) em (5.16), tem-se

$$
\vec{v}=-\frac{f}{Z^{2}}(\vec{R} \times \vec{T}+\vec{R} \times(\vec{\omega} \times \vec{R})) \times \hat{\mathbf{z}} .
$$

Aplicando-se a equação de Lagrange para produtos vetoriais e a equação de rebatimento expressa em (5.15), obtém-se a expressão geral do vetor de movimento dos pontos do cenário rebatidos no plano da imagem:

$$
\vec{v}=-\frac{\vec{r} \times \vec{T}}{Z} \times \hat{\mathbf{z}}-\frac{r^{2} \vec{\omega}-(\vec{r} \cdot \vec{\omega}) \vec{r}}{f} \times \hat{\mathbf{z}}
$$

que é a expressão geral para o campo de movimento para o caso de navegação passiva. Depreende-se de (5.19) que o campo de movimento depende basicamente de parâmetros intrínsecos da câmera e do seu movimento. O único parâmetro 
extrínseco é a profundidade do cenário $(Z)$. Outra característica interessante é que a expressão é composta de dois termos independentes: um depende apenas da parte translacional do movimento $(\vec{T})$ e o outro apenas da parte rotacional $(\vec{\omega})$. A profundidade afeta apenas o termo dependente da translação, sendo que o termo dependente da rotação é afetado apenas por parâmetros intrínsecos da câmera e da imagem.

Agora considere o movimento da câmera solidário ao movimento de um robô móvel não holonômico que se locomove sobre um plano, de acordo com a figura 5.1. Dessa forma, as velocidades de translação e rotação são expressas por

$$
\vec{T}=T \hat{\mathbf{z}} \quad \text { e } \quad \vec{\omega}=-\omega \hat{\mathbf{y}}
$$

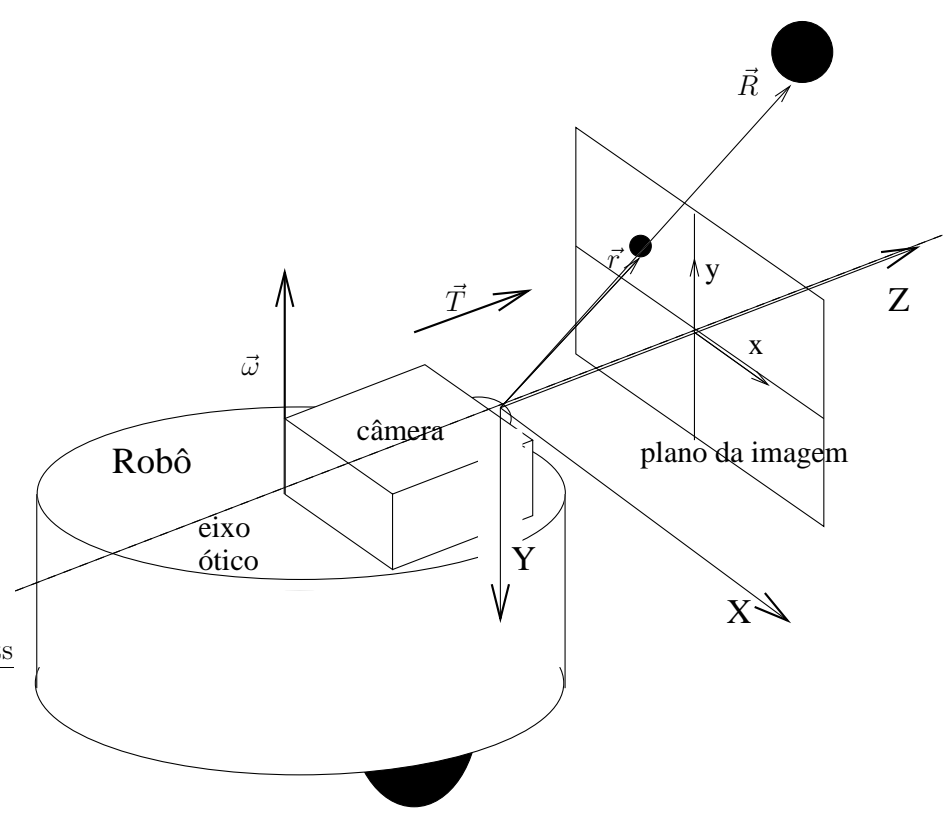

Representação do cenário considerado para a dedução do campo de movimento captado pela câmera do robô. O sistema de coordenadas é originado no centro ótico da câmera. O movimento do robô é descrito pela velocidade de translação $\vec{T}$ na direção do eixo $Z$ e pela velocidade angular $\vec{\omega}$ ao longo do eixo $Y$.

Figura 5.1: Representação do cenário considerado para a dedução do campo de movimento captado pela câmera do robô.

Assim, a expressão do campo de movimento fica

$$
\begin{aligned}
\dot{x} & =\frac{T}{Z} x+\omega\left(\frac{x^{2}}{f}+f\right) \quad \mathrm{e} \\
\dot{y} & =\frac{T}{Z} y+\frac{\omega}{f} x y .
\end{aligned}
$$


Depreende-se de (5.21) e de (5.22) que, no caso de interesse, não é possível separar a velocidade de translação da profundidade do cenário. O termo $\lambda=T / Z$ tem unidade inversa à do tempo. Dessa forma, define-se a quantidade $\tau=1 / \lambda=$ $Z / T$, denominada tempo para colisão. Ela corresponde ao tempo estimado para a câmera atingir a mesma profundidade do objeto, e eventualmente colidir com ele, caso mantenha a mesma velocidade e não mude de trajetória. Como a velocidade de translação é um parâmetro intrínseco ao movimento da câmera, o tempo para colisão pode ser usado para estimar as distâncias relativas na imagem, ou seja, descobrir que objetos estão mais distantes e quais estão mais próximos.

\subsection{Cálculo do tempo para colisão a partir do fluxo ótico}

Um método para obter os valores de $\tau$ na imagem usando o fluxo ótico para o caso de interesse é descrito por Dev, Kröse e Groen (1997). A suposição básica é que o fluxo ótico seja uma boa aproximação para o campo de movimento. Considerando-se os componentes $u$ e $v$ do fluxo ótico já disponíveis, primeiramente se estima a velocidade rotacional da câmera. Fazendo-se as identidades $u=\dot{x}$ e $v=\dot{y}$, e combinando (5.21) e (5.22), obtemos a expressão para a rotação do robô:

$$
\omega=\frac{y u-x v}{f y} .
$$

Uma estimação mais robusta pode ser obtida através da aplicação de mínimos quadrados em uma região $R$ da imagem onde se tenha mais confiança no valor do fluxo calculado:

$$
\omega=\frac{\sum_{R}\left(y^{2} u-y x v\right)}{f \sum_{R} y^{2}}
$$

Dessa maneira, o tempo para colisão é calculado fazendo

$$
\tau=\frac{x}{u-\left(\frac{x^{2}}{f}+f\right) \omega} \quad \text { ou } \quad \tau=\frac{y}{v-\frac{x y}{f} \omega} .
$$

Entretanto, o cálculo do tempo para colisão na presença de rotação apresenta algumas dificuldades. A primeira delas é a necessidade de se conhecer previamente a distância focal da lente utilizada. Isso pode ser um parâmetro definido previamente, utilizando o valor fornecido pelo fabricante, ou pode ser obtido 
através de algum tipo de calibração.

Outra dificuldade se refere ao cálculo do fluxo ótico. Os algoritmos baseados na equação de restrição, que costumam ser computacionalmente menos custosos, são aplicáveis apenas em situações onde haja pequenos deslocamentos dos pixels entre os quadros de imagem. Porém, pequenas rotações da câmera costumam produzir grandes deslocamentos na imagem. Para um câmera com $30^{\circ}$ de abertura e imagens sendo capturadas com uma resolução de $320 \times 240$ pixels, uma rotação de apenas $1^{\circ}$ produz deslocamentos maiores do que 10 pixels em toda a imagem. Dessa forma, é interessante corrigir previamente o efeito da rotação através de algum outro método e então efetuar o cálculo do tempo para colisão considerando que não houve rotação. Assim, calcula-se o tempo para colisão fazendo simplesmente

$$
\tau=\frac{x}{u} \quad \text { ou } \quad \tau=\frac{y}{v}
$$

Segundo Sarcinelli-Filho, Schneebeli e Caldeira (2001), os algoritmos para o cálculo do fluxo ótico aplicados à navegação de robôs móveis, além de apresentarem bons resultados, devem ter baixo custo computacional. Uma vez que as informações resultantes do processamento das imagens são utilizadas para controlar o robô, faz-se necessário realizar esse processamento em tempo real. Por outro lado, os sistemas computacionais embarcados possuem poder de processamento limitado: a restrição do espaço físico dificulta a montagem de clusters de computadores e a utilização de um computador com mais de um processador é financeiramente onerosa. Uma saída seria a transmissão das imagens para serem processadas em um computador externo, o que acarretaria perda na qualidade das mesmas em muitos casos. Por isso, o custo computacional é um fator crítico nesses algoritmos. Um algoritmo bastante apropriado para robótica móvel é o de Lucas e Kanade (1981), que, como explicado na seção 5.1, considera o fluxo constante em determinadas regiões da imagem. Entretanto, as equações do campo de movimento (5.21) e (5.22) mostram variação da intensidade do fluxo com a posição na imagem para uma região de profundidade constante. Como se espera que cada objeto na imagem tenha sua profundidade aproximadamente constante, seria melhor um algoritmo que incorporasse as variações esperadas do fluxo ótico nessa situação. 


\subsection{Cálculo direto do tempo para colisão}

Seja a equação de restrição do fluxo ótico dada por (5.4). Assumindo que o fluxo ótico é uma boa estimativa para o campo de movimento, pode-se fazer as identidades $u=\dot{x}$ e $v=\dot{y}$. Dessa forma, substituir (5.21) e (5.22) em (5.4) resulta em

$$
E_{x}\left[\lambda x+\omega\left(\frac{x^{2}}{f}+f\right)\right]+E_{y}\left[\lambda y+\frac{\omega}{f} x y\right]+E_{t}=0,
$$

onde $\lambda=1 / \tau$ é o inverso do tempo para colisão.

Da mesma forma que Lucas e Kanade (1981) impõem a restrição de $u$ e $v$ constantes em uma dada região $R$ da imagem para o cálculo do fluxo ótico, com mais razão, neste caso, pode-se fazer a mesma restrição para $\tau$ e $\omega$. Uma vez que $\omega$ é a velocidade de rotação do robô, esse parâmetro é invariante em toda a imagem, e espera-se que $\tau$ seja aproximadamente constante para cada objeto. Entretanto, devido às dificuldades no cálculo de $\omega$ mencionadas na seção 5.4 , é mais interessante corrigir previamente o efeito da rotação na imagem e efetuar o cálculo do tempo para colisão considerando apenas o efeito do movimento de translação. Dessa forma, (5.27) fica

$$
E_{x} \lambda x+E_{y} \lambda y+E_{t}=0
$$

A única incógnita em (5.28) é o inverso do tempo para colisão, de forma que ele pode ser calculado pontualmente:

$$
\lambda=-\frac{E_{t}}{E_{x} x+E_{y} y}
$$

Devido ao ruído na obtenção das derivadas da imagem, é interessante utilizar um estimador mais robusto. O estimador de mínimos quadrados para a obtenção de $\lambda$ é

$$
\hat{\lambda}=-\frac{\sum_{R}\left(E_{x} x+E_{y} y\right) E_{t}}{\sum_{R}\left(E_{x} x+E_{y} y\right)^{2}} .
$$




\subsection{Descrição do sensor de distâncias desenvol- vido}

O sensor de distâncias desenvolvido é inspirado no trabalho de Sarcinelli-Filho, Schneebeli e Caldeira (2002), onde é descrito um sensor unidimensional de distâncias baseado no tempo para colisão, calculado através do método indireto de Dev, Kröse e Groen (1997). O fluxo ótico é calculado em toda a imagem utilizando uma versão modificada do algoritmo de Lucas e Kanade (1981), que utiliza menos pontos para estimar o vetor de fluxo, posteriormente descartando vetores não confiáveis. O resultado é então segmentado em regiões com fluxo similar, definindo pseudo-objetos. Um mapa bidimensional de tempos para colisão é obtido segundo a proposta de Dev, Kröse e Groen (1997), sendo que a cada pseudo-objeto é atribuído um valor, obtendo-se um mapa segmentado. Finalmente, para cada coluna desse mapa bidimensional, toma-se o menor valor de tempo para colisão como o representante daquela coluna. Assim, obtém-se um sensor unidimensional de distâncias.

A estrutura de processamento da imagem adotada neste trabalho é semelhante, mas possui um passo a menos (não calcula o fluxo ótico) e difere no método usado para segmentar o resultado (SELVATICI; COSTA, 2004b). Primeiramente, usam-se dois quadros consecutivos da seqüência de imagens para determinar as suas derivadas. A derivada temporal é computada subtraindo os valores da luminância de um quadro para outro. As derivadas espaciais são obtidas em três passos:

1. Aplicam-se os filtros de Sobel (GONZALEZ; WOODS, 1992) para detecção dos gradientes horizontal e vertical na imagem de cada quadro, resultando nas derivadas espaciais auxiliares $E_{x_{1}}$ e $E_{y_{1}}$ para o primeiro quadro e $E_{x_{2}}$ e $E_{y_{2}}$ para o segundo.

2. Utilizam-se critérios de confiabilidade propostos por Pardo et al. (2002) para validar os valores de derivadas obtidos. Se o valor de uma derivada espacial em uma mesma posição difere muito de um quadro para outro, esse 
ponto não é válido. O critério de validação é

$$
\begin{aligned}
& \left|E_{x_{1}}-E_{x_{2}}\right|<T_{1} \\
& \left|E_{y_{1}}-E_{y_{2}}\right|<T_{1},
\end{aligned}
$$

sendo $T_{1}$ um valor definido empiricamente.

3. As derivadas espaciais definitivas então assumem o valor médio entre os valores das derivadas auxiliares nos pontos válidos. Como sugerido por Pardo et al. (2002), pequenos valores de derivadas espaciais são também descartados. Assim

$$
\left.\begin{array}{c}
E_{x}=\frac{1}{2}\left(E_{x_{1}}+E_{x_{2}}\right) \\
E_{y}=\frac{1}{2}\left(E_{y_{1}}+E_{y_{2}}\right)
\end{array}\right\} \begin{gathered}
\text { válidos se } \\
\left|E_{x}\right|+\left|E_{y}\right|>T_{2}
\end{gathered}
$$

sendo $T_{2}$ um valor definido empiricamente.

Para valores de luminância variando de 0 a 1 , experimentos mostram que valores próximos de 0,07 para $T_{1}$ e 0,04 para $T_{2}$ parecem ser boas alternativas.

O passo seguinte é a obtenção de um mapa da grandeza $\lambda$, que representa o inverso do tempo para colisão. Divide-se o espaço da seqüência de imagens em regiões de $N \times N$ pixels e aplica-se o estimador LS em (5.30) para cada uma. São usados apenas valores válidos de derivadas da imagem. Depois de obtido o mapa, que possui resolução $N$ vezes menor do que as imagens originais, pode haver alguns pontos inválidos, que correspondem a regiões das imagens onde só havia derivadas inválidas. Além do mais, todos os valores negativos são invalidados, uma vez que o robô só se move para frente, fazendo que os valores válidos sejam sempre positivos.

Então, pseudo-objetos são definidos pela segmentação do mapa em regiões de valores similares. Inicia-se uma varredura por linha procurando por um valor válido e não classificado. Ao encontrar um, o contador de pseudo-objetos é incrementado e um algoritmo recursivo de crescimento de regiões (BALLARD; BROWN, 1982) é utilizado para encontrar todos os pontos que pertencem àquele pseudo-objeto. O critério de similaridade sugerido é

$$
\left|\lambda_{i, j}-\lambda_{i+k, j+l}\right|<\min \left\{T ; \frac{1}{2} \lambda_{i, j}\right\}
$$


onde o índice $(i, j)$ indica a posição no mapa de valores de $\lambda$ e $(k, l)$ indica o deslocamento nesse mesmo mapa do vizinho sendo analisado. Utilizou-se vizinhança 4. O limiar $T$ é igual à uma fração do primeiro valor classificado como pertencendo àquele pseudo-objeto; neste projeto essa fração assumiu o valor de 0,3. Os pseudo-objetos compostos por menos de 3 pontos foram considerados inválidos e descartados, pois possuem boa chance de terem sido gerados por ruído.

Então, o tempo para colisão de cada pseudo-objeto é calculado através do inverso do valor médio de $\lambda$ nos pontos correspondentes. O resultado é um mapa segmentado onde a cada pseudo-objeto corresponde um único valor de tempo para colisão. Finalmente, para cada coluna do mapa segmentado, o menor valor de tempo para colisão é adotado, resultando em um sensor unidimensional de distâncias. Os valores resultantes do sensor de distâncias para a seqüência de imagens representada na figura 5.2 estão graficamente representados na figura 5.3.

\subsection{Experimentos com o sensor de distâncias}

Foram realizados alguns testes com o sensor de visão desenvolvido para averiguar a qualidade de sua resposta. Em uma primeira bateria de testes, foi analisado apenas o algoritmo de cálculo dos tempos para colisão, sem a preocupação em obter o vetor de valores. Nesses testes, foram simuladas algumas seqüências de imagens de planos movendo-se em direção a uma câmera virtual com uma dada velocidade e a uma certa distância. Então, foram calculados os valores da medida inversa ao tempo para colisão nas imagens, $\lambda$, sem no entanto partir para a segmentação dos resultados em pseudo-objetos. Os valores de $\lambda$ obtidos em cada seqüência de imagens foram analisados em termos da média e do desvio padrão, uma vez que era esperado um único valor de tempo para colisão em cada uma delas. Os resultados estão apresentados na tabela 5.1.

Os resultados obtidos mostram que o algoritmo fornece resultados bastante próximos do esperado. Também fica evidenciado que existe uma faixa de valores de tempo para colisão para a qual os resultados são melhores e mais constantes na imagem, resultando em um menor desvio padrão. Na verdade, a qualidade do resultado depende da qualidade obtida no cálculo das derivadas da imagem. Quando os deslocamentos de uma imagem para outra são pequenos, da ordem 


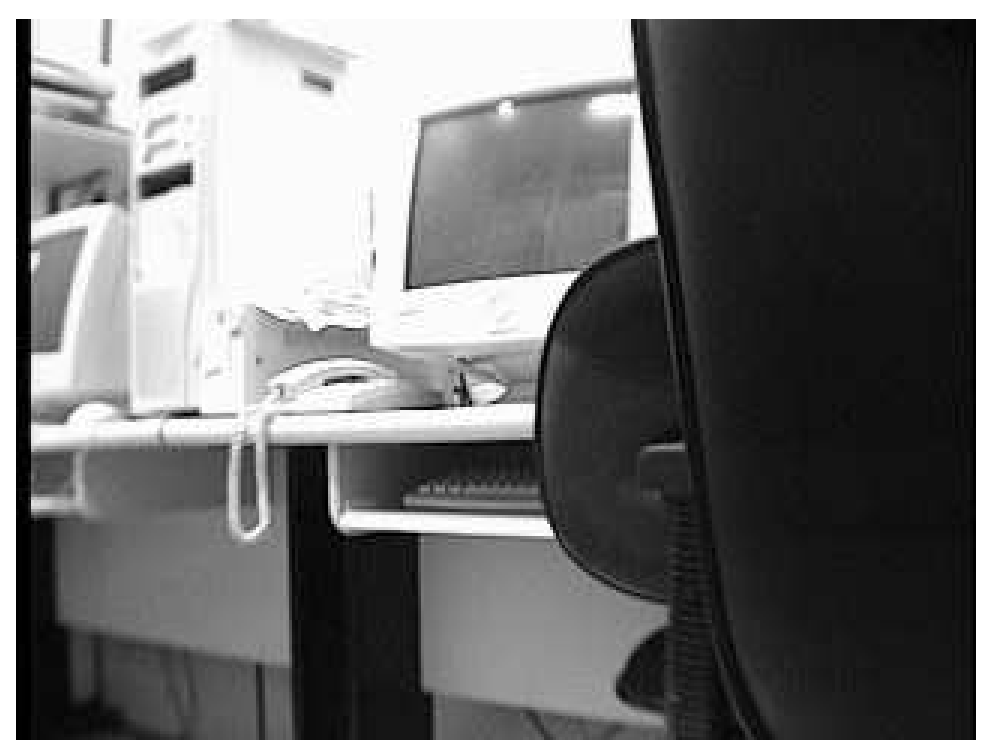

Quadro de uma sequiência de imagens. A câmera se move em direção ao móvel com os computadores.

Figura 5.2: Quadro de uma seqüência de imagens.

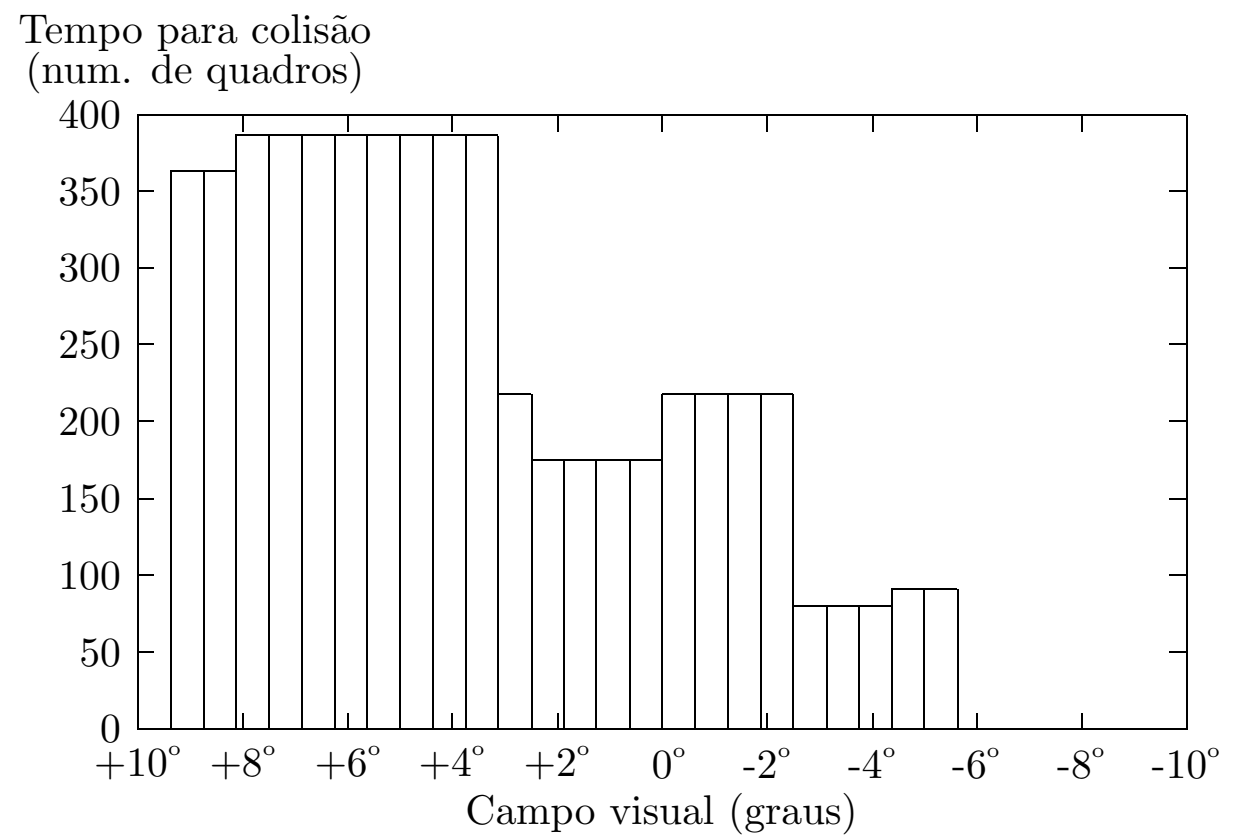

Representação dos valores do sensor de distâncias obtidos a partir da seqüência de imagens representada na figura 5.2. Valores iguais a zero são inválidos. Observar que as cadeiras à direita na imagem da original são identificadas como objetos mais próximos, ou seja, de menor tempo para colisão.

Figura 5.3: Representação dos valores do sensor de distâncias. 
Tabela 5.1: Resultados dos testes experimentais do algoritmo de cálculo de $\lambda$ realizado com seqüências de imagens simuladas.

\begin{tabular}{ccc}
\hline $\begin{array}{c}\text { Valor de } \lambda \text { esperado } \\
\left(s^{-1}\right)\end{array}$ & $\begin{array}{c}\text { Média } \\
\left(s^{-1}\right)\end{array}$ & $\begin{array}{c}\text { Desvio padrão } \\
\left(s^{-1}\right)\end{array}$ \\
\hline 0.163 & 0.17 & 0.018 \\
0.200 & 0.20 & 0.010 \\
0.249 & 0.24 & 0.0086 \\
0.285 & 0.26 & 0.0089 \\
0.444 & 0.38 & 0.017 \\
\hline
\end{tabular}

de até 3 pixels, as derivadas espaciais e temporal conseguem ser obtidas com boa precisão, gerando um bom resultado.

Entretanto, o objetivo do sensor é permitir a distinção entre objetos mais próximos e objetos mais distantes em uma seqüência de imagens. Dessa forma, foi realizada uma outra bateria de testes para analisar a capacidade do sensor em fazer essa distinção. Para tanto, foram capturadas algumas seqüências de imagens reais através de uma câmera de vídeo, ou ainda foram utilizadas seqüências artificiais. Então foi calculada a saída do sensor para cada uma dessas seqüências, verificando posteriormente a coerência dos resultados com o que se pode esperar pela análise das imagens. Alguns exemplos de resultados obtidos estão apresentados na figura 5.4 .

Os resultados obtidos, em geral, foram bons, de modo que, na maior parte das seqüências observadas, as regiões onde os objetos estavam mais distantes eram apontadas corretamente pelo sensor. No entanto, ficou evidenciada também a dificuldade do algoritmo utilizado em processar imagens com baixo nível de textura. Nas regiões das imagens onde havia uma tonalidade aproximadamente constante, o sensor não conseguia calcular um valor válido.

\subsection{Conclusões sobre o sistema de visão}

O sensor de visão desenvolvido demonstrou grande capacidade em distinguir objetos distantes de objetos mais próximos na imagem. Isso o torna um bom complemento para o sonar, já que este tem boa precisão para objetos mais próximos, mas muitas vezes não consegue detectar objetos mais distantes. De fato, quando 


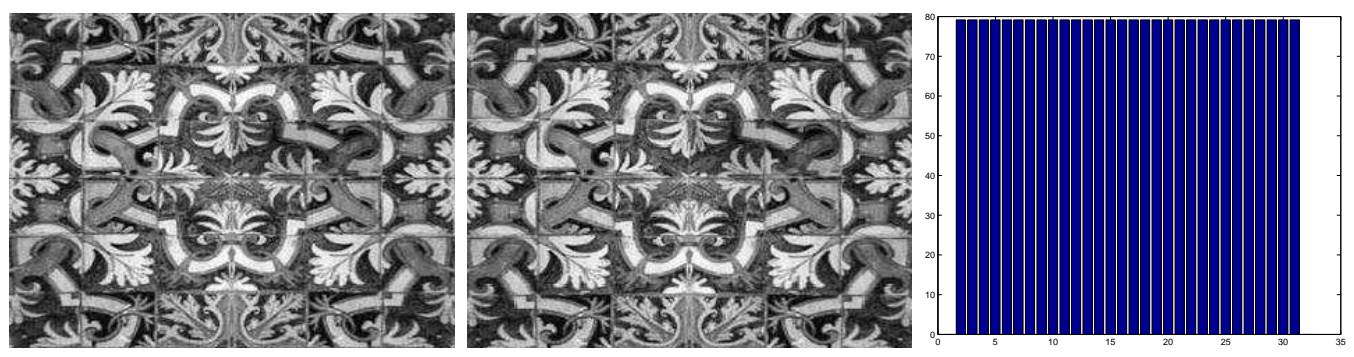

(a) Imagem plana se aproximando.
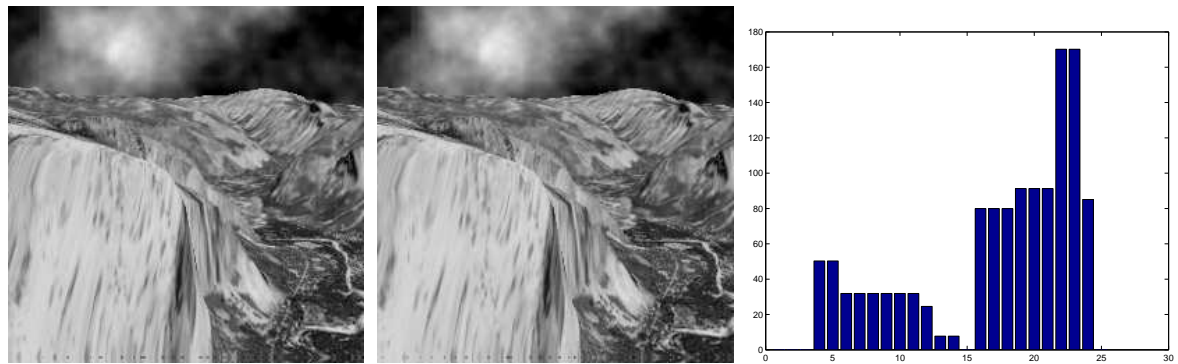

(b) Seqüência realizada por computação gráfica.
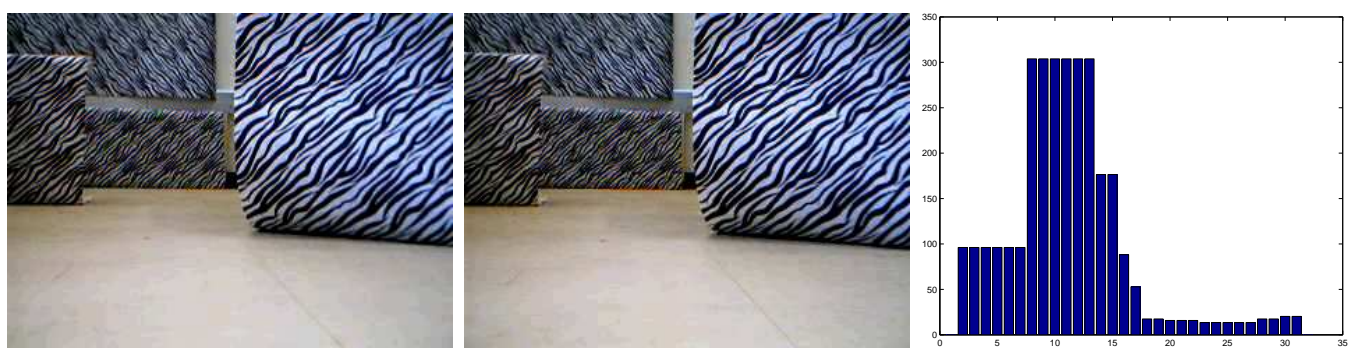

(c) Seqüência de imagens reais

Figura 5.4: Resultados do sensor de distâncias obtidos com algumas seqüências de imagens. 
os obstáculos estão longe, não há necessidade de se saber com precisão a sua distância. Basta identificar a direção em que estão, de forma a iniciar a manobra de desvio com antecedência.

Com efeito, observou-se que a direção indicada como de maior tempo para colisão na maior parte das imagens analisadas de fato coincidia com aquela onde os obstáculos estão mais longe, configurando um caminho livre por onde se poderia trafegar. Dessa forma, esse sensor de distâncias é bastante adequado para complementar a percepção de um robô que originalmente disponha apenas do sonar para detectar obstáculos, e assim procurar caminhos livres entre eles.

No entanto, o sensor apresentou problemas com imagens de baixo nível de textura. Dessa forma, devem ser tomados alguns cuidados na sua aplicação na navegação de robôs móveis em ambiente interno. Caso as paredes apresentem cor uniforme, possivelmente não serão percebidas pelo sensor, o que pode gerar problemas. Por outro lado, caso o chão apresente cor uniforme, o algoritmo de processamento de imagens o ignora, de forma que ele não interfere no resultado do sensor. Caso contrário, ajustes devem ser feitos no sistema de visão para que não leve em consideração os tempos para colisão calculados a partir de regiões da imagem ocupadas pelo chão, que pode, erroneamente, ser identificado como um obstáculo próximo. 


\section{O comportamento moveToFree}

Uma vez conhecidos os sensores a serem utilizados em uma plataforma robótica, é necessário definir como será feita a combinação das suas informações para a determinação das ações do robô. A abordagem comportamental sugere um modo muito simples para isso: a cooperação de comportamentos que utilizam sensores diferentes.

Por apresentarem estrutura modular, as arquiteturas para robôs móveis baseadas em comportamentos primitivos possibilitam a combinação de sensores diferentes através da coordenação das saídas dos comportamentos, mantendo assim a independência entre as informações sensoriais. Como neste caso não é necessário realizar explicitamente a fusão sensorial, a incorporação de novos sensores tornase simples, e caso um deles venha a faltar, basta desligar o comportamento que processa a informação daquele sensor, eventualmente necessitando de um pequeno ajuste nos outros comportamentos.

A maior dificuldade desta abordagem está em codificar a atuação dos comportamentos utilizando diferentes sensores de forma que um complemente e reforce ou corrija o outro, e não haja conflitos que possam ocasionar um comportamento global indesejável para o robô.

O comportamento proposto neste trabalho, moveToFree, tem como objetivo perceber a presença de obstáculos à frente do robô e desviar a sua trajetória de forma a passar ao largo. Procura fazer com que o robô sempre tenha a tendência de mover-se para a direção à frente onde os obstáculos estejam mais distantes. A direção a seguir é determinada a partir do processamento das imagens obtidas através do sensor de visão desenvolvido neste trabalho, descrito no capítulo 5 . 


\subsection{A codificação do comportamento moveTo- Free}

A codificação deste comportamento é bastante simples, e foi elaborada de forma a tentar colaborar com o comportamento avoidCollision, que possui finalidade semelhante. Uma vez que avoidCollision tenta conduzir o robô no sentido de repulsão dos obstáculos em uma direção radial com relação a eles, objetos que estiverem à frente do robô provocariam redução de sua velocidade, atrapalhando sua trajetória. Por isso, moveToFree foi codificado de forma que os obstáculos à frente do robô fossem anteriormente identificados e evitados, ajustando sua trajetória para uma que estivesse livre deles. Assim, o módulo de codificação cria um campo de magnitude constante $\left(V_{M T F}\right)$, cuja direção é aquela indicada pelo sistema de visão como a de maior tempo para colisão $\left(\phi_{\text {visão }}\right)$. A codificação do comportamento fica

$$
\begin{aligned}
& V=V_{M T F} \\
& \phi=\phi_{\text {visão }} .
\end{aligned}
$$

\subsection{Experimentos com o comportamento move- ToFree na arquitetura REACT}

O comportamento moveToFree foi implementado em software de modo a ser integrado na arquitetura REACT previamente implementada. No entanto, alguns ajustes tiveram que ser realizados no código que envia os comandos de movimento para o robô.

Uma vez que a implementação original da arquitetura REACT não utilizava um sensor de distâncias baseado em visão monocular, não havia a preocupação com a rotação no movimento do robô. Assim, o comando de transladar com uma velocidade $V$ era enviado concomitantemente com o comando de rotacionar de um ângulo $\phi$. No entanto, como o sensor desenvolvido considera que as imagens são capturadas durante um movimento de translação pura, o código teve de ser alterado de modo que o movimento fosse executado em duas fases: primeiro o robô executa a rotação desejada ao mesmo tempo que avança com a velocidade comandada, e, então, na segunda fase, o robô executa uma translação pura durante o tempo suficiente para a captura e processamento das imagens. 


\subsubsection{Plataforma robótica utilizada}

Para esses primeiros experimentos realizados com o comportamento moveToFree, foi utilizado um sistema robótico com processamento embarcado, constituído de um laptop usando um processador Intel Pentium II ${ }^{\circledR} 300 \mathrm{MHz}$ posicionado sobre

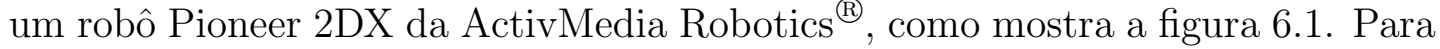
a captura das imagens foi utilizada uma câmera de vídeo digital PC-CAM 300 da Creative ${ }^{\circledR}$, capturando imagens de resolução $320 \times 240$ e com abertura de $20^{\circ}$, conectada ao laptop.

O sistema de captura e processamento de imagens é executado no laptop, que envia comandos ao robô através do software Saphira (ACTIVMEDIA ROBOTICS, 2001).

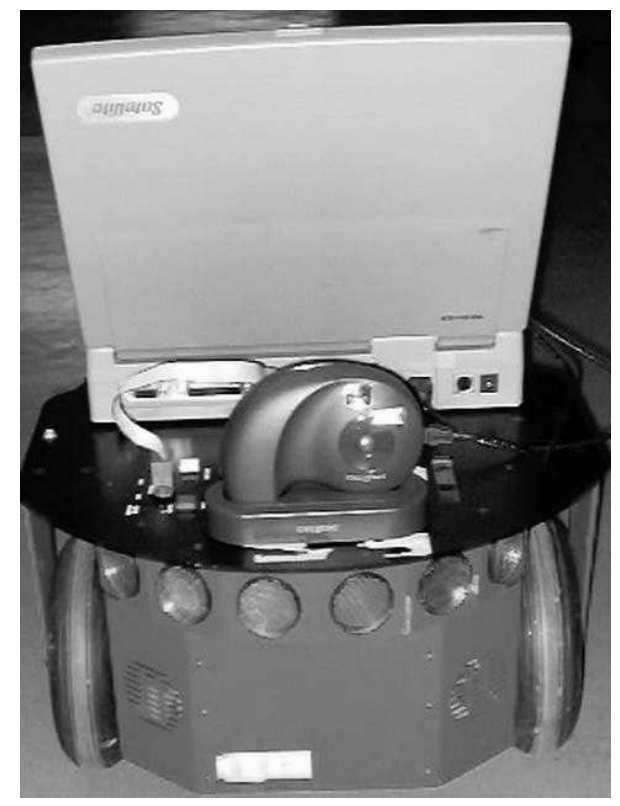

Figura 6.1: Sistema robótico utilizado nos primeiros experimentos com a arquitetura REACT.

Os parâmetros utilizados nos comportamentos implementados foram:

- Stand off: $S=20 \mathrm{~cm}$

- Constante de decaimento: $T=10 \mathrm{~cm}$ 
- Velocidade moveAhead: $V_{M A}=7,8 \mathrm{~cm} / \mathrm{s}$

- Velocidade moveToFree: $V_{M T F}=7,8 \mathrm{~cm} / \mathrm{s}$

- Velocidade avoidCollision: $V_{A C}=13 \mathrm{~cm} / \mathrm{s}$

- Velocidade moveToGoal: $V_{M T G}=5,2 \mathrm{~cm} / \mathrm{s}$

Os valores dos parâmetros foram acertados experimentalmente. As constantes de decaimento, standoff, e as velocidades moveAhead, movetoGoal e avoidCollision já estavam determinadas por experiências realizadas em outros trabalhos, de forma que o robô já exibia uma boa atuação sem o comportamento moveToFree.

\subsubsection{Experimento utilizando somente movetoFree}

Primeiramente, foi realizado um experimento para averiguar a capacidade de desvio de obstáculos do comportamento baseado em visão. Para isso, os outros comportamentos foram desligados. Foi montado um cenário muito simples composto de alguns poucos obstáculos, sendo que o robô deveria percorrê-lo comandado somente pelo comportamento moveToFree. Uma vez que o comportamento moveToGoal ficou inativo durante o experimento, o robô procurava sempre andar para frente, desviando dos obstáculos assim que eram detectados.

Foi observado que, na maior parte das situações, o robô conseguia evitar a colisão com obstáculos frontais. Além disso, seu modo de se comportar reforçou a idéia de que há uma faixa de operação para o sensor de distâncias desenvolvido: enquanto objetos muito distantes eram ignorados, o robô se perdia quando se aproximava muito de um obstáculo. Esse efeito também se deve, em parte, ao fato de que um objeto frontal muito próximo ocupa quase todo o campo de visão da câmera, não sendo possível identificar um caminho livre para seguir.

Finalmente, esse experimento permitiu concluir que seria importante aumentar o campo de visão da câmera de vídeo. Um pequeno ângulo de abertura da câmera não permite que o robô perceba várias possibilidades à frente, tendo que 
encontrar um caminho livre numa faixa estreita de visão. Além do mais, pequenos ângulo de abertura implicam em um maior fator de aproximação (zoom), de forma que as trepidações resultantes do movimento do robô tenham grande efeito sobre as imagens capturadas, atrapalhando o processamento da visão.

\subsubsection{Experimento com os demais comportamentos}

Para averiguar o impacto do novo comportamento no desempenho do robô foram realizados alguns testes comparativos entre a implementação da arquitetura REACT com o comportamento moveToFree e aquela sem esse comportamento (SELVATICI; COSTA, 2004a). Na implementação em que o comportamento baseado em visão estava ativado, com exceção do comportamento moveAhead, todos os outros permaneceram ativos durante o experimento. Uma vez que o ângulo de abertura da câmera era pequeno (apenas 20), o comportamento moveToFree só poderia comandar giros de $10^{\circ}$ de amplitude máxima, o que ainda seria atenuado caso o comportamento inercial permanecesse ativo.

Foi utilizado um cenário no qual a arquitetura empregada se comporta bem. Fixou-se um objetivo virtual para o robô: uma posição espacial da qual ele deve se aproximar com uma certa margem de tolerância. Sua localização com relação ao objetivo vem da informação dos odômetros. Foi verificado que a arquitetura utilizando visão apresentou, no geral, um melhor desempenho, realizando trajetos mais curtos e diretos. Isso se deve a uma percepção antecipada do obstáculo, o que permite ao comportamento moveToFree determinar uma trajetória mais desimpedida. O maior problema apresentado na utilização da visão foi o seu elevado tempo de processamento, o que acarretou em um grande intervalo de atuação do controle, resultando assim em manobras mais bruscas feitas pelo robô. Isso se deve basicamente à pouca ênfase dada na eficiência do software de captura e processamento de imagens em tempo real implementado e à pouca capacidade de processamento do computador utilizado. A figura 6.2 exemplifica os comportamentos apresentados pelo robô utilizando ambas implementações da arquitetura. Observa-se que no trajeto feito com o comportamento moveToFree ativo, ao contrário do que ocorre sem a sua ativação, o robô não se detém na frente do obstáculo, e por isso tem uma trajetória mais curta e direta. Entretanto, também se observa um desvio com relação ao objetivo no final da trajetória exibida pela 
implementação utilizando visão devido a uma ponderação inadequada entre os efeitos dos comportamentos primitivos nesse segmento. Como o comportamento moveToFree continua ativo mesmo com o alvo próximo, ele respondeu à percepção de um obstáculo que se encontrava mais à frente e acabou atrapalhando a atuação do robô.

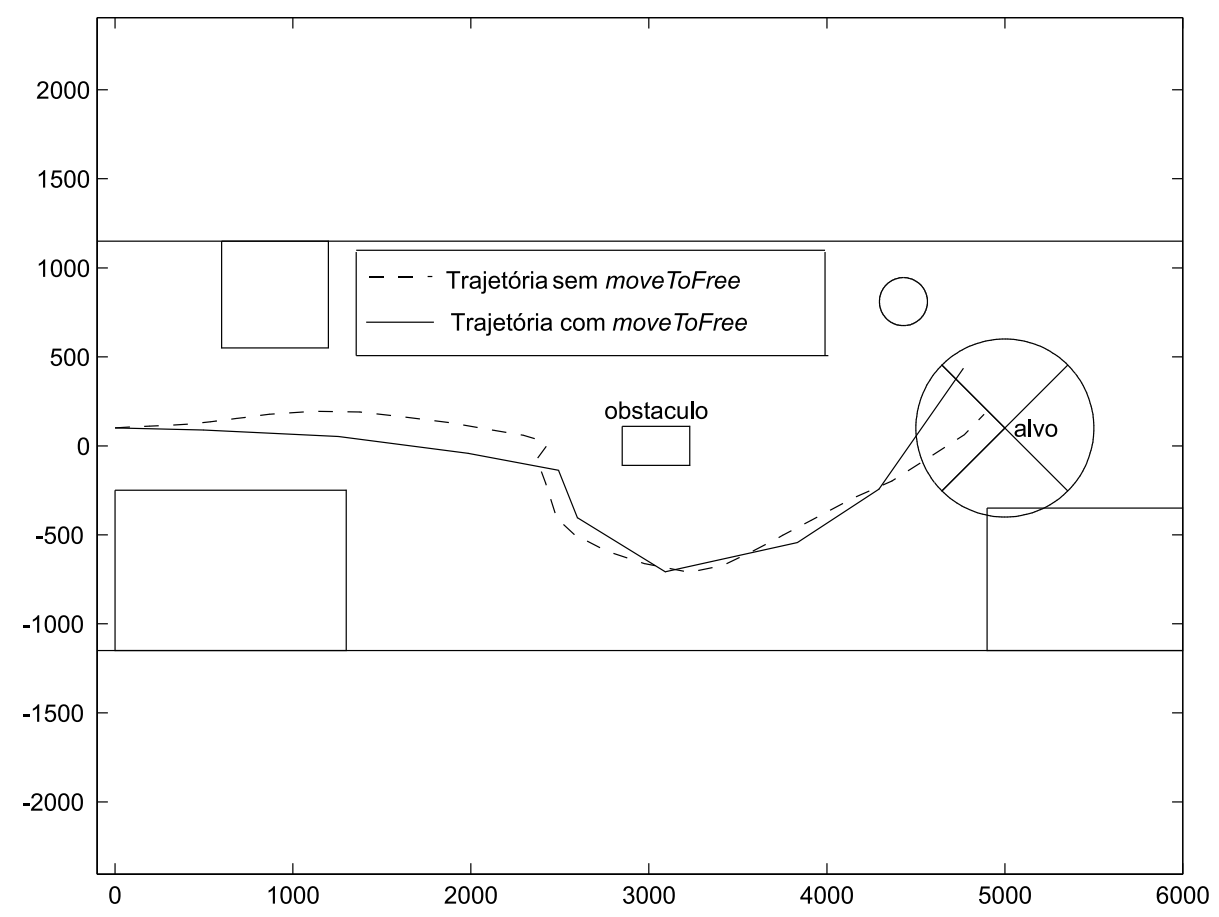

Ilustração das trajetórias do robô em um dos experimentos utilizando ambas as implementações da arquitetura REACT. Utilizando a arquitetura sem visão computacional, o robô percorreu $561 \mathrm{~cm}$, enquanto que com a arquitetura utilizando o novo comportamento foram percorridos $551 \mathrm{~cm}$.

Figura 6.2: Ilustração das trajetórias do robô em um dos experimentos utilizando ambas as implementações da arquitetura REACT.

\subsection{Conclusão sobre a arquitetura REACT}

Os experimentos realizados mostram que a arquitetura REACT, de modo geral, atinge seus objetivos, e que o comportamento move ToFree de fato ajuda a melhorar o seu desempenho. No entanto, há situações em que a simples soma dos vetores resultantes dos comportamentos gera ações indesejáveis. Além do exemplo mencionado na seção 6.2.3, em que um dos comportamentos passa a atrapalhar a atuação do robô, há casos em que o problema se encontra no próprio modo como é feita a coordenação dos comportamentos. A literatura tradicionalmente aponta 
duas falhas nas arquiteturas reativas baseadas em Campos Potenciais (KOREN; BORESTEIN, 1991). A primeira é a possibilidade da existência de mínimos locais do campo potencial gerado pelos comportamentos, configurando regiões de atração indevidas para onde o robô pode se dirigir e permanecer. A outra falha é a forte oscilação apresentada pelo robô quando passa dentro de corredores estreitos, efeito que, na arquitetura REACT, é em parte atenuado pelo comportamento moveAhead.

Esses problemas ocorrem porque o campo gerado pelos comportamentos nessas arquiteturas é fixo. Assim, caso o campo resultante possua regiões de atração diferentes do objetivo ou ainda regiões de oscilação, nada impede o robô de entrar nessas regiões. Diversas alternativas foram propostas para evitar esses problemas intrínsecos às arquiteturas baseadas em Campos Potenciais. Em geral, quando essas alternativas se mantêm na abordagem comportamental, acabam por incorporar um elemento de planejamento que atua sobre esses comportamentos.

A arquitetura híbrida proposta neste trabalho procura fazer com que a coordenação dos comportamentos se adapte às situações encontradas pelo robô através de aprendizado por reforço. Assim, como o peso de cada comportamento na atuação do robô muda com o tempo, o campo potencial gerado é dinâmico, evitando situações de mínimos locais permanentes. Além disso, como a adaptação dos pesos é aprendida de acordo com a experiência do robô, podem ser identificadas as situações em que comportamentos específicos atrapalhem sua atuação, possibilitando a inibição desses comportamentos. 


\section{A arquitetura AAREACT}

O papel do aprendizado dentro de uma arquitetura de agentes é ajustar as partes dessa arquitetura de forma que o agente melhore seu desempenho. Assim sendo, o aprendizado realizado dentro de uma arquitetura robótica baseada em comportamentos pode atuar tanto sobre os parâmetros internos desses comportamentos quanto sobre a coordenação dos mesmos.

De modo geral, os comportamentos para robôs móveis são projetados em vista do ambiente e do tipo de tarefa do robô, cumprindo bem o seu objetivo específico. No entanto, o modo como é realizada a coordenação entre eles pode apresentar problemas. Discutiu-se, no final do capítulo anterior, os problemas causados pela coordenação fixa de comportamentos na arquitetura REACT, onde a parcela de cada comportamento na atuação final do robô tem sempre o mesmo peso. A arquitetura com aprendizado proposta neste trabalho procura contornar esses problemas através do aprendizado de uma função de coordenação adaptativa, que ajuste o peso de cada comportamento dependendo da situação encontrada pelo robô. Dessa forma, a arquitetura proposta realiza a adaptação automática de parâmetros da arquitetura REACT, gerando o acrônimo AAREACT.

\subsection{O aprendizado na AAREACT}

Muitas vezes, em vez de um comportamento ótimo — no sentido de minimização de trajetória ou de tempo, por exemplo - espera-se que um robô móvel inteligente apresente uma boa atuação em todas as situações que encontrar. Isso significa que ele deve ser capaz de atingir seu objetivo em qualquer configuração do ambiente para o qual tenha sido projetado. Entretanto, encontrar um critério quantitativo que expresse a qualidade da atuação do robô é uma tarefa difícil, já que uma boa atuação pode corresponder a características abstratas que expressam o desejo do 
projetista, como "desenvoltura".

O objetivo do aprendizado na arquitetura AAREACT é fazer com que o robô ajuste o grau de participação de cada comportamento na sua atuação final dependendo da situação em que ele se encontre, de modo a se comportar bem independentemente da configuração do ambiente. Assim, o resultado do aprendizado não é válido apenas no ambiente onde o robô iniciou sua atuação, mas pode ser aplicado também em outros ambientes.

Para tanto, antes da etapa de coordenação, os comportamentos na arquitetura AAREACT têm suas saídas ponderadas por uma função de ponderação, que atribui um peso a cada comportamento a partir da situação observada para o ambiente. Além disso, essa função de ponderação é aprendida através de aprendizado por reforço com base na experiência do robô, constituindo assim uma função adaptativa. Ela é implementada por uma camada de supervisão/crítica/aprendizado, que tem a capacidade de supervisionar e criticar (por meio dos sensores e dos reforços obtidos) a atuação do robô e modificar o conjunto de pesos dos comportamentos.

Dessa forma, o agente com aprendizado (vide capítulo 2) implementado pela arquitetura AAREACT possui, como elemento de desempenho, o agente implementado pela arquitetura REACT, composta pelos comportamentos moveToGoal, avoidCollision, moveAhead e moveToFree, descritos nos capítulos 4 e 6 . O elemento de aprendizado é implementado por aprendizado por reforço. A supervisão e crítica são realizadas, respectivamente, pelo módulo de observação do estado e pelo módulo de cálculo da função de reforço. O gerador de problemas atua segundo uma estratégia que escolhe uma ação aleatória, para exploração, com uma probabilidade $\epsilon$, enquanto, no restante da atuação, segue uma política "gulosa" (greedy, em inglês), visando explicitamente à explotação das ações. A política $\epsilon$-greedy, seguida pelo gerador de problemas, garante um bom compromisso entre exploração e explotação feita pelo agente aprendiz. A arquitetura AAREACT implementada encontra-se esquematizada na figura 7.1. 


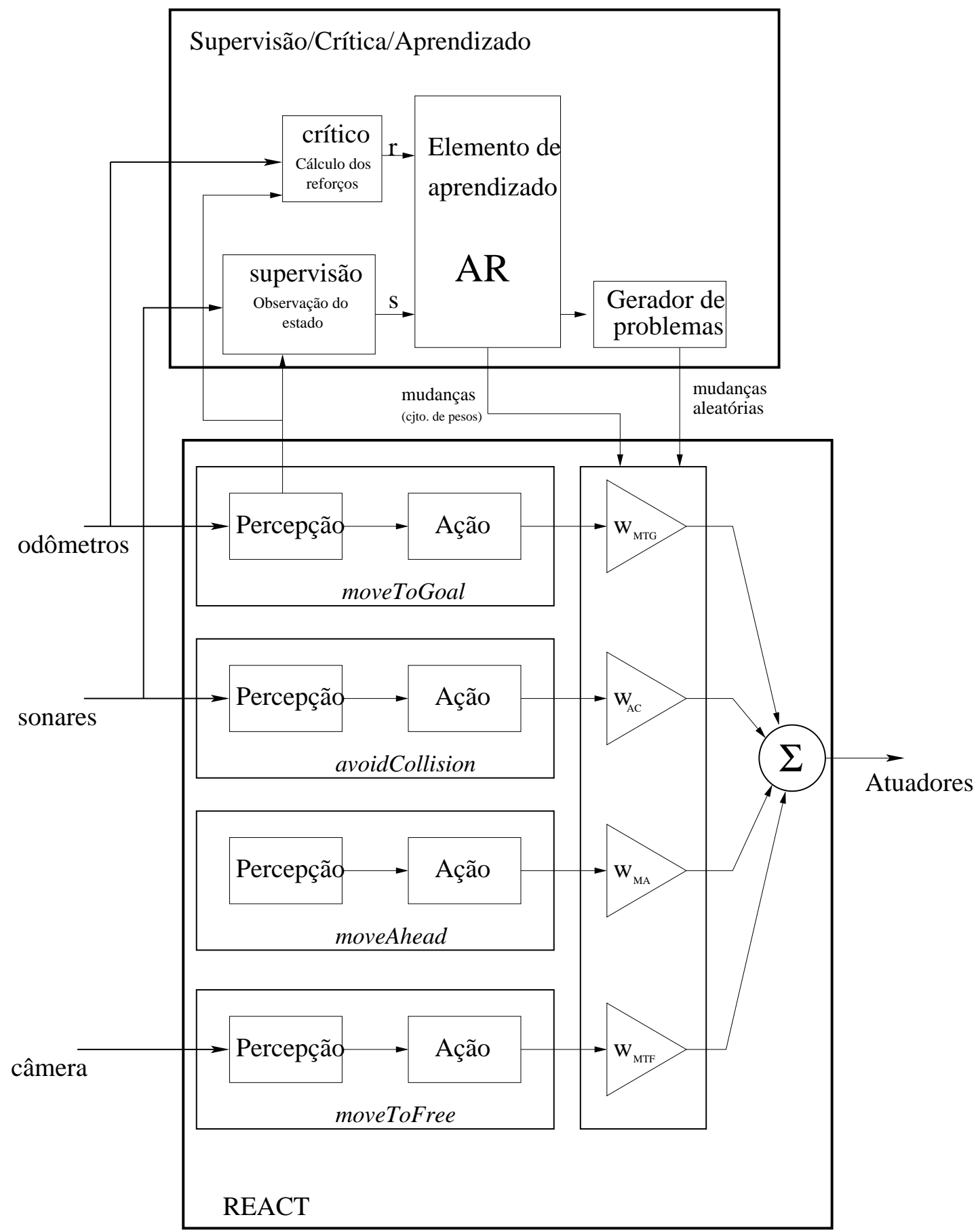

Figura 7.1: Diagrama de blocos da arquitetura AAREACT implementada 


\subsection{Aprendizado por reforço}

A proposta do aprendizado por reforço (AR) é ser um modo de programar agentes através de recompensas e punições, sem especificar como a tarefa deve ser realizada. AR é o problema encontrado por um agente que deve aprender uma política de atuação na base de interações do tipo tentativa e erro com um ambiente dinâmico (KAELBLING; LITTMAN; MOORE, 1996).

Existem duas estratégias principais para resolver problemas de AR. A primeira é buscar no espaço de comportamentos aquele que possui bom desempenho no ambiente. Trabalhos em algoritmos genéticos e programação genética, bem como outras novas técnicas de busca, têm adotado esta abordagem. A segunda é utilizar técnicas de estatística e métodos de programação dinâmica para estimar a utilidade de se tomar ações nos estados do mundo, abordagem adotada neste trabalho.

\subsubsection{O modelo de AR}

No modelo padrão de AR, um agente interage com seu ambiente através de percepção e ação. Em cada passo de interação o agente recebe como entrada, $i$, uma indicação do estado atual $s$ do ambiente; o agente escolhe, então, uma ação a para gerar como saída. A ação muda o estado do ambiente, e o valor dessa transição de estado é comunicada ao agente através de um valor escalar, o sinal de reforço $r$. O agente deve escolher ações que tendem a aumentar a soma de valores do sinal de reforço a longo prazo. Ele pode aprender a fazer isso através de tentativas sistemáticas guiadas por uma grande variedade de algoritmos.

Formalmente, o modelo consiste de:

- um conjunto de $N_{s}$ possíveis estados para o ambiente, $S$;

- um conjunto discreto de $N_{a}$ ações do agente, $A$;

- um conjunto escalar $R$ de sinais de reforço, sendo $r(s, a)$ a função reforço, que pode ser não-determinística.

Um problema de AR é caracterizado, então, por: 
- um agente atuando em um ambiente;

- entradas $i$ vindas do ambiente;

- estados $s$ do ambiente;

- reforço $r$, que depende do estado e da ação tomada;

- ação $a$ do agente que modifica o estado;

- política $\pi$ que caracteriza a atuação do agente, indicando qual a melhor ação a ser executada em cada instante.

O trabalho do agente é encontrar uma política ótima $\pi^{*}$, mapeando os estados em ações, que maximize alguma medida de reforço a longo prazo, que representa um modelo de otimalidade para a atuação do agente. Uma possibilidade é o modelo de horizonte infinito com desconto, que leva em consideração a recompensa a longo prazo, mas as recompensas que são recebidas no futuro são descontadas de acordo com um fator de desconto $\gamma$, com $0<\gamma<1$ :

$$
R_{T}=E\left[\sum_{t=0}^{\infty} \gamma^{t} r_{t}\right]
$$

Pode-se interpretar $\gamma$ de diversos modos. Pode ser visto como uma taxa de interesse - quanto mais distante o reforço, menos interessa —, uma probabilidade de dar um novo passo ou um truque matemático para limitar o valor da série. Este é o modelo utilizado na maior parte dos trabalhos em AR.

Para o estudo dos algoritmos de AR, assume-se que a função entrada, $I$, que determina como o agente vê o ambiente, é a função identidade, ou seja, o agente percebe o seu estado completa e corretamente. Da mesma forma, assume-se que o ambiente é estacionário, isto é, que as probabilidades de transição de estados, dada uma ação executada e os valores de reforço, não mudam com o tempo. Na prática, tem-se ambientes não determinísticos, ou seja, tomar a mesma ação no mesmo estado em dois momentos diferentes pode levar a estados diferentes do ambiente e/ou a diferentes valores do reforço. Porém, espera-se que assumir essas restrições leve a uma política que seja de sucesso também nesse ambiente real ao longo do tempo, incorporando um "comportamento médio" do ambiente. 


\subsection{Processos markovianos de decisão (MDPs)}

Para ambientes estacionários, a teoria de processos markovianos de decisão Markov Decision Processes, ou MDPs - garante um tratamento matemático adequado. De fato, a maior parte dos trabalhos em AR se baseiam em MDPs, embora os conceitos envolvidos possam ser aplicados de forma mais genérica (MONTEIRO, 2002).

Processos markovianos de decisão são aqueles onde um agente deve decidir que ação tomar dado que o ambiente se encontra no estado $s$ e satisfaz a condição de Markov. A condição de Markov diz que o estado corrente do ambiente resume o passado de forma compacta, de forma que estados futuros não dependem de estados anteriores caso se conheça o estado corrente. Isto é, pode-se predizer qual será o próximo estado dado o estado corrente e a ação a ser tomada (SUTTON; BARTO, 1998).

Formalmente, um MDP consiste de:

- um conjunto de estados do ambiente $S=s_{1}, s_{2}, \ldots, s_{N_{s}}$;

- um conjunto de possíveis ações $A=a_{1}, a_{2}, \ldots, a_{N_{a}}$;

- uma função de probabilidade de transição $P\left(s^{\prime} \mid s, a\right)$, que determina a probabilidade de se ir para o estado $s^{\prime}$ dado que se está no estado $s$ e é tomada a ação $a$;

- reforços associados à ação $a$ tomada no estado $s, r(s, a) \in R$.

Dessa forma, um MDP é caracterizado por todos os elementos que caracterizam um problema de $\mathrm{AR}$ - a tripla $\langle S, A, R\rangle$ - mais a função de transição $P$, que caracteriza um modelo do ambiente. Uma política $\pi$, em um MDP, é aquela que relaciona um estado a uma ação a ser tomada. Da mesma forma que em AR, a política ótima $\pi^{*}$ é aquela que garante a maior soma dos reforços a longo prazo (no caso, é utilizado o modelo de horizonte infinito com desconto).

Uma vez escolhido esse modelo de otimalidade, pode-se definir um valor ótimo para a atuação do agente como sendo:

$$
V^{*}=\max _{\pi} R_{T}=\max _{\pi} E\left[\sum_{t=0}^{\infty} \gamma^{t} r_{t}\right] .
$$


Esse valor ótimo só depende do estado corrente e, para cada estado, pode ser definido como a solução do sistema de equações recursivas

$$
\begin{aligned}
V^{*}\left(s_{i}\right) & =\max _{a}\left(r\left(s_{i}, a\right)+\gamma \sum_{s^{\prime} \in S} P\left(s^{\prime} \mid s_{i}, a\right) V^{*}\left(s^{\prime}\right)\right) \\
& =\max _{a} Q^{*}\left(s_{i}, a\right), \quad i=1,2, \ldots, N_{s}
\end{aligned}
$$

onde $Q^{*}(s, a)$ é o reforço total esperado caso se tome a ação $a$ no estado $s$ e depois se siga agindo otimamente. Isso significa que o valor de um estado $s$ é dado pela recompensa instantânea esperada mais o valor esperado para o próximo estado, descontado de $\gamma$, quando se usa a melhor ação disponível. Dada a função valor $\left(V^{*}(s)\right)$, a política ótima é aquela que garante (7.2), ou seja,

$$
\pi^{*}(s)=\arg \max _{a} Q^{*}(s, a)
$$

A função $Q^{*}(s, a)$ também pode ser definida de forma recursiva como

$$
Q^{*}\left(s_{i}, a\right)=r\left(s_{i}, a\right)+\gamma \sum_{s^{\prime} \in S} P\left(s^{\prime} \mid s_{i}, a\right) \max _{a^{\prime}} Q^{*}\left(s^{\prime}, a^{\prime}\right)
$$

\subsubsection{Algoritmos de AR}

No entanto, em um problema de AR, o ambiente é inicialmente desconhecido, de forma que as probabilidades de transição devem ser, implícita ou explicitamente, aprendidas com o passar do tempo. Os algoritmos de AR que aprendem diretamente a política ótima, incorporando implicitamente essas probabilidades de transição - chamados de algoritmos livres de modelo - são geralmente os mais populares, por serem mais simples e fáceis de implementar. Este trabalho se detém no uso desse tipo de algoritmo.

\section{Q-learning}

O mais popular algoritmo de AR livre de modelo é o Q-learning. Ele procura aprender a função $Q^{*}(s, a)$ diretamente da experiência do agente, de forma que a política ótima é dada por (7.4).

Quando o agente se encontra no estado $s$ e executa a ação $a$, obtém como resposta do ambiente um reforço $r$ e um novo estado $s^{\prime}$. Assim, a partir dessa 
quádrupla $\left\langle s, a, r, s^{\prime}>\right.$, tem-se a regra de aprendizado do algoritmo Q-learning (KAELBLING; LITTMAN; MOORE, 1996):

$$
Q(s, a):=Q(s, a)+\alpha\left(r+\gamma \max _{a^{\prime}} Q\left(s^{\prime}, a^{\prime}\right)-Q(s, a)\right)
$$

onde $\alpha \in] 0,1[$ é uma taxa de aprendizado e $\gamma$ é a taxa de desconto, sendo ambas parâmetros de projeto.

Dessa forma, uma tabela com os valores de $Q(s, a)$ (tabela Q) é construída conforme o agente percorre o espaço de estados do ambiente e explora seu espaço de ações. Isso significa que o resultado do aprendizado é registrado em uma tabela Q. Prova-se que os valores dessa tabela convergem para os valores de $Q^{*}(s, a)$ caso todos os pares (estado, ação) sejam visitados infinitas vezes (MITCHELL, 1997). Satisfazer essa condição é impossível na prática, mas esse resultado teórico é uma indicação de que após os estados serem visitados muitas vezes, a política determinada a partir da tabela $Q(s, a)$ corresponderá, muito provavelmente, à política ótima.

No entanto, para garantir a visitação dos estados é necessário que a estratégia de atuação do agente se preocupe com a exploração do ambiente, além de tentar garantir a maior soma dos reforços, através de explotação.

\section{SARSA-learning}

O algoritmo Q-learning atualiza o valor de $Q(s, a)$ a partir do valor na tabela $\mathrm{Q}$ correspondente ao estado seguinte $s^{\prime}$ e à melhor ação que pode ser tomada nesse estado $s^{\prime}$, com base no conhecimento momentâneo do agente. Isso independe da ação que ele de fato vai executar. Caso sua estratégia de atuação seja greedy, a ação a ser executada corresponde de fato àquela que se acredita ser a melhor ação, determinada por $\arg \max _{a^{\prime}} Q\left(s^{\prime}, a^{\prime}\right)$. No entanto, caso o agente se preocupe em explorar o ambiente, segundo uma política $\epsilon$-greedy, por exemplo, isso pode não se aplicar.

O algoritmo SARSA-learning (SUTTON; BARTO, 1998) é uma modificação do Q-learning que atualiza o valor de $Q(s, a)$ a partir do valor na tabela $\mathrm{Q}$ correspondente ao estado seguinte $s^{\prime}$ e à ação $a^{\prime}$ efetivamente executada nesse estado $s^{\prime}$. Dessa forma, a regra de aprendizado do $S A R S A$-learning é baseada na coletânea 
$<s, a, r, s^{\prime}, a^{\prime}>$ — daí o nome $S A R S A$ - para atualizar a tabela Q:

$$
Q(s, a):=Q(s, a)+\alpha\left(r+\gamma Q\left(s^{\prime}, a^{\prime}\right)-Q(s, a)\right) .
$$

É interessante notar que a garantia da convergência dos valores de $Q(s, a)$ para $Q^{*}(s, a)$ está atrelada à adoção de uma estratégia greedy pelo agente, o que torna Q-learning e SARSA-learning equivalentes. No entanto, é suficiente garantir que a estratégia do agente (no caso, $\epsilon$-greedy) convirja após certo tempo para a estratégia greedy, permitindo que ele execute uma certa exploração do ambiente no início do aprendizado. Neste trabalho, o algoritmo utilizado foi o SARSA-learning.

\subsection{A implementação do aprendizado por re- forço}

Assim, um problema de AR é caracterizado por:

- um conjunto discreto de estados;

- um conjunto discreto de ações;

- uma função de reforço.

Portanto, o primeiro passo para o projeto da camada de supervisão, crítica e aprendizado da AAREACT é especificar o espaço de possíveis estados, o espaço de ações e a função de reforço.

\subsubsection{A definição dos estados}

A principal dificuldade na caracterização do problema de AR no caso da arquitetura AAREACT reside na especificação do espaço de estados. Kalmár, Szepesvári e Lörincz (1998) enfrentaram um problema semelhante. A arquitetura do trabalho deles é composta por comportamentos reativos de codificação discreta, coordenados de forma competitiva, isto é, apenas um comportamento é ativado por vez. A função de coordenação é aprendida através de aprendizado por reforço, de modo que a camada de aprendizado deve determinar o comportamento ativo 
com base na situação observada para o ambiente. Assim, naquele trabalho, uma ação para a camada de aprendizado equivale à escolha de um comportamento. No caso da AAREACT, essa ação corresponde à escolha de um conjunto de pesos para a ponderação dos comportamentos.

Uma vez que o espaço de posições e orientações do robô é contínuo e há infinitas configurações possíveis para os obstáculos no ambiente, o espaço de estados do mundo real é, a rigor, contínuo e infinito. No entanto, a aplicação de AR para o aprendizado do robô necessita da especificação de um espaço de estados finito e discreto, que reflita apenas algumas características mais relevantes do ambiente.

Kalmár, Szepesvári e Lörincz (1998) propõem que seja definido um conjunto de atributos ou características binárias, de forma que elas podem estar ou não presentes. Então, o estado do ambiente é definido por um vetor indicando a presença ou ausência de cada atributo, denominado de vetor de atributos ou features vector. Esses atributos são abstraídos dos dados sensoriais do robô e definem uma situação para o ambiente. Dessa forma, o espaço de estados a ser considerado para o problema de AR corresponde ao espaço discreto de situações definidas pelas possíveis configurações do vetor de atributos.

É importante mencionar que, no trabalho de Kalmár, Szepesvári e Lörincz (1998), cada comportamento está relacionado com um dos atributos do ambiente, de forma que a presença isolada de um determinado atributo dispara o comportamento correspondente. No entanto, na maior parte das situações, mais de um atributo está presente ao mesmo tempo. Dessa forma, a camada de aprendizado decide o melhor comportamento para cada situação, com base na experiência adquirida.

A especificação da situação do ambiente observada pela camada de supervisão/crítica/aprendizado da arquitetura AAREACT segue a mesma filosofia. Foram definidos atributos binários que representam características relevantes do ambiente, cuja presença ou ausência é determinada a partir da leitura dos sonares e odômetros do robô. A cada atributo definido está atrelado um conjunto de pesos para os comportamentos, elaborados de maneira ad hoc, de forma que a camada de AR deve determinar quais pesos devem ser escolhidos quando mais de um atributo estiver presente. Os conjuntos de pesos definidos estão relacionados na seção 7.4.2. 
Os atributos definidos foram:

FreeTarget: este atributo está presente quando o robô detecta que não há obstáculos entre ele e o alvo, ou ainda que os obstáculos na direção do alvo estão muito distantes. Um obstáculo distante é caracterizado por uma leitura de sonar superior a um limiar $L_{f a r}$, definido arbitrariamente.

BackTarget: a presença deste atributo se dá quando o alvo se encontra atrás do robô, de forma que os sonares, dispostos em um anel na parte frontal do robô, não conseguem detectar se há algum impedimento entre ele e o alvo.

SideObstacle: este atributo se faz presente quando um dos sonares laterais do robô detecta a presença de um obstáculo próximo, o que equivale a uma leitura de sonar inferior a um limiar $L_{n e a r}$, definido arbitrariamente.

DiagonalObstacle: esta característica é ativada quando um dos sonares das diagonais anteriores do robô detecta a presença de um obstáculo próximo, com leitura de distância inferior a $L_{\text {near }}$.

MiddleObstacle: o que determina a presença deste atributo é a detecção de algum obstáculo a uma distância média do robô, caracterizada por uma leitura de sonar entre os limiares $L_{\text {near }}$ e $L_{\text {far }}$. A presença isolada deste atributo configura uma situação confortável, onde não há perigo iminente de obstáculo.

NarrowPath: este atributo está presente quando ambos os sonares laterais do robô detectam a presença de um obstáculo próximo, caracterizando a passagem do robô por um corredor estreito. Quando este atributo é detectado, os demais descritos anteriormente (FreeTarget, BackTarget, SideObstacle, DiagonalObstacle e MiddleObstacle) são ignorados, uma vez que a navegação em um corredor estreito é uma situação especial na qual não se deve preocupar com a posição do alvo ou a presença dos obstáculos fora do corredor.

FrontalObstacle: este atributo está presente quando um dos sonares frontais do robô detecta a presença de um obstáculo próximo, caracterizando um perigo iminente de colisão. Quando este atributo é detectado, todos os demais são ignorados, já que a reação mais prudente do robô é se afastar 
desse obstáculo e não se preocupar com o alvo ou com obstáculos mais distantes.

Assim, uma situação do ambiente é caracterizada pelo vetor de atributos que indica quais atributos estão presentes e quais estão ausentes. Uma mudança de situação ocorre quando há a deteç̧ão de um ou mais atributos antes ausentes, ou ainda quando um ou mais atributos deixam de estar presentes. A princípio, dado o número de atributos definidos, pode-se pensar que o número de possíveis situações é igual a $2^{7}=128$. No entanto, o modo como estão definidos os atributos resulta em que vários sejam mutuamente exclusivos, reduzindo drasticamente o tamanho do espaço de situações. Uma análise dos atributos definidos mostra que há apenas 24 situações possíveis para o ambiente.

\subsubsection{Definição das ações}

A camada de aprendizado dentro da arquitetura AAREACT não atua diretamente sobre os atuadores do robô, mas influencia nas suas ações através de modificações em parâmetros da arquitetura. Dessa forma, para o problema de aprendizado por reforço, uma ação não pode ser entendida como um comando aos atuadores do robô, mas sim como a escolha de um conjunto de parâmetros.

Assim, uma ação da camada de aprendizado é definida por um conjunto de pesos atribuídos às saídas dos comportamentos, da mesma forma que, para o módulo de aprendizado da arquitetura de Kalmár, Szepesvári e Lörincz (1998), uma ação equivale à escolha de um comportamento. Como o espaço de ações possíveis deve ser composto por elementos discretos e indexados, nesse caso o espaço de ações é expresso através de conjuntos de pesos predefinidos. Esses conjuntos foram definidos de maneira ad hoc, e estão discriminado na tabela 7.1.

A definição desses pesos foi baseada na idéia de se atrelar uma ação da camada de aprendizado a cada atributo definido. Assim, quando a situação do ambiente for definida pela presença isolada de um único atributo, o conjunto de pesos escolhido é aquele atrelado ao atributo em questão. Nas demais situações, nas quais há mais de um atributo presente, o módulo de AR deve decidir o melhor conjunto de pesos dentre aqueles relacionados na tabela 7.1. O modo como foram definidos os atributos garante que não há a possibilidade de todos os atributos 
Tabela 7.1: Relação dos conjuntos de pesos dos comportamentos que definem as possíveis ações do módulo de AR.

\begin{tabular}{cc}
\hline Índice & $\begin{array}{c}\text { Conjunto de pesos } \\
\left\{w_{M A} ; w_{M T F} ; w_{M T G} ; w_{A C}\right\}\end{array}$ \\
\hline 1 & $\{0,0 ; 0,0 ; 1,0 ; 0,0\}$ \\
2 & $\{0,0 ; 0,0 ; 1,0 ; 1,0\}$ \\
3 & $\{0,0 ; 1,0 ; 0,0 ; 0,3\}$ \\
4 & $\{1,0 ; 0,0 ; 0,0 ; 1,0\}$ \\
5 & $\{0,0 ; 0,6 ; 0,4 ; 1,0\}$ \\
6 & $\{1,0 ; 0,0 ; 0,0 ; 0,3\}$ \\
7 & $\{0,3 ; 0,0 ; 0,0 ; 1,0\}$ \\
8 & $\{0,0 ; 0,5 ; 1,0 ; 0,7\}$ \\
\hline
\end{tabular}

estarem ausentes simultaneamente.

Ao atributo Free Target está atrelado o conjunto de pesos 1, onde somente o comportamento moveToGoal está ativo, uma vez que não há a preocupação com o desvio de obstáculos. Já o atributo BackTarget requer o conjunto de pesos 2, no qual, além do comportamento de buscar o objetivo moveTogoal, está ativo também o comportamento avoidCollision, de modo a se evitar a colisão com obstáculos previamente não percebidos. O conjunto de pesos 3, associado ao atributo SideObstacle, ativa o comportamento move ToFree com participação total e o comportamento avoidCollision com pequena participação, representada pelo peso 0,3, definido arbitrariamente. Dessa forma, além do afastamento do perigo causado por obstáculos laterais próximos, o robô se preocupa em evitar possíveis obstáculos frontais mais adiante. Já o atributo DiagonalObstacle requer a desativação de moveToFree, pois, como um obstáculo na diagonal representa um maior perigo de colisão, o robô não deve se preocupar com obstáculos mais adiante, ativando somente os comportamentos avoidCollision e moveAhead (para a estabilização do movimento), gerando o conjunto de pesos 4 .

Dadas as relações entre as magnitudes máximas dos comportamentos na arquitetura REACT, que apresenta ponderação fixa, o conjunto de pesos equivalente é de 0,6 para moveToFree, 0,4 para moveToGoal e 1,0 para avoidCollision (conjunto de pesos 5). Como a presença isolada do atributo MiddleObstacle configura uma situação confortável, onde não há perigo iminente de obstáculo, decidiu-se atrelar o conjunto de pesos 5 a esse atributo. NarrowPath e FrontalObstacle ativam moveAhead e avoidCollision, reforçando um ou outro comportamento (con- 
junto de pesos 6 e 7 , respectivamente). A tabela 7.2 relaciona cada atributo com o conjunto de pesos correspondente.

Tabela 7.2: Relação entre os atributos definidos e o conjunto de pesos dos comportamentos associados a cada um.

\begin{tabular}{cc}
\hline Atributo & $\begin{array}{c}\text { Conjunto de pesos associado } \\
\left\{w_{M A} ; w_{M T F} ; w_{M T G} ; w_{A C}\right\}\end{array}$ \\
\hline FreeTarget & $\{0,0 ; 0,0 ; 1,0 ; 0,0\}$ \\
BackTarget & $\{0,0 ; 0,0 ; 1,0 ; 1,0\}$ \\
SideObstacle & $\{0,0 ; 1,0 ; 0,0 ; 0,3\}$ \\
DiagonalObstacle & $\{1,0 ; 0,0 ; 0,0 ; 1,0\}$ \\
MiddleObstacle & $\{0,0 ; 0,6 ; 0,4 ; 1,0\}$ \\
NarrowPath & $\{1,0 ; 0,0 ; 0,0 ; 0,3\}$ \\
FrontalObstcle & $\{0,3 ; 0,0 ; 0,0 ; 1,0\}$ \\
\hline
\end{tabular}

No entanto, não há garantias de que apenas os conjuntos de pesos relacionados com algum atributo específico são suficientes para uma boa atuação do robô. Por isso, foi também definido o conjunto de pesos 8, que não está atrelado a nenhum atributo do ambiente (vide tabela 7.1). Ele foi elaborado de modo a ser bastante diferente dos demais definidos até então: além dele, apenas o conjunto 5 conjuga três comportamentos simultaneamente, mas ambos os conjuntos de peso enfatizam comportamentos diferentes. Dessa forma, o conjunto de pesos 8 está presente entre as possíveis ações do módulo de AR como uma opção a mais a ser explorada no caso de mais de um atributo estar presente ao mesmo tempo.

\subsubsection{O reforço utilizado}

Em AR, reforços positivos devem ser utilizados para premiar situações desejáveis para o agente, podendo-se aplicar também penalidades para situações indesejáveis. O objetivo primário do robô é chegar à posição alvo. Dessa forma, a camada de aprendizado recebe um grande reforço positivo quando isso ocorre, definido por $r_{\text {goal }}$.

No entanto, é desejável também que o robô apresente um bom desempenho na sua atuação, o que é difícil de expressar quantitativamente. Neste trabalho, tentou-se modelar esse desempenho através de dois parâmetros: a velocidade média desenvolvida e a velocidade média de aproximação do alvo. Assim, recompensas proporcionais a essas medidas de desempenho são fornecidas à camada 
de aprendizado sempre que é percebida uma mudança na situação do ambiente, caracterizando um reforço intermediário, recebido antes do cumprimento da tarefa especificada. Esse reforço, no entanto, deve ser bem inferior àquele recebido quando o robô atinge o alvo. O reforço intermediário recebido é dado por

$$
r_{i n t}=K_{1} v_{m}+K_{2} v_{a}
$$

onde:

- $K_{1}$ e $K_{2}$ são ganhos arbitrariamente definidos;

- $v_{m}$ é a velocidade média desenvolvida pelo robô durante o tempo em que o ambiente se encontra num determinado estado ou situação;

- $v_{a}$ é a velocidade média de aproximação do alvo pelo robô durante o tempo de duração de uma situação, dada pela diferença entre as distâncias inicial e final do alvo, dividida pelo tempo de permanência na situação.

A formulação acima permite valores positivos e negativos para $r_{\text {int }}$. O valor desse reforço intermediário é saturado em $\pm \bar{r}$, para garantir que será menor do que $r_{\text {goal }}$. 


\section{Resultados experimentais da AAREACT}

Este capítulo apresenta os resultados experimentais obtidos com a arquitetura AAREACT. Uma vez que não é definida uma política inicial ${ }^{1}$ de atuação, ou seja, para cada situação do ambiente, todos os conjuntos de pesos têm a mesma probabilidade inicial de ocorrência, decidiu-se por dividir os experimentos em duas fases. Na primeira fase, denominada de aprendizado inicial, o módulo de AR procura combinar a explotação dos supostamente melhores conjuntos de pesos — dado o conhecimento adquirido até então — com a exploração das diversas possibilidades através de uma estratégia $\epsilon$-greedy. Nessa fase é esperada uma atuação ruim para o robô, que, inicialmente, deve apresentar até mesmo um comportamento errante. Com isso, espera-se que ele experimente várias situações diferentes e aprenda a lidar com elas, resultando assim em uma política inicial satisfatória, válida para qualquer ambiente, definida a partir da tabela Q obtida.

Na segunda fase, utiliza-se o conhecimento adquirido no aprendizado inicial, de forma que já é esperado um bom desempenho do robô em qualquer ambiente que venha a atuar. Nessa fase, o módulo de AR não mais explora os possíveis conjuntos de pesos, passando apenas a explotar os que julga mais convenientes para cada situação através de uma estratégia greedy, visando apenas a obter um bom desempenho. No entanto, vale ressaltar que o aprendizado por reforço continua ativo. Os experimentos que avaliam o desempenho da arquitetura AAREACT são realizados nessa fase.

\footnotetext{
${ }^{1} \mathrm{~A}$ única política predefinida é a que relaciona a ativação de um único atributo do ambiente com o respectivo conjunto de pesos; esta porém é fixa e não é influenciada pelo resultado do aprendizado.
} 


\subsection{O aprendizado inicial}

Como o conhecimento adquirido pela AAREACT se estende a diversos ambientes, é interessante aproveitar o aprendizado inicial para treinar o robô em um ambiente que apresente diversas situações possíveis a serem exploradas. No entanto, como o robô inicialmente tem muita dificuldade para atingir seu objetivo, o aprendizado inicial é necessariamente longo, de forma que a utilização de um robô real para esse intuito é inviável. Por isso, foi necessário recorrer ao simulador do robô Pioneer, que acompanha o pacote Saphira (ACTIVMEDIA ROBOTICS, 2001).

Foi elaborado um cenário onde o robô é obrigado a passar por vários tipos de configurações de obstáculos para atingir seu objetivo. Esse cenário é constituído de uma sala retangular, onde foram definidas quatro posições alvo de modo a ficarem próximas das quinas da sala, conforme mostra a figura 8.1. O robô foi então comandado a procurar um alvo por vez, de modo a garantir que, ao percorrer os quatro alvos consecutivos, o robô circunde a sala. A diversidade de configurações apresentadas pela disposição dos obstáculos, aliada ao comportamento errante esperado para o robô no início do aprendizado, contribuem para que o espaço de situações seja bastante explorado na fase de aprendizado inicial.

O simulador reproduz muito bem as leituras do odômetro e do sonar do robô. No entanto, não foi possível simular o sensor de visão no simulador. Uma vez que, no experimento descrito no capítulo 6 , o comportamento baseado em visão moveToFree substitui o comportamento inercial moveAhead, decidiu-se por utilizar o comportamento moveAhead em substituição ao comportamento moveToFree para que se pudesse utilizar o simulador, de forma que os pesos que ponderariam a influência do comportamento moveToFree passam a ponderar moveAhead. Isso só é possível porque ambos os comportamentos produzem ações similares (magnitude fixa e direção à frente do robô).

Para a implementação da arquitetura AAREACT realizada, os parâmetros utilizados foram:

- Parâmetros dos comportamentos

- Stand off: $S=40 \mathrm{~cm}$

- Constante de decaimento: $T=15 \mathrm{~cm}$ 


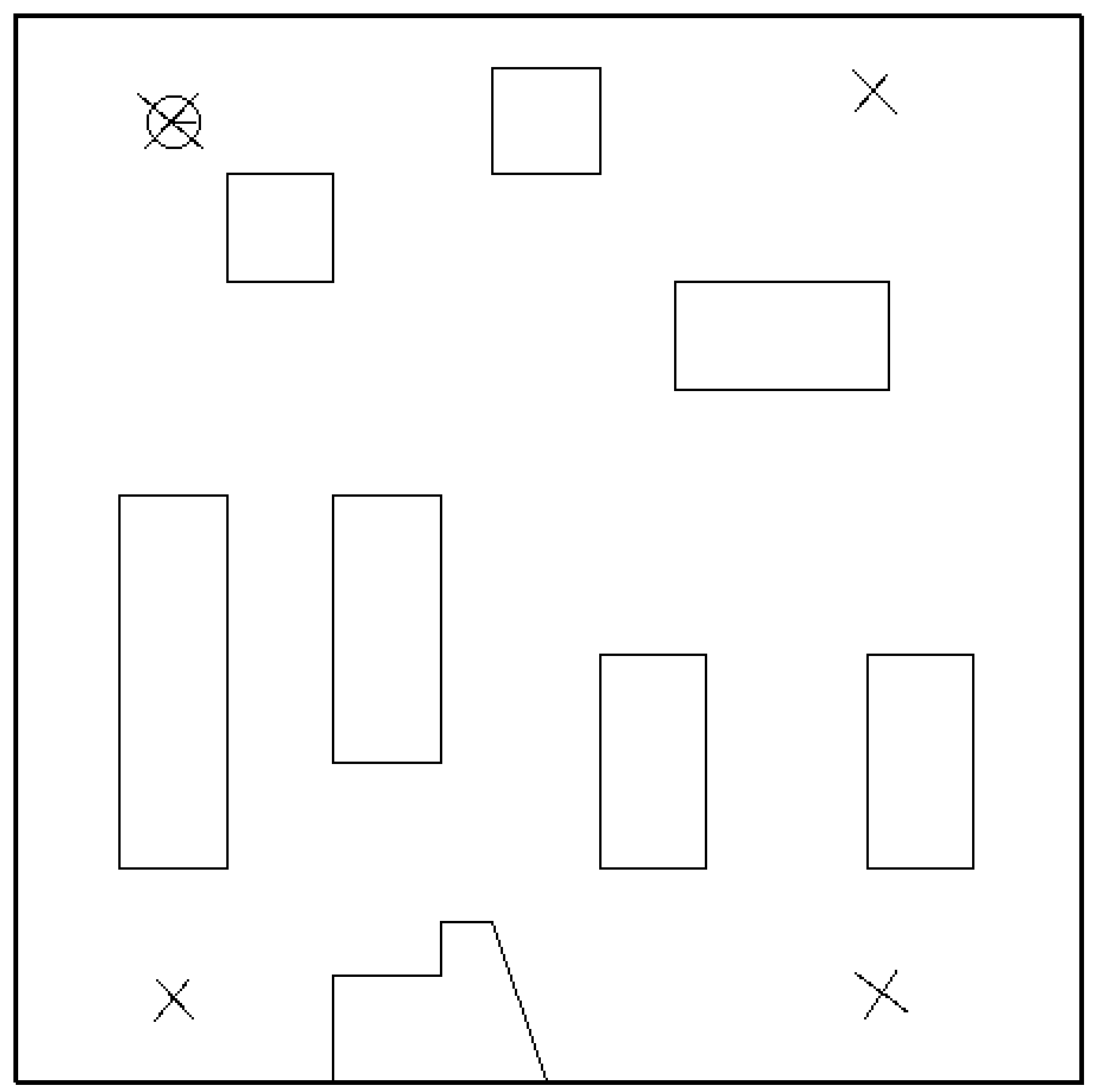

As arestas representadas na figura definem os limites dos obstáculos. As posições indicadas com um $\times$ são os alvos. O círculo indica a posição do robô, sendo que o segmento de reta em seu interior indica sua orientação.

Figura 8.1: Ambiente que o robô simulado iniciou seu aprendizado. 
- Velocidade moveAhead: $V_{M A}=15,0 \mathrm{~cm} / \mathrm{s}$

- Velocidade moveToFree: $V_{M T F}=15,0 \mathrm{~cm} / \mathrm{s}$

- Velocidade avoidCollision: $V_{A C}=15,0 \mathrm{~cm} / \mathrm{s}$

- Velocidade moveToGoal: $V_{M T G}=15,0 \mathrm{~cm} / \mathrm{s}$

- Parâmetros dos atributos

- Limiar de detecção de obstáculo próximo: $L_{\text {near }}=50 \mathrm{~cm}$

- Limiar de detecção de obstáculo distante: $L_{f a r}=200 \mathrm{~cm}$

- Parâmetros do aprendizado

- Taxa de aprendizado: $\alpha=0,3$

- Taxa de desconto: $\gamma=0,99$

- Probabilidade de exploração: $\epsilon=20 \%$

- Parâmetros do reforço

- Reforço no objetivo: $r_{\text {goal }}=100$

- Reforço máximo intermediário: $\bar{r}=3$

- Ganho sobre a velocidade média desenvolvida: $K_{1}=0,02 \mathrm{~s} / \mathrm{mm}$

- Ganho sobre a velocidade média de aproximação do alvo: $K_{2}=0,002 \mathrm{~s} / \mathrm{mm}$

Uma vez que o aprendizado por reforço acompanha toda a vida do agente, ou seja, sempre está ativo, não houve preocupação em formalizar um critério de parada para o aprendizado inicial. A permanência prolongada nessa fase não acarreta nenhum prejuízo para o conhecimento adquirido, de modo que o experimento foi executado por um tempo bastante longo. O desempenho do robô foi medido através do tempo gasto para completar cada volta no circuito, o que corresponde a passar pelos quatro alvos estipulados. Notou-se que, após completar o circuito pela primeira vez - o que levou bastante tempo — os tempos das voltas posteriores ficaram limitados em uma faixa de menor valor. Dessa forma, considerou-se que o período de aprendizado inicial foi executado por um tempo suficiente para garantir um bom desempenho ao robô. A tabela Q resultante foi então adotada para outros experimentos, realizados numa fase posterior. No entanto, como a melhor política é executada apenas quando o algoritmo de AR adota a estratégia 
greedy para sua atuação, nos demais experimentos a probabilidade de exploração $\epsilon$ é fixada em zero.

\subsection{Experimentos comparativos com o simula- dor}

Para averiguar o efeito do aprendizado sobre a arquitetura de comportamentos, foram realizados alguns testes para comparar o desempenho da arquitetura AAREACT com relação ao da arquitetura REACT. Ambas as arquiteturas foram implementadas no simulador do robô Pioneer.

O primeiro cenário utilizado foi aquele usado no aprendizado inicial da AAREACT. Da mesma forma que no aprendizado inicial, o robô deve percorrer o circuito formado pelos quatro alvos intercalados. Caso o robô demore muito a cumprir seu objetivo (mais do que 2000s), considera-se que possivelmente ele ficou "perdido", de modo que o simulador recoloca o robô na sua posição inicial, iniciando um novo ciclo. A arquitetura com aprendizado AAREACT apresentou melhor resultado, enquanto que a arquitetura com coordenação fixa REACT freqüentemente não conseguiu cumprir os objetivos durante o tempo máximo estipulado. Os resultados de desempenho obtidos estão apresentados na figura 8.2, enquanto que a figura 8.3 compara trajetórias típicas obtidas com as arquiteturas REACT e AAREACT.

Em outro experimento, foi utilizado um segundo cenário, mostrado na figura 8.4. Nesse cenário há dois alvos que se alternam, de modo que o robô deve percorrer um circuito de ida e volta entre eles.

No entanto, observou-se que nesse cenário, a arquitetura aprendiz apresentou desempenho muito melhor, já que, enquanto a arquitetura REACT se mostrou incapaz de, muitas vezes, cumprir o objetivo, a arquitetura AAREACT iniciou sua atuação com um desempenho satisfatório, e, à medida em que se adaptava ao ambiente específico, melhorava seu desempenho de modo visível, como mostra a figura 8.5. 


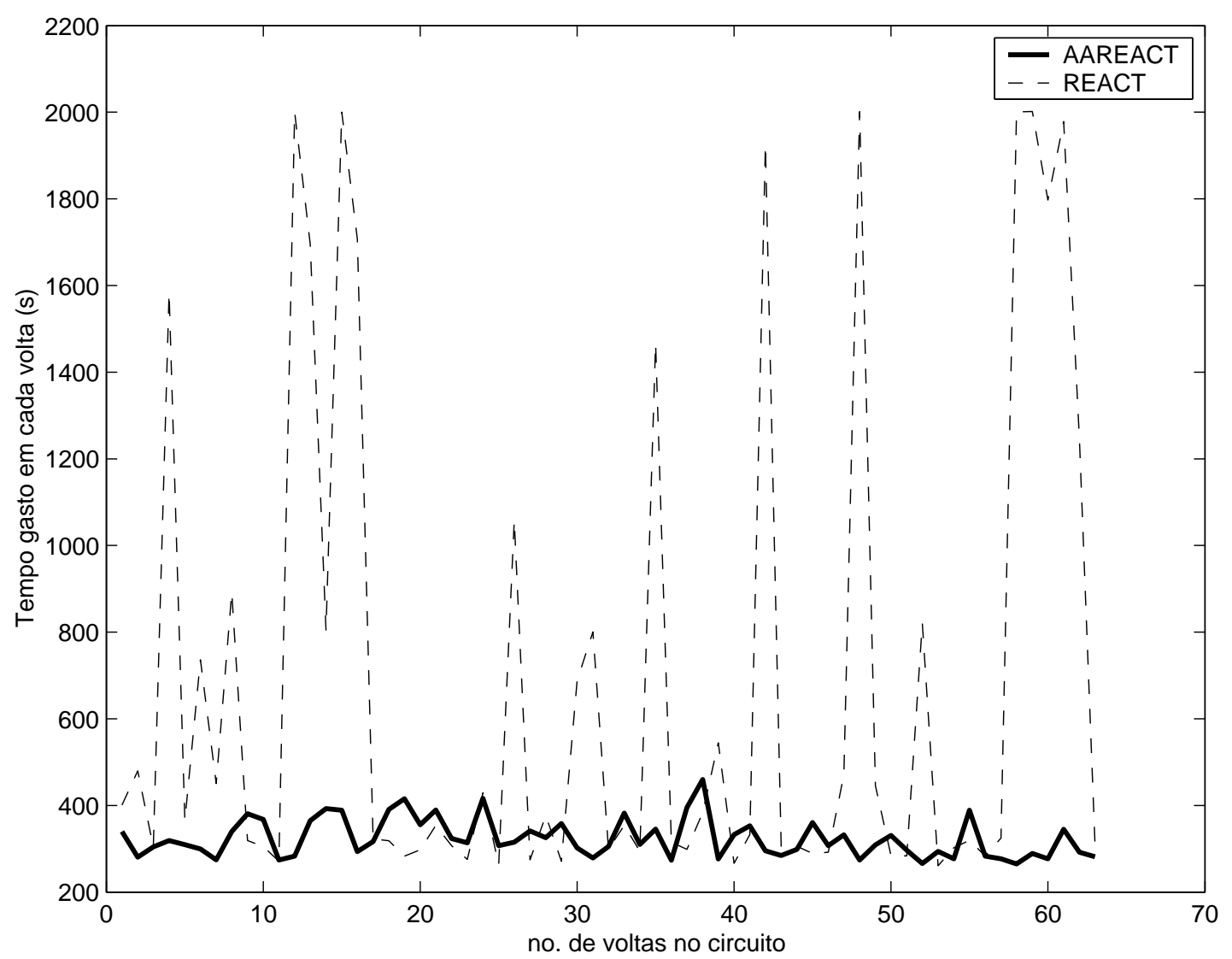

Curvas de desempenho da REACT e da AAREACT no cenário utilizado para o aprendizado inicial. A AAREACT utiliza o conhecimento previamente adquirido. As oscilações nas curvas se devem ao fato de que, mesmo para uma determinada arquitetura, os trajetos percorridos são diferentes a cada volta no cenário. Observa-se uma grande variação no desempenho da arquitetura REACT neste cenário, de forma que ela apresenta bons resultados apenas esporadicamente. Enquanto isso, a AAREACT se mostra mais constante, sendo que, na grande maioria dos casos, ela apresenta um resultado muito melhor do que a REACT.

Figura 8.2: Comparação gráfica dos resultados desempenhados pelas arquiteturas AAREAC e REACT no simulador para o cenário utilizado no aprendizado inicial. 


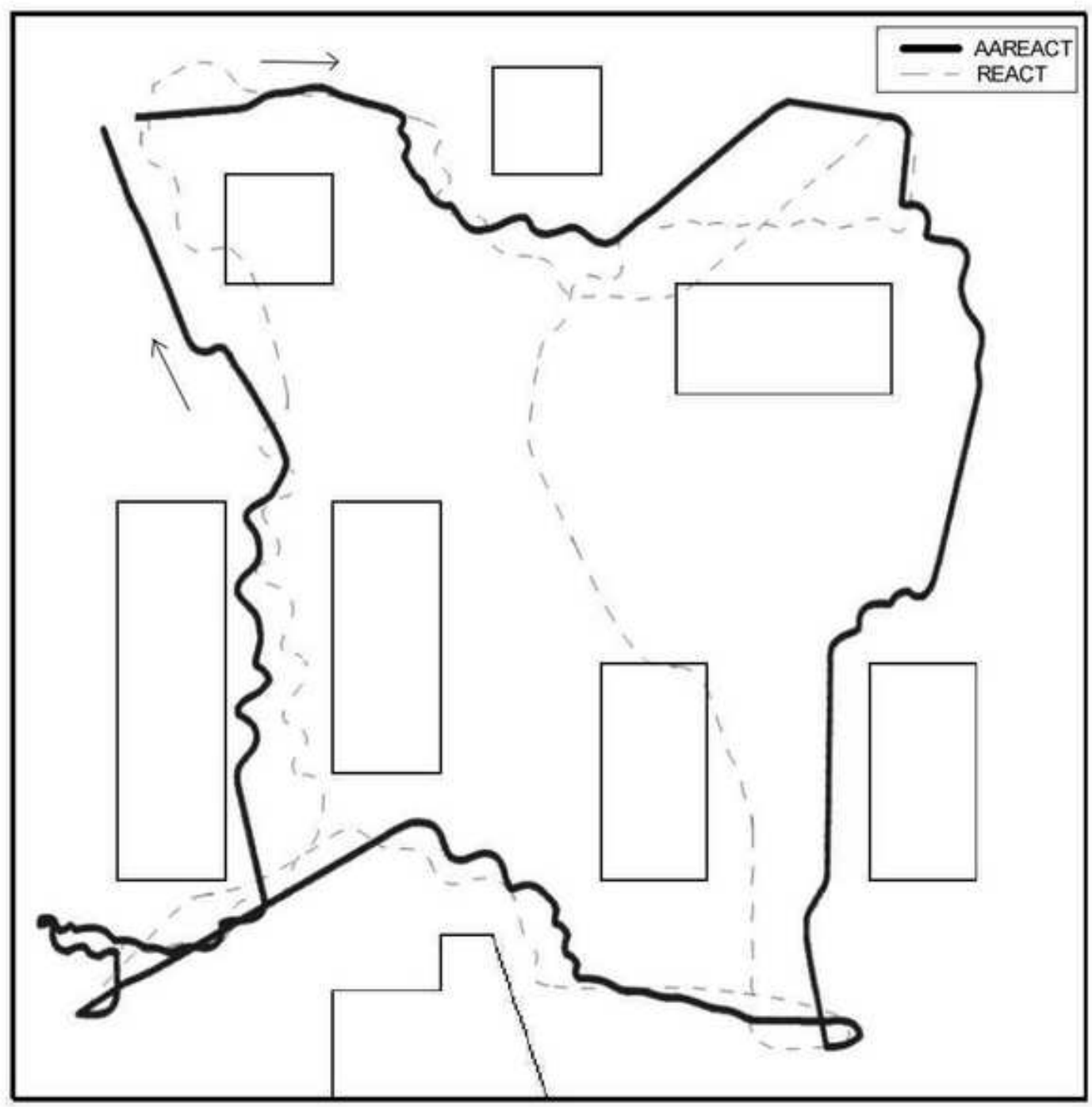

Trajetórias típicas apresentadas pelas arquiteturas REACT e AAREACT nos experimentos realizados no simulador, com o cenário do aprendizado inicial. As trajetórias foram obtidas através do modelo de odometria com erro apresentado pelo simulador do robô Pioneer. Dessa forma, as trajetórias indicam apenas um caminho aproximado. As regiões onde as trajetórias se sobrepõem aos obstáculos são conseqüência desse erro de odometria. As setas indicam o sentido do movimento do robô.

Figura 8.3: Comparação entre trajetórias típicas apresentadas pelas arquiteturas REACT e AAREACT nos experimentos realizados no simulador, com o cenário do aprendizado inicial. 


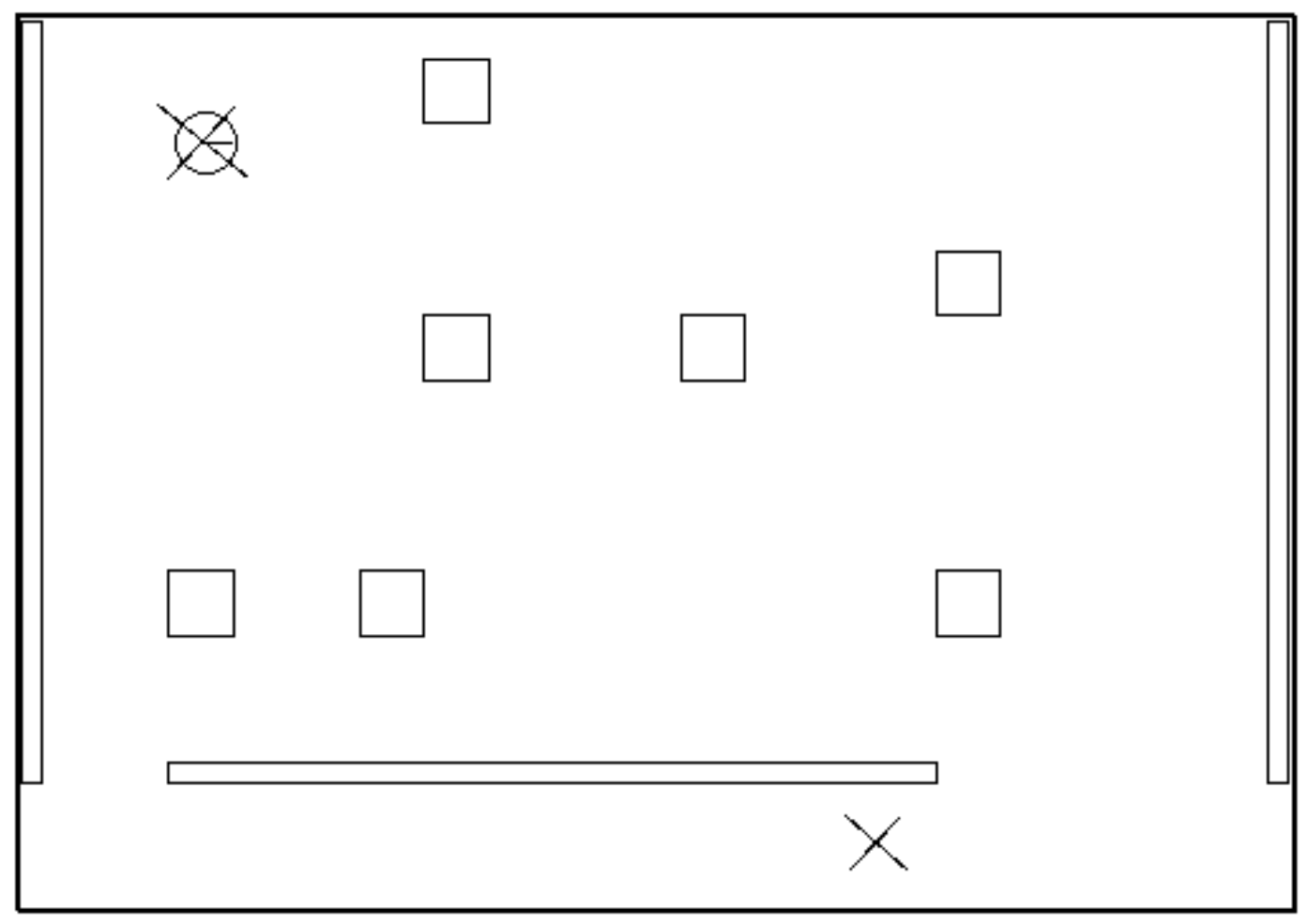

Figura 8.4: Ambiente da segunda experiência no simulador. Os alvos estão indicados com um $\times$. 


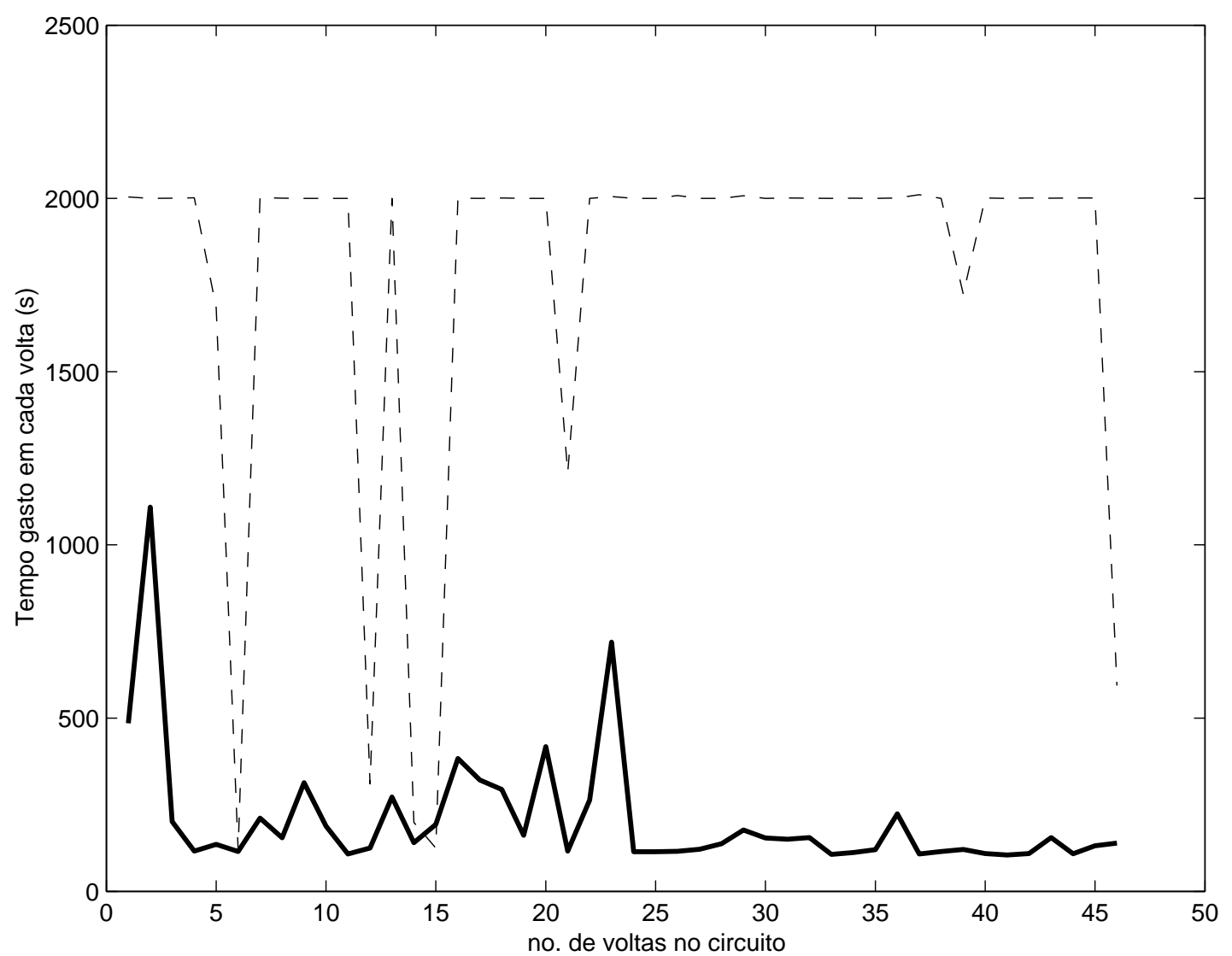

Desempenhos obtidos pelas arquiteturas REACT e AAREACT no simulador do robô Pioneer, com o segundo cenário utilizado. Notar que a arquitetura AAREACT apresenta capacidade de adaptação ao ambiente. No entanto, a fase de adaptação é caracterizada por uma grande oscilação na curva de desempenho, resultando nos "picos" observados no gráfico referente à AAREACT até a $24^{\mathrm{a}}$ volta.

Figura 8.5: Comparação gráfica dos resultados entre os desempenhos das arquiteturas AAREACT e REACT no segundo cenário do simulador. 


\subsection{Experimentos com um robô real}

Foi realizado um experimento comparativo para averiguar o impacto das modificações realizadas na arquitetura reativa original REACT. Mais especificamente, desejou-se averiguar quais melhorias traziam à arquitetura original o acréscimo de visão e aprendizado à arquitetura. Para tal, foi montado um cenário de testes, ilustrado na figura 8.6.

A plataforma robótica utilizada é composta pelo robô Pioneer 2DX utilizado nos experimentos descritos no capítulo 6, utilizando no entanto um laptop Toshiba ${ }^{\circledR}$ com processador Intel Pentium IV ${ }^{\circledR} 2.0 \mathrm{GHz}$ para o processamento embarcado, conforme mostra a figura 8.7. O sistema de aquisição de imagens também foi modificado, sendo composto por uma câmera Ceeper KC-3380, de saída analógica, com ângulo de abertura de $45^{\circ}$, e um equipamento de captura de imagens Hauppauge ${ }^{\circledR}$ WinTV USB. A utilização desse novo hardware permitiu que alguns problemas do sensor de visão fossem solucionados, como a lentidão de processamento e o pequeno ângulo de abertura da câmera. Dessa forma, foram testadas as implementações da arquitetura REACT com e sem o uso do sistema de visão, bem como uma implementação da AAREACT dispondo de todos os comportamentos.

Foi medido o tempo total de ida e de volta em um percurso especificado para esse cenário: saída do canto superior esquerdo da figura 8.6, chegando ao canto inferior direito, com retorno à posição de saída. Observou-se que a arquitetura AAREACT obteve o melhor desempenho, de modo que o robô demorou 45,1s para o percurso de ida e 51,2s para o de volta, num total de 96,3s. A arquitetura REACT utilizando o comportamento moveToFree, executou o percurso de ida em 49,9s e o de volta em 56,9s, totalizando 106,8s para o percurso total. Finalmente, quando o robô foi controlado pela arquitetura REACT sem moveToFree, o percurso de ida foi realizado em 54,1s, e o de volta, em 72,3s, num total de $126,4 \mathrm{~s}$. A figura 8.8 ilustra as trajetórias desenvolvidas pelo robô durante o experimento.

Dessa forma, tanto o uso do comportamento baseado em visão proposto na arquitetura quanto o uso de aprendizado para coordenar comportamentos demonstraram a capacidade de melhorar o desempenho do robô. 


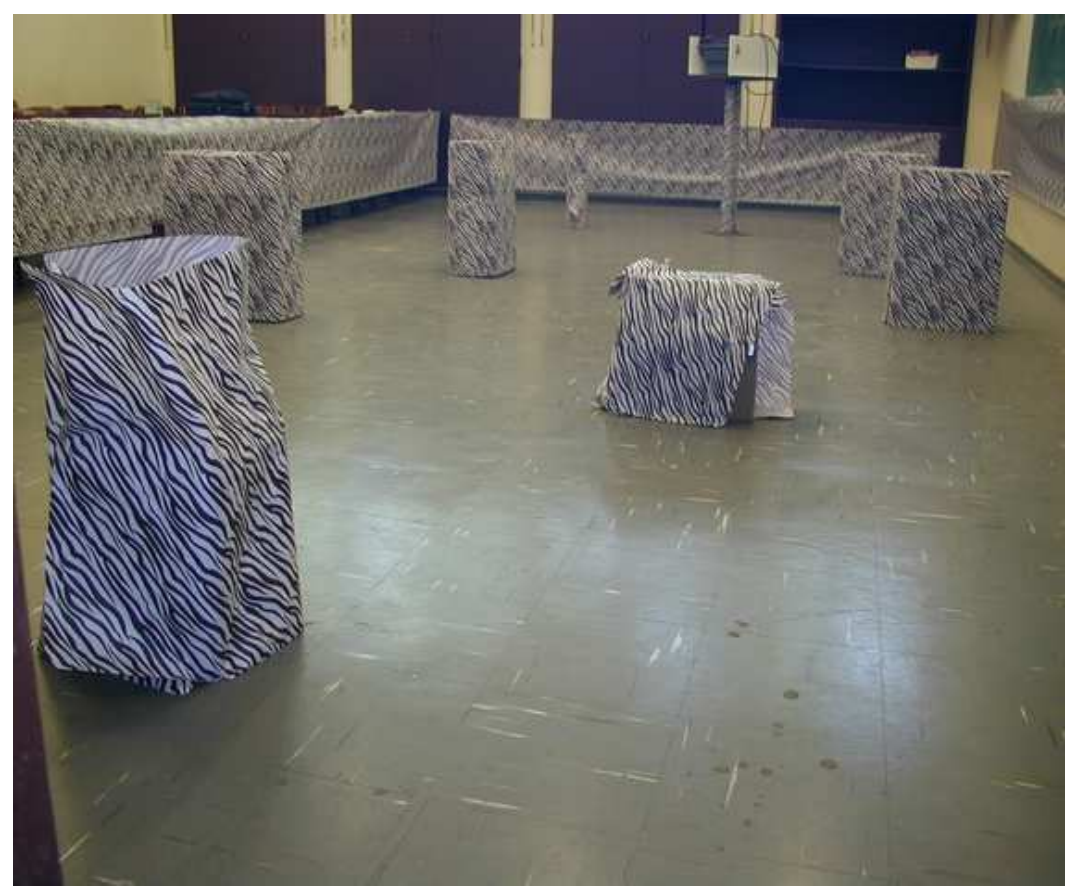

Figura 8.6: Ambiente da experiência real com o robô.

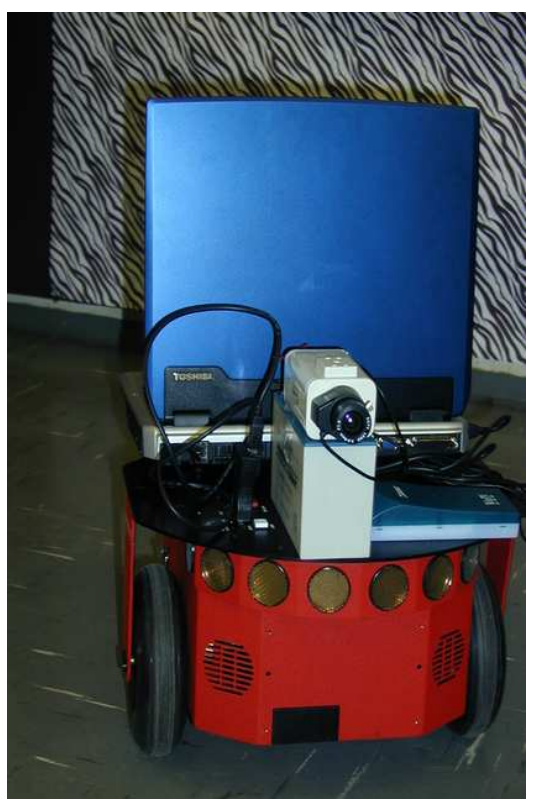

Figura 8.7: Plataforma robótica utilizada nos experimentos finais. 


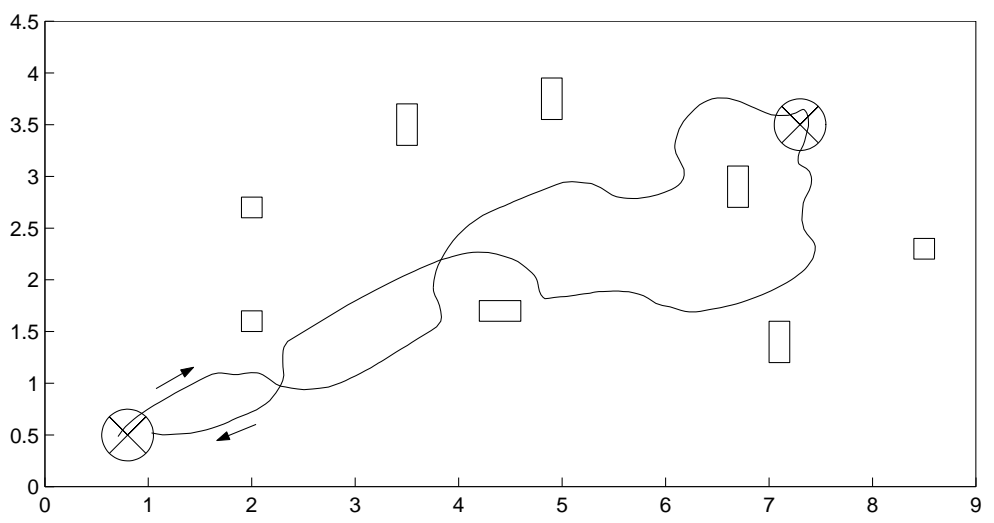

(a) Trajetória desenvolvida com a REACT sem o comportamento move ToFree.

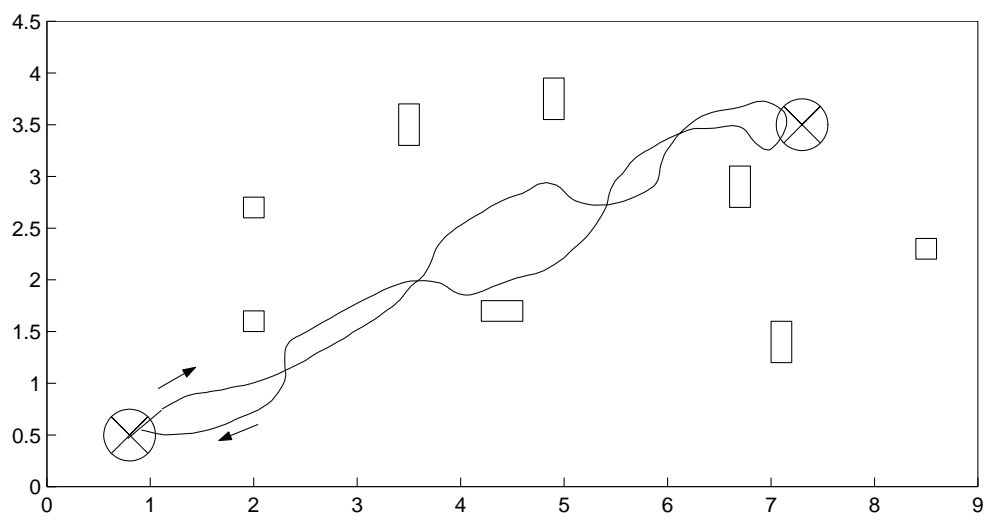

(b) Trajetória desenvolvida com a REACT utilizando o comportamento moveToFree.

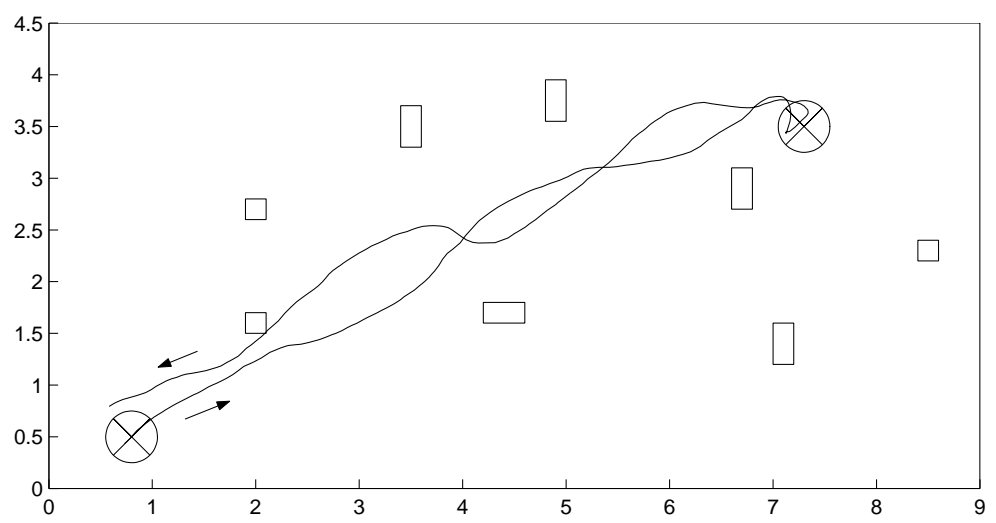

(c) Trajetória desenvolvida com a AAREACT.

Figura 8.8: Trajetórias desenvolvidas durante os experimentos com o robô Pioneer. As setas indicam o sentido do movimento do robô. 


\section{Conclusão}

Este trabalho apresentou uma arquitetura híbrida para robôs móveis baseada em comportamentos reativos, com capacidade de aprendizado. O aprendizado se dá na determinação de uma função adaptativa que adequa a influência de cada comportamento na atuação final do robô de acordo com a percepção da situação na qual o mesmo se encontra. A arquitetura proposta se mostrou eficiente na integração dos sensores de visão, sonar e odometria para a navegação do robô em ambiente não estruturado. Tanto o sensor de visão, desenvolvido neste trabalho, quanto o sonar, indicam as distâncias dos objetos presentes no ambiente. Ambos se complementam por terem campos de atuação diversos: a visão ocupa-se mais com objetos distantes do robô, enquanto que o sonar, com objetos mais próximos. Assim sendo, a arquitetura AAREACT demonstrou competência em combinar as informações desses sensores para cumprir a tarefa de desvio de obstáculos.

A maior contribuição a ser destacada neste trabalho é a incorporação de aprendizado por reforço na estrutura de uma arquitetura comportamental. Embora o assunto seja objeto de outros trabalhos em Robótica, este trabalho contribui com uma proposta inédita e específica para a implantação de AR para o aprendizado da coordenação de comportamentos reativos codificados pelo método de Campos Potenciais. A definição da arquitetura, dos atributos do ambiente a serem utilizados para caracterizar um estado, e a definição da função de recompensa para o problema em questão constituem contribuições importantes.

No sensor de visão desenvolvido, a maior contribuição a ser destacada é a integração de técnicas preexistentes para a obtenção de um bom resultado final. Embora a estrutura do processamento de imagens seja inspirado em um trabalho anterior, o sensor incorpora diferenças importantes, tais como o algoritmo direto de cálculo dos tempos para colisão e o processo de seleção dos valores de derivadas da imagem a serem utilizados no processamento. 
Com isso, foram dadas contribuições em áreas do conhecimento relevantes e bastante atuais, ligadas à Robótica Móvel Inteligente: arquiteturas de robôs, visão computacional e aprendizado de máquina.

\subsection{Discussão dos resultados}

Os testes realizados com o sensor de visão em imagens simuladas mostram que o algoritmo utilizado para o cálculo dos tempos para colisão geram resultados próximos aos esperados. No entanto, para a aplicação de interesse neste trabalho, é mais importante o fato de que ele demonstra grande capacidade em distinguir objetos próximos de objetos mais distantes, o que o torna bastante adequado para aplicação em navegação de robôs móveis como um sensor de distâncias adicional. Isso fica claro com a análise dos resultados obtidos na incorporação do comportamento MoveToFree na arquitetura REACT. No entanto, a sua utilização como único sensor não é aconselhada. Uma vez que a câmera de vídeo capta apenas uma parte da região à frente do robô, delimitada pelo seu ângulo de abertura, é possível que obstáculos laterais não sejam detectados, principalmente quando estão próximos. Isso pode ser resolvido através da construção de um mapa de curto alcance com as informações do sensor de visão, onde ficaria registrada a localização de obstáculos que, uma vez percebidos, podem chegar a sair do campo de visão da câmera após se aproximarem do robô. No entanto, tal recurso, por se tratar de uma modelagem do ambiente, não se enquadra na abordagem reativa pura utilizada nos comportamentos.

Há ainda outras limitações do sensor de visão desenvolvido que desaconselham o seu uso como única fonte de percepção do robô. Uma vez que as regiões que apresentam baixo nível de contraste na imagem não são consideradas para o processamento, é necessário garantir que os objetos que devem ser identificados apresentem certa riqueza de textura nas tonalidades. A presença do chão nas imagens capturadas também pode gerar problemas. Há grande probabilidade de que a região ocupada pelo chão na imagem apresente profundidades menores do que aquelas ocupadas pelos obstáculos. Com isso, de acordo com o critério que elege o menor tempo para colisão em uma coluna da seqüência de imagens como a medida que representa os valores daquela coluna, o solo pode ser detectado no lugar dos obstáculos de interesse, alertando o robô, erroneamente, da existência 
de um objeto na iminência de colisão. Nos experimentos em que o sensor de visão foi utilizado para auxiliar na navegação do robô, o piso apresentava cor aproximadamente uniforme, de modo que dificilmente influenciava no resultado final.

Os resultados obtidos com a aplicação da arquitetura AAREACT demonstram que a adaptação da influência de cada comportamento na atuação do robô de acordo com a situação encontrada de fato melhora o seu desempenho, quando comparado com o obtido pela ponderação fixa dos comportamentos na coordenação cooperativa dos mesmos. Alguns experimentos mostraram, inclusive, que a arquitetura adaptativa é capaz de fazer o robô atingir seu objetivo em alguns ambientes nos quais a arquitetura REACT dificilmente tem sucesso.

Também fica evidenciado que o aprendizado na arquitetura proposta é satisfatório. Dessa forma, a escolha do algoritmo de AR se mostra adequada. Também ficam validadas a definição dos atributos que caracterizam um estado do ambiente e a função de reforço utilizada. No entanto, não é possível concluir que o conjunto de atributos e função reforço utilizados são realmente os que proporcionam melhor resultado para o aprendizado.

Não se pode esperar, contudo, que o aprendizado atuando sobre a coordenação de comportamentos resulte em uma trajetória ótima, tanto no sentido do menor tempo quanto no sentido da menor distância percorrida. Para isso, o aprendizado deveria atuar diretamente sobre as ações de movimento do robô, controlando a sua posição. Os seus estados também deveriam ser definidos em termos da posição do robô no ambiente, de forma a existirem seqüências de estados bem definidas que garantam a trajetória ótima. Nesse caso, no entanto, o aprendizado realizado em um determinado ambiente só teria validade local, não podendo ser utilizado em outra configuração.

O aprendizado da AAREACT procura ajustar a atuação do robô a uma situação percebida localmente. Assim, ela não foi projetada para se adaptar a um ambiente específico, mas seu aprendizado é orientado de forma a ajustar a atuação do robô de modo a se comportar bem nas várias configurações possíveis do ambiente. Por isso, o resultado do aprendizado inicial, realizado em um ambiente específico, é utilizado pela arquitetura em todos os outros ambientes, onde o aprendizado continua a ser realizado, de forma incremental. Mesmo que o robô 
opere sempre em um ambiente específico e se especialize nele, a transição para outro ambiente ocorre facilmente, uma vez que o aprendizado evolui naturalmente.

\subsection{Sugestões de trabalhos futuros}

Como neste trabalho foram abordados assuntos muito variados, há um grande número de aspectos que podem ser explorados em trabalhos futuros. Com relação à arquitetura proposta, cabe serem feitas análises comparativas de desempenho com outras arquiteturas híbridas baseadas em comportamentos, uma vez que este trabalho só analisou o efeito da camada de aprendizado sobre uma arquitetura reativa preexistente. Dessa forma, é possível averiguar que tipo de deliberação sobre os comportamentos fornece os melhores resultados: planejamento ou aprendizado. Com relação ao projeto de comportamentos, pode ser estudado um comportamento que utiliza a fusão sensorial da visão e dos sonares para substituir os comportamentos moveToFree e avoidCollision.

Com relação à camada de supervisão/crítica/aprendizado, pode-se aprofundar muito ainda. Em primeiro lugar, pode-se fazer um estudo comparativo de algoritmos de aprendizado por reforço para averiguar qual se adapta melhor ao problema em questão. Pode-se também aprofundar no tema dos atributos utilizados para a definição dos estados. É possível averiguar que atributos são mais relevantes, quais são menos relevantes, que atributos ainda faltam. Também pode-se estudar atributos que podem assumir mais valores do que somente "ativo" e "inativo". Além disso, seria interessante o estudo de outros tipos de função reforço.

Com relação ao sensor de visão, muita pesquisa ainda pode ser feita. Em primeiro lugar, pode-se procurar corrigir as suas limitações. A primeira delas é a limitação da incapacidade de processar áreas na imagem com baixo nível de contraste do algoritmo. Horn (1986) propõe um algoritmo para o cálculo do fluxo ótico baseado na sua equação de restrição que pode muito bem ser adaptado ao cálculo direto do tempo para colisão. Esse algoritmo faz uma restrição de suavidade à variação dos vetores de fluxo, de modo que regiões onde ele é indefinido acabam sendo interpoladas No entanto, esse algoritmo é iterativo e muito custoso, de forma que pode ser explorada uma solução alternativa. Outra limitação

a ser abordada é o tratamento de deslocamentos da imagem. É comum, durante 
a navegação do robô, qua ocorram trepidações que afetem a aquisição da imagem. É possível explorar um método de correções de deslocamentos por trepidação nas imagens, chamdos métodos de estabilização eletrônica (MORIMOTO, 1997). Com relação ao algoritmo de cálculo dos tempos para colisão, pode fazer uma análise do melhor filtro a ser usado para e extração das derivadas espaciais, bem como um estudo mais aprofundado sobre a faixa de valores para as quais o algoritmo responde melhor. 


\section{Referências Bibliográficas}

ACTIVMEDIA ROBOTICS. Saphira's Manual. Menlo Park, CA, 2001. Version 8.0a.

ARKIN, R. C. Behavior-Based Robotics. Cambridge, MA: The MIT Press, 1998.

ASTRÖM, K.; WITTENMARK, B. Adaptative Control. 2. ed. [S.l.]:

Addison-Wesley Publishing Company, Inc., Reading, 1995.

BALLARD, D. H.; BROWN, C. M. Computer vision. New Jersey: Englewood Cliffs: PrenticeHall, 1982.

BROOKS, R. A robust layered control system for a mobile robot. IEEE Journal of Robotics and Automation, v. 1, p. 1-10, 1986.

BROOKS, R. Elephants don't play chess. Designing Autonomous Agents, Cambridge, MA, p. 3-15, 1990.

CAMUS, T. et al. Real-time single-workstation obstacle avoidance using only wide-field flow divergence. In: IEEE COMPUTER SOCIETY. Proceedings of the 13th International Conference on Pattern Recognition. Vienna, Áustria, 1996. v. 3, p. 323-330.

DEV, A.; KRÖSE, B. J. A.; GROEN, F. C. A. Navigation of a mobile robot on the temporal development of the optic flow. In: Proceedings of the 1997 IEEE/RSJ/GI International Conference on Intelligent Robots and Systems. Grenoble, França: [s.n.], 1997. p. 558-563.

GONZALEZ, R. C.; WOODS, R. E. Digital Image Processing. Boston, MA: Addison Wesley Publishing Company, 1992.

HORN, B. K. P. Robot Vision. Cambridge, MA: The MIT Press, 1986.

KAELBLING, L. P.; LITTMAN, M. L.; MOORE, A. Reinforcement learning: A survey. Journal of Artificial Intelligence Research, v. 4, p. 237-285, 1996.

KALMÁR, Z.; SZEPESVÁRI, C.; LÖRINCZ, A. Module-based reinforcement learning: Experiments with a real robot. Machine Learning, n. 31, p. 55-85, 1998.

KOENIG, S.; LIKHACHEV, M. Improved fast replanning for robot navigation in unknown terrain. In: Proceedings of the IEEE International Conference on Robotics and Automation. Washington D. C., Estados Unidos: [s.n.], 2002. p. 968-975. 
KOREN, Y.; BORESTEIN, J. Potential field methods and their inherent limitations for mobile robot navigation. In: Proceedings of the IEEE Conference on Robotics and Automation. Sacramento, California: [s.n.], 1991. p. 1398-1404.

LUCAS, B. D.; KANADE, T. An iterative image registration technique with an application to stereo vision. In: Proceedings of the 7th International Joint Conference on Artificial Intelligence. Vancouver, Canadá: [s.n.], 1981. p. $674-679$.

MITCHELL, T. Machine Learning. Boston, MA: McGraw-Hill, 1997. ISBN 0-07-042807-7.

MONTEIRO, S. T. Estudo de desempenho de agoritmos de aprendizagem sob condições de ambigüidade sensorial. Dissertação (Mestrado) — ITA, São José dos Campos, Brasil, junho 2002.

MORIMOTO, H. Electronic Digital Image Stabilization: Design and Evaluation, with Applications. Tese (Doutorado) - University Of Maryland At College Park, Estados Unidos, 1997.

MURPHY, R. Introduction to AI Robotics. Cambridge, MA: The MIT Press, 2000 .

PACHECO, R. N.; COSTA, A. H. R. Navegação de robôs móveis utilizando o método de campos potenciais. In: SAKUDE, M. T. S.; CESAR, C. de A. C. (Ed.). Workshop de Computação - WORKCOMP'2002. Instituto Tecnológico de Aeronáutica - ITA, São José dos Campos, SP: ITA, 2002. p. 125-130.

PARDO, F. et al. High speed log-polar time to crash calculation for mobile vehicles. Image Processing $\&$ Communications, v. 8, n. 2, p. 23-32, 2002.

RANGANATHAN, A.; KOENIG, S. A reactive robot architecture with planning on demand. In: Proceedings of the IEEE/RSJ Int. Conf. on Intelligent Robots and Systems. Las Vegas, Califórnia: [s.n.], 2003.

RIBEIRO, C. H. C.; COSTA, A. H. R.; ROMERO, R. A. F. Robôs móveis inteligentes: princípios e técnicas. In: MARTINS, A. T.; BORGES, D. L. (Ed.). I Jornada de Atualização em Inteligência Artificial - JAIA. Anais do XXI Congresso da Sociedade Brasileira de Computação. Fortaleza, CE, 2001. v. 3, p. 257-306.

RUSSEL, S.; NORVIG, P. Inteligência Artificial. Rio de Janeiro, Brasil: Editora Elsevier, 2004. Tradução da $2^{\mathrm{a}}$ edição. ISBN 85-352-1177-2.

SARCINELLI-FILHO, M.; SCHNEEBELI, H. A.; CALDEIRA, E. M. O. Cálculo do fluxo óptico em tempo real e sua utilização na navegação de robôs móveis. In: Anais do V Simpósio Brasileiro de Automação Inteligente. Canela, RS: [s.n.], 2001. In CD. 
SARCINELLI-FILHO, M.; SCHNEEBELI, H. A.; CALDEIRA, E. M. O. Using optical flow to control mobile robot navigation. In: Proceedings of the 15th IFAC World Congress on Automatic Control. Barcelona, Spain: [s.n.], 2002.

SElVATICI, A. H. P.; COSTA, A. H. R. Combinação de sensores através da cooperação de comportamentos primitivos. In: Anais do XV Congresso Brasileiro de Automática CBA'2004. Gramado, RS: [s.n.], 2004.

SELVATICI, A. H. P.; COSTA, A. H. R. Obstacle avoidance using timeto-contact information. In: RIBEIRO, M. I.; SANTOS-VICTOR, J. (Ed.). Proceedings of the 5th IFAC Symposium on Intelligent Autonomous Vehicles, IAV'2004. Lisboa, Portugal, 2004. Preprints.

SUTTON, R. S.; BARTO, A. G. Reinforcement Learning: An Introduction. Massachussets, MA: MIT Press, 1998.

TRUCCO, E.; VERRI, A. Introductory Techniques for 3-D Computer Vision. Upper Saddle River, NJ: Prentice Hall, 1998. 